\title{
Acute dissociation predicts rapid habituation of skin conductance responses to aversive auditory probes
}

Citation for published version (APA):

Giesbrecht, T. M., Merckelbach, H. L. G. J., ter Burg, L., Cima, M. J., \& Simeon, D. (2008). Acute

dissociation predicts rapid habituation of skin conductance responses to aversive auditory probes. Journal of Traumatic Stress, 21(2), 247-250. https://doi.org/10.1002/jts.20323

Document status and date:

Published: 01/01/2008

DOI:

$10.1002 /$ jts.20323

Document Version:

Publisher's PDF, also known as Version of record

\section{Please check the document version of this publication:}

- A submitted manuscript is the version of the article upon submission and before peer-review. There can be important differences between the submitted version and the official published version of record.

People interested in the research are advised to contact the author for the final version of the publication, or visit the DOI to the publisher's website.

- The final author version and the galley proof are versions of the publication after peer review.

- The final published version features the final layout of the paper including the volume, issue and page numbers.

Link to publication

\footnotetext{
General rights rights.

- You may freely distribute the URL identifying the publication in the public portal. please follow below link for the End User Agreement:

www.umlib.nl/taverne-license

Take down policy

If you believe that this document breaches copyright please contact us at:

repository@maastrichtuniversity.nl

providing details and we will investigate your claim.
}

Copyright and moral rights for the publications made accessible in the public portal are retained by the authors and/or other copyright owners and it is a condition of accessing publications that users recognise and abide by the legal requirements associated with these

- Users may download and print one copy of any publication from the public portal for the purpose of private study or research.

- You may not further distribute the material or use it for any profit-making activity or commercial gain

If the publication is distributed under the terms of Article $25 \mathrm{fa}$ of the Dutch Copyright Act, indicated by the "Taverne" license above, 


\title{
Cognitive Processes in Dissociation: An Analysis of Core Theoretical Assumptions
}

\author{
Timo Giesbrecht \\ Scott O. Lilienfeld \\ Emory University
}

Maastricht University and Mount Sinai School of Medicine

\author{
Steven Jay Lynn \\ Harald Merckelbach \\ Maastricht University
}

State University of New York, Binghamton

\begin{abstract}
Dissociation is typically defined as the lack of normal integration of thoughts, feelings, and experiences into consciousness and memory. The present article critically evaluates the research literature on cognitive processes in dissociation. The authors' review indicates that dissociation is characterized by subtle deficits in neuropsychological performance (e.g., heightened distractibility). Some of the cognitive phenomena (e.g., weakened cognitive inhibition) associated with dissociation appear to be dependent on the emotional or attentional context. Contrary to a widespread assumption in the clinical literature, dissociation does not appear to be related to avoidant information processing. Rather, it is associated with an enhanced propensity toward pseudo-memories, possibly mediated by heightened levels of interrogative suggestibility, fantasy proneness, and cognitive failures. Evidence for a link between dissociation and either memory fragmentation or early trauma based on objective measures is conspicuously lacking. The authors identify a variety of methodological issues and discrepancies that make it difficult to articulate a comprehensive framework for cognitive mechanisms in dissociation. The authors conclude with a discussion of research domains (e.g., sleep-related experiences, drug-related dissociation) that promise to advance our understanding of cognition and dissociation.
\end{abstract}

Keywords: dissociation, trauma, neuropsychology, information processing, memory

Dissociation is defined by the fourth edition of the Diagnostic and Statistical Manual of Mental Disorders (DSM-IV-TR; American Psychiatric Association, 2000, p. 519) as "a disruption in the usually integrated function of consciousness, memory, identity, or perception of the environment." Whereas many authors regard symptoms of derealization, depersonalization, and psychogenic amnesia as core features of dissociation, the concept of dissociation is semantically open and lacks a precise and generally accepted definition. Accordingly, workers in the field have invoked dissociation to describe disparate phenomena, including perception without awareness and hypnosis (Cardeña, 1994).

More widely accepted, however, is the idea that dissociative symptoms are manifestations of an automatic defense mechanism

Timo Giesbrecht, Department of Clinical Psychological Science, Maastricht University, Maastricht, the Netherlands, and Department of Psychiatry, Mount Sinai School of Medicine; Steven Jay Lynn, Department of Psychology, State University of New York, Binghamton; Scott O. Lilienfeld, Department of Psychology, Emory University; and Harald Merckelbach, Department of Clinical Psychological Science, Maastricht University.

Preparation of this article was supported by a grant from the Netherlands Organization for Scientific Research (N. W. O.) to Timo Giesbrecht (Grant No. 446-06-010) and by a grant from the National Institute of Mental Health to Steven Jay Lynn (1 R01 MH67483-01).

Correspondence concerning this article should be addressed to Timo Giesbrecht, Department of Experimental Psychology, University of Maastricht, P.O. Box 616, 6200 MD Maastricht, The Netherlands. E-mail: T.Giesbrecht@psychology.unimaas.nl that serves to mitigate the impact of highly aversive or traumatic events (van IJzendoorn \& Schuengel, 1996). Moreover, there is little dispute that many dissociative symptoms reflect profound cognitive aberrations. Indeed, the often quoted DSM-IV-TR definition cited above alludes to serious memory and attention problems. The current review examines the empirical basis of the claim that marked cognitive deficits lie at the core of dissociative phenomena.

In their mild form, dissociative experiences are common in the general population (e.g., Ross, Joshi, \& Currie, 1991), yet they are especially frequent and severe in certain diagnostic groups, including borderline personality disorder, posttraumatic stress disorder (PTSD), and schizophrenia (e.g., Holmes et al., 2005; Merckelbach, à Campo, Hardy, \& Giesbrecht, 2005), and they are hallmark features of the dissociative disorders, including dissociative identity disorder (DID) and depersonalization disorder (DPD). The DSM-IV-TR (American Psychiatric Association, 2000) definition of dissociation (see also E. M. Bernstein \& Putnam, 1986) along with widely held clinical assumptions (van der Hart, Nijenhuis, Steele, \& Brown, 2006) imply that individuals who experience high levels of dissociation exhibit attention and memory dysfunctions, engendered by the purported defensive function of dissociation (e.g., Gershuny \& Thayer, 1999; van der Hart, Nijenhuis, Steele, \& Brown, 2004).

The idea of dissociation serving a defensive function can be traced back to Pierre Janet's (1889/1973) pioneering investigations of dissociative phenomena. Janet coined the term "désaggrégation," which was later translated as "dissociation." He is widely 
acknowledged to be the first scientist to link dissociation to stress and psychological trauma (Hacking, 1995; van der Kolk \& van der Hart, 1989). Janet regarded dissociation as a coping mechanism that individuals invoke unconsciously to blunt the impact of traumatic experiences, a view echoed by modern dissociation researchers like Gershuny and Thayer (1999, p. 647), who argued that "when emotional pain is acute and deemed unbearable by the sufferer, dissociation may be called upon as means of escape." Accordingly, dissociative symptoms are thought to manifest themselves in the form of "freezing, analgesia, and emotional numbing [which] are elicited automatically" (Nijenhuis, Spinhoven, Vanderlinden, van Dyck, \& van der Hart, 1998, p. 65). Once individuals have learned to use dissociation to cope with a highly aversive event, dissociation can presumably become automatized and invoked on a habitual basis in response to even minor stressors. Habitual dissociation, in turn, engenders emotional constriction and numerous and varied manifestations of psychopathology (van der Kolk \& van der Hart, 1989). The idea that trauma directly causes dissociation is ubiquitous in contemporary clinical literature (see, for a critical review, Kihlstrom, 2005; Merckelbach \& Muris, 2001) and often is presented as an uncontroversial issue or incontrovertible fact (Gast, Rodewald, Nickel, \& Emrich, 2001; Gershuny \& Thayer, 1999; Irwin, 1998; Reinders et al., 2006).

Dissociative symptoms range from common cognitive failures, such as lapses in attention, to nonpathological absorption and daydreaming, to more pathological manifestations of dissociation, as represented by the dissociative disorders (Holmes et al., 2005). Even within these categories, individual dissociative symptoms differ widely in their expression. Based on the phenomenological differences among dissociative amnesia, absorption, depersonalization, and derealization, one might speculate that at least some of these symptoms have relatively little in common etiologically and depend on distinct biological substrates. Accordingly, a number of authors have criticized the notion of dissociation as a unitary conceptual domain (Hacking, 1995; Holmes et al., 2005; Jureidini, 2003).

In line with Cardeña (1994) and J. G. Allen (2001), Holmes et al. (2005) proposed two distinct forms of dissociation, namely detachment and compartmentalization. Detachment consists of depersonalization, derealization, and related phenomena, like outof-body experiences. Psychopathological conditions that reflect symptoms of detachment are DPD and feelings of "nowness" during flashbacks in PTSD (Ehlers \& Clark, 2000). Compartmentalization, in contrast, encompasses dissociative amnesia and somatoform dissociation, such as sensory loss and "unexplained" neurological symptoms (Nijenhuis, Spinhoven, van Dyck, van der Hart, \& Vanderlinden, 1998). The core feature of compartmentalization is a deficit in deliberate control of processes or actions that would normally be amenable to control, as is evident in DID or somatization disorder. Although clinicians may find it helpful to subdivide dissociative symptoms into different symptom clusters (Bernstein-Carlson \& Putnam, 1993), attempts to psychometrically differentiate separate symptom clusters have not been uniformly successful, as we explain in the course of our discussion.

Partly on the basis of Putnam's (1997) discrete behavioral states model, van der Hart et al. $(2004,2006)$ recently argued for a qualitative demarcation between pathological dissociation-which they refer to as trauma-related dissociation or structural dissociation of the personality — and nonpathological dissociative experiences (i.e., alter- ations in the levels and field of consciousness, such as absorption and altered sense of time). van der Hart et al. (2004, p. 910) considered structural dissociation to be a "dimensional construct" but described three prototypal levels of structural dissociation for heuristic purposes. Thus, primary structural dissociation consists of one apparently normal part of the personality and one emotional part of the personality, with the emotional part of the personality suffering with "partial or complete amnesia" but also experiencing "hypermnesia and reexperiencing of the trauma" (van der Hart et al., 2004, p. 910). In contrast, the most extreme manifestation of structural dissociation, tertiary structural dissociation, is ostensibly limited to DID and is characterized by several apparently normal and emotional parts of the personality. However, as our review will demonstrate, researchers' attempts to discriminate pathological from nonpathological dissociative experiences psychometrically have largely yielded disappointing results.

Whatever the precise subdivision among dissociative symptoms, there are compelling reasons to question a number of long and widely held assumptions concerning dissociation, many of which have been extremely influential in the clinical literature. In this article, we specifically address the idea that dissociation is accompanied by serious cognitive aberrations. We begin our review with an examination of crucial issues in the measurement of dissociation. We next describe personality traits, including fantasy proneness, interrogative suggestibility, and susceptibility to cognitive failures, which map onto the construct of dissociation. Then, we evaluate neuropsychological studies of dissociation; studies of the relationships among dissociation, memory, and memory fragmentation; and the link between dissociation, on the one hand, and information-processing capabilities and superior forgetting of neutral and emotional information, on the other. We conclude with a discussion of possible future research avenues that promise to bridge the wide gap between dissociation theory and research.

\section{Measurement of Dissociation}

To make psychiatric diagnoses more reliable, researchers developed the Structured Clinical Interview for DSM-III-R (Spitzer, Williams, Gibbon, \& First, 1990) and DSM-IV disorders (First, Spitzer, Gibbon, \& Williams, 1994). However, these interviews do not include procedures to diagnose the dissociative disorders. To remedy this shortcoming, Steinberg $(1993,1994)$ developed the Structured Clinical Interview for the Dissociative Disorders (SCID-D), widely considered the preferred instrument for the diagnosis of the these disorders (Draijer \& Boon, 1993). Ross et al. (1989) developed the Dissociative Disorders Interview Schedule as an alternative structured diagnostic interview. However, Kihlstrom (2005, p. 3) pointed out that "even with relatively strict criteria in place, it can be difficult to discriminate between the dissociative disorders and bipolar disorder, borderline personality disorder, and even schizophrenia."

The official inclusion of dissociative disorders in the third edition of the Diagnostic and Statistical Manual of Mental Disorders (DSM-III; American Psychiatric Association, 1980) led to the development of the Dissociative Experiences Scale (DES; E. M. Bernstein \& Putnam, 1986), which became the standard instrument to quantify the frequency of dissociative symptoms (Wright \& Loftus, 1999). The DES has been used extensively in both clinical and nonclinical samples (van IJzendoorn \& Schuengel, 1996). Its 
widespread use is reflected by the fact that a computerized search in February 2008 using PsycINFO indicated that at least 631 articles have employed this measure since it was developed in 1986. The DES quantifies the frequency with which respondents experience 28 dissociative phenomena in daily life. These phenomena include experiences of autobiographical amnesia, derealization, depersonalization, and absorption, and they are measured on $100-\mathrm{mm}$ visual analogue scales. The revised version of the DES, the DES-II, no longer uses a visual analogue format and instead relies on a Likert-type format (Bernstein-Carlson \& Putnam, 1993). Respondents are asked to indicate how often (in percent of the time) they experience specific dissociative symptoms. The DES total score consists of the arithmetic mean of all 28 items and can vary between 0 and 100 . Higher values imply an increased frequency of dissociative experiences. Values above 25 or 30 are thought to indicate potential dissociative psychopathology (Putnam, Carlson, Ross, \& Anderson, 1996).

In their meta-analysis, van IJzendoorn and Schuengel (1996) evaluated the validity of the DES by investigating the correlations between this instrument and various self-report questionnaires and semi-structured interviews. They reported significant correlations of the DES with measures of related phenomena (e.g., Perceptual Aberration Scale, Questionnaire of Experiences of Dissociation, Bliss Scale, Dissociation Questionnaire; see below), and even higher correlations with the outcomes of semi-structured interviews (e.g., Structured Clinical Interview for the Dissociative Disorders). Additionally, the researchers concluded that the DES exhibits excellent internal consistency (Cronbach's $\alpha=.93$ ) and good temporal reliability, with test-retest correlations ranging from .74 to .84 (Holtgraves \& Stockdale, 1997).

Although the DES was developed to measure a unidimensional dissociative construct, other researchers were quick to point out that the DES may be multidimensional. Carlson et al.'s (1991) factor analysis yielded three factors: amnesia, absorption, and depersonalization. However, even today, there is no consensus regarding the factor structure of the DES. Whereas various studies have replicated Carlson et al.'s three factor solution (Ross, Ellason, \& Anderson, 1995; B. Sanders \& Green, 1994) or have identified four factors (Ray \& Faith, 1994), other research has suggested that the DES is unidimensional. For example, N. G. Waller (1995) reanalyzed Carlson et al.'s (1991) original data and concluded that their three factor solution could reflect the skewed distribution of the DES items and thus could be a statistical artifact reflecting the presence of difficulty factors or "artifactors" (for a recent contribution to this discussion, see Holmes et al., 2005).

One criticism of the DES is that it contains a substantial number of items that assess absorption, which is "a characteristic of the individual that involves an openness to experience emotional and cognitive alterations across a variety of situations" (Roche \& McConkey, 1990, p. 92). Absorption is closely related to the superordinate trait of openness to experience and is not inherently psychopathological (Rauschenberger \& Lynn, 1995). To resolve this issue, and to discriminate benign from pathological forms of dissociation, N. G. Waller, Putnam, and Carlson (1996) developed the DES-Taxon (DES-T). They extracted eight items from the DES measuring derealization, depersonalization, psychogenic amnesia, and identity alteration, and they excluded items tapping nonpathological features of dissociation, notably absorption. Developed with taxometric methods (Meehl \& Golden, 1982), the
DES-T calculates the probability that a respondent belongs to a presumed pathological taxon (natural category) of dissociation.

The DES-T has been widely employed in clinical studies (Irwin, 1999; Simeon, Guralnik, Schmeidler, Sirof, \& Knutelska, 2001; Tampke \& Irwin, 1999; Waldo \& Merritt, 2000; G. Waller, Ohanian, Meyer, Everill, \& Rouse, 2001). Simeon et al.'s (1998) finding - that the DES-T total score performs better than the standard DES total score in discriminating patients with DPD from healthy control participants - has provided support for the validity of the DES-T.

However, other studies have cast doubt on the DES-T's utility. For example, Simeon, Knutelska, Nelson, Guralnik, and Schmeidler (2003) found that within a sample of patients with DPD $(N=100)$, the DES-T classified only $64 \%$ of patients with DPD as having a dissociative disorder. Additionally, researchers (Giesbrecht, Merckelbach, \& Geraerts, 2007; Leavitt, 1999) have argued that the DES-T may yield a high proportion of false positive classifications (i.e., erroneously diagnosing asymptomatic individuals with a dissociative disorder), especially in samples with low rates of dissociative disorders. Moreover, Modestin and Erni (2004, p. 81) "were unable to find a statistically significant relationship between dissociative disorder diagnosis and taxon membership." Testing the DES-T's construct validity, Watson (2003a) investigated the temporal stability of dissociative taxon membership probability in a sample of 465 undergraduates. His study yielded a disappointing test-retest correlation of .34 for taxon membership probability. Watson (2003a) noted that "reduced stabilities raise very serious concerns about the ultimate existence of a pathological dissociative taxon" (p. 303) and cautioned researchers about employing the taxon probability as a measure of pathological dissociation in nonclinical samples. Moreover, although the DES-T was designed to exclude experiences of absorption, it is highly related to the absorption items of the DES (Giesbrecht, Merckelbach, \& Geraerts, 2007) and the remaining 20 nonpathological items of the DES (Davis-Merritt \& You, 2008), which led Leavitt (1999, p. 437) to conclude that "the parallels between DES, DES-T, and absorption continua in samples of dissociative disordered patients are striking." Nevertheless, it would be informative if future studies would systematically examine the independent contribution of absorption and more pathological dissociation items as predictors of research outcomes (e.g., memory performance). That said, many studies we review documented differences between high and low scorers on the DES and the DES-T with respect to a variety of measures of memory and cognition.

Researchers have developed a number of alternative questionnaires to quantify dissociative symptoms. They include the Perceptual Alterations Scale (S. Sanders, 1986), the Questionnaire of Experiences of Dissociation (Riley, 1988), the Dissociation Questionnaire (Vanderlinden, Van Dyck, Vandereycken, \& Vertommen, 1991), the Dissociative Processes Scale (Watson, 2003a), and the Mini-Structured Clinical Interview for DSM-IV Dissociative Disorders (Steinberg, Rounsaville, Buchanan, \& Cicchetti, 1992). Except for the Mini-Structured Clinical Interview for DSM-IV Dissociative Disorders, which is modeled after the Structured Clinical Interview for the Dissociative Disorders (Steinberg, 1993), all these questionnaires contain many items measuring nonpathological dissociative symptoms (i.e., absorption).

Recently, researchers have developed questionnaires to measure only part of the dissociative spectrum, such as somatoform disso- 
ciation (Somatoform Dissociation Questionnaire; Nijenhuis, Spinhoven, Van Dyck, Van der Hart, \& Vanderlinden, 1996) or depersonalization/derealization (Cambridge Depersonalization Scale, Sierra \& Berrios, 2000; Depersonalization Severity Scale, Simeon, Guralnik, \& Schmeidler, 2001). However, the discriminant validity of these two scales with respect to nonpathological dissociation (i.e., fantasy immersion) is unknown. In addition, Simeon, Smith, Knutelska, and Smith (in press) showed that even the Cambridge Depersonalization Scale and the Somatoform Dissociation Questionnaire, two measures designed to measure distinct manifestations of dissociation, are moderately correlated in patients with DPD $(r=.50)$. Thus, the discriminant correlation between these two measures is comparable with the convergent correlations of the DES with other measures of dissociation (van IJzendoorn \& Schuengel, 1996).

In sum, it is essential to understand the shortcomings of the DES, as discussed above, when interpreting the findings from studies that rely on the DES or similar instruments. Nevertheless, the DES has proven to be valuable across a variety of studies using different experimental paradigms and has substantially contributed to the accumulation of our knowledge about the concomitants of dissociative symptoms. Although the reader will note that some disparities in findings we report may be accounted for in terms of measurement issues, there also are notable convergences in outcomes across studies based on the DES and other self-report measures of dissociation. Here, we discuss research relying on self-report measures administered to individuals with dissociative tendencies and examine independently findings pertinent to patients with formally diagnosed dissociative disorders.

Given its centrality in any discussion of dissociation, we weave considerations regarding the trauma-dissociation link into our review and examine how research findings related to the cognitive concomitants of dissociation bear on the hypothetical association between trauma and dissociation later in our discussion. However, our main focus throughout is on cognitive processes in dissociation.

\section{Questionnaire Correlates of Dissociative Tendencies}

\section{Study Selection}

Studies on questionnaire correlates of dissociative tendencies were identified through searches of the Medline and PsycINFO electronic databases by using the entry terms dissociation, multiple personality disorder, dissociative, depersonalization, or depersonalisation, in combination with other terms including cognitive failures, fantasy, and suggestibility. We limited our search to articles written in English and published after 1980, the year in which the dissociative disorders were introduced in the third edition of the DSM (American Psychiatric Association, 1980).

Our literature search yielded 357 hits. We then examined titles and abstracts to identify studies using a standardized empirical methodology, adult samples, and at least one other relevant selfreport measure. To be included, studies were required to (a) include at least one (sub)sample of patients with a dissociative disorder $(n \geq 10)$ or (b) rely on a standardized self-report measure of dissociation (e.g., DES) in a clinical or nonclinical sample $(N \geq$ 20) and present statistics directly relevant to the relation between dissociation and the questionnaire at hand. This procedure yielded
30 eligible studies. We then identified additional articles that might be relevant by examining references in articles selected during the literature search. Studies from the authors' archives were also included.

\section{Fantasy Proneness}

Fantasy, daydreaming, and imagination are associated with healthy psychological functioning. Although the inability to control these processes is associated with, if not causally related to, psychological problems (Rauschenberger \& Lynn, 1995), most individuals who fantasize extensively exhibit no signs of serious psychopathology (Merckelbach \& Muris, 2001). Meanwhile, researchers have established that dissociative experiences and fantasy proneness are related. By using the Inventory of Childhood Memories and Imaginings (S. C. Wilson \& Barber, 1983), Rauschenberger and Lynn (1995) compared 26 participants who reported extensive fantasizing with 26 participants with less extensive fantasy histories. They found that fantasy-prone individuals (i.e., fantasizers) had higher levels of dissociative symptoms than did nonfantasizers. Similarly, Silva and Kirsch (1992) found a correlation of $r=.42$ between the Inventory of Childhood Memories and Imaginings and the DES. Green, Kvaal, Lynn, Mare, and Sandberg (1991) administered a measure of fantasy proneness along with four widely used dissociation measures to 1,249 college students and found that fantasy proneness and dissociation correlated in the order of $r=.47-.63$. Segal and Lynn (1992-1993) also found evidence for moderate correlations $(r=.40-.44)$ between two measures of dissociation and scales of daydreaming and poor attentional control. Moreover, Ruiz, Pincus, and Ray (1999) found that dissociation overlaps with openness to experience (but see Kwapil, Wrobel, \& Pope, 2002). Finally, in a sample of children, Rhue, Lynn, and Sandberg (1995) determined that a measure of childhood dissociation correlated at $r=.54$ with a measure of childhood fantasy. Other studies obtained similar results, with correlations between dissociation and fantasy proneness ranging from $r=.43$ to $r=.58$ (Geraerts, Merckelbach, Jelicic, Smeets, \& van Heerden, 2006; Gow, Lang, \& Chant, 2004; Maltby, Day, McCutcheon, Houran, \& Ashe, 2006; Merckelbach, Horselenberg, \& Schmidt, 2002; Merckelbach, Muris, \& Rassin, 1999; Merckelbach, Muris, Rassin, \& Horselenberg, 2000).

Researchers have found that dissociative experiences and fantasy proneness are associated with each other not only in healthy samples but also in clinical populations (Merckelbach et al., 2005; Pekala et al.,, 1999-2000). Pekala et al. (1999-2000) reported a correlation of $r=.41$ between measures of the two constructs in a sample of 1,229 drug addicts (see also Pekala, Angelini, \& Kumar, 2001), and Merckelbach et al. (2005) reported an overall correlation of $r=.55$ in a mixed sample of psychiatric patients (e.g., patients with schizophrenia, borderline personality disorder, and major depressive disorder). Importantly, the dissociation-fantasy proneness link cannot be explained by the fact that the DES includes absorption items, which are closely related to fantasy proneness: Correlations between fantasy proneness and the DES Amnesia and Depersonalization subscales (Giesbrecht, Merckelbach, Kater, \& Sluis, 2007) and the DES-T (Giesbrecht, Merckelbach, \& Geraerts, 2007) remain in the $r=.40-.48$ range. Furthermore, Levin, Sirof, Simeon, and Guralnick (2004) and Huntjens et al. (2006) reported elevated levels of fantasy proneness 
in patients with DPD and DID as compared with those of nonsymptomatic participants.

The fact that individuals who dissociate frequently engage in fantasizing may have profound consequences for understanding the origins of dissociative experiences. Notably, imaginative tendencies may compromise the validity of self-report questionnaires that measure trauma on a retrospective basis. Fantasy proneness could affect responses to such questionnaires in two ways. First, fantasizers may confuse imagined events with factual autobiographical memories. The failure to differentiate imagined from real memories is termed a reality monitoring error (M. K. Johnson, Hashtroudi, \& Lindsay, 1993). Second, fantasy-prone individuals may adopt a more liberal response criterion for reporting an experience as genuine (i.e., a "real" memory), thus exhibiting a positive response bias, or in more extreme cases, a tendency to confabulate, as we discuss in more depth later.

\section{Suggestibility}

Several investigators have speculated that high levels of dissociation would predict the tendency to incorporate misleading information into memory. Using a staged event paradigm, Eisen and Carlson (1998) noted that undergraduate students' DES scores were related to their errors on misleading questions about the event. However, Eisen, Qin, Goodman, and Davis (2002) found no evidence for such a link in their sample of children. The authors attributed their failure to replicate their earlier research to the age of their participants, as dissociation, and especially imaginative involvement, is much more prevalent in younger individuals.

Interrogative suggestibility involves "the tendency of an individual's account of events to be altered by misleading information and inter-personal pressure within an interview" (Singh \& Gudjonsson, 1992, p. 155). Gudjonsson and his colleagues developed the Gudjonsson Scale of Interrogative Suggestibility (GSS; Gudjonsson, 1984) to predict susceptibility to highly suggestive questioning during a police interrogation (e.g., Gudjonsson, 1984; Gudjonsson \& Clark, 1986).

The GSS involves three phases. First, the experimenter reads a story to participants. Next, participants respond to 20 questions about the story: 5 are nonleading and concern information presented in the story (e.g., "Did the woman have a husband called Simon?"- correct answer: yes), and 15 are highly suggestive and concern information not present in the story (e.g., "Were the assailants convicted six weeks after their arrest?"- correct answer: do not know). Wrong answers to these latter questions make up the Yield scale of the GSS. Finally, participants receive negative feedback about their performance and are asked to answer all questions once more. Changes in responses following negative feedback compose the Shift scale of the GSS. The sum of both scales represents the total GSS score. Wolfradt and Meyer (1998) found correlations of $r=.53$ between the DES and the Yield scale and $r=.44$ between the DES and the Shift scale in a mixed sample of 37 anxious patients and 44 nonsymptomatic participants. Moreover, the DES and the total GSS score were correlated at $r=.54$. Merckelbach, Muris, Rassin, and Horselenberg (2000) reported a smaller, albeit significant, correlation $(r=.37)$ between the DES and the GSS total score in an undergraduate sample $(N=56)$ and a correlation of $r=.29$ between the DES and the Yield score. In contrast, the correlation between the DES and the Shift scale failed to attain significance ( $r=.22$; see also Polczyk, 2005). Additionally, when the researchers controlled statistically for the influence of cognitive failures, as measured by the Cognitive Failures Questionnaire (Broadbent, Cooper, Fitzgerald, \& Parkes, 1982), the significant correlations between DES and suggestibility indices disappeared.

\section{Cognitive Failures}

The latter finding is not surprising inasmuch as individuals who are prone to dissociation also report more cognitive failures, as measured by the Cognitive Failures Questionnaire. This questionnaire asks respondents to indicate on a 5-point scale how frequently they experience everyday cognitive failures, including forgetting names, missing signs on the road, or being distracted. The correlation between the DES and the Cognitive Failures Questionnaire ranges from $r=.43$ to .61 (Merckelbach, Horselenberg, \& Schmidt, 2002; Merckelbach et al., 1999; Wright \& Osborne, 2005). Moreover, the Cognitive Failures Questionnaire correlates with all DES subscales, with correlations ranging from $r=.34$ to .46 (Bruce, Ray, \& Carlson, 2007), and so these correlations are not solely due to an overlap between nonpathological manifestations of dissociation and cognitive failures. Studies have shown that dissociative symptoms change with age. In fact, there is a well-documented age-related reduction in dissociative tendencies after the 4th decade (Walker, Gregory, Oakley, Bloch, \& Gardener, 1996). Scores on instruments like the Cognitive Failures Questionnaire also tend to decline with age. One reason for this could be the less taxing lifestyles that often accompany old age (Reason, 1993).

Merckelbach, Horselenberg, et al. (2002) investigated the hypothesis that the relation between self-reported trauma and dissociation is due to individual differences in cognitive failures and fantasy proneness. They used structural equation modeling in a nonclinical sample of 109 undergraduates and tested two contrasting models. Model 1 was the classical trauma-dissociation model, which assumes that trauma precedes dissociation, which in turn potentiates fantasy proneness and cognitive failures. In contrast, Model 2 presumes that dissociation is the starting point, leading to fantasy proneness and cognitive failures. In this model, fantasy proneness and cognitive failures would be expected to contribute to retrospective reports of traumatic experiences. The authors found support for both models, which means that their data do not contradict the possibility that fantasy proneness and cognitive failures fuel overreporting of trauma.

Model 2 begs the question of the origins of dissociative experiences. Research investigating the heritability of cognitive failures and fantasy proneness may shed light on this question. Relying on a sample of monozygotic and dizygotic twins, Boomsma (1998, p. 321) noted that "a substantial part of the inter-individual variation in everyday cognitive failures in memory, perception and motor control can be attributed to genetic factors." Likewise, fantasy proneness can be regarded as a lower-order facet of the superordinate personality trait of "openness to experience," which itself has substantial heritability (Bergeman et al., 1993). By using twin registry data, Lang, Paris, Zweig-Frank, and Livesley (1998) investigated the heritability of dissociative experiences and reported that about half of the variability in dissociative experiences can be attributed to genetic factors. However, the evidence from twin 
studies for the heritability of dissociative experiences is mixed: N. G. Waller and Ross (1997) found no indications for a genetic basis, whereas a recent study of children and adolescents found "a substantial genetic contribution to dissociation scores" (BeckerBlease et al., 2004, p. 530).

To summarize, dissociation shares a moderate-to-large proportion of variance with fantasy proneness, (interrogative) suggestibility, and susceptibility to cognitive failures. The overlap between fantasy involvement and dissociation raises the possibility that dissociation is associated with a heightened risk of confabulation and pseudo-memories (Merckelbach, Muris, Horselenberg, $\&$ Stougie, 2000). Furthermore, cognitive failures in the context of dissociation may serve as a confound in studies that solicit retrospective reports about exposure to traumatic experiences, such as a history of early abuse. More specifically, individuals who report many cognitive failures are probably more prone to mistrust their memories, which might increase their susceptibility to misleading post hoc information (Loftus, 1993). Accordingly, a combination of fantasy proneness, interrogative suggestibility, and the susceptibility to cognitive failures may undermine the accuracy of retrospective reports of traumatic experiences, resulting in overestimates of childhood trauma rates (i.e., false positives).

Although we have assumed that susceptibility to cognitive failures and a tendency to fantasize should engender overreporting of traumatic experiences, one could also argue that the opposite is true. Hypothetically, individuals high on dissociation could also report a relatively smaller number of traumatic experiences, as compared with actual trauma rates, due to higher rates of forgetfulness (i.e., cognitive failures). Alternatively, high dissociators with profound imaginative abilities may develop pseudo-memories of a trauma-free childhood, which could lead to systematic underestimates of traumatic experiences and their relation to dissociation (i.e., false negatives).

Meanwhile, there are good empirical reasons to suspect that in this context, false positives are more likely to occur than false negatives. Gilbert (1991) reviewed a large body of experimental evidence concerning people's tendencies to believe and disbelieve and concluded that "people are credulous creatures who find it very easy to believe and very difficult to doubt" (p. 177). According to Gilbert (1991), disbelief tends to occur after initial acceptance of an idea or belief, even when the content is of unknown truth value or known to be false. Evidence for this contention comes from a broad range of studies, many published after Gilbert's (1991) review. For example, Hasson and Glucksberg (2006) used a lexical decision task and found that both affirmative and negated assertions facilitate access to affirmative-related terms in early stages of comprehension. Relatedly, Pandelaere and Dewitte (2006) found that when readers process questions, they initially represent the questions as true statements. Moreover, Gilbert, Tafarodi, and Malone (1993) determined that cognitive load and time pressure increased individuals' tendencies to believe false information.

Brewer, Lillie, and Hallman's (2006) research illustrated that the difficulties that people experience to disbelieve are not limited to laboratory settings. The investigators determined that $65 \%$ of Gulf War veterans believed they had been exposed to biological or chemical warfare agents. This claim stands in sharp contrast to the U.S. military's statement denying any exposure. Interestingly, the authors found that many of these soldiers failed to disbelieve prior exposure alerts from the military. Although it seems that believing is cognitively easier than disbelieving, Merckelbach, van Roermund, and Candel (2007) and Wright, Loftus, and Hall (2001) used naturalistic paradigms and determined that with the use of appropriate manipulations, people's reports of actual memories can be inhibited (but see Pezdek \& Roe, 1997).

With respect to the relation between self-reported traumatic experiences and dissociation, it is noteworthy that widely used self-report instruments such as the Childhood Trauma Questionnaire (D. P. Bernstein et al., 1994; D. P. Bernstein et al., 2003) contain broadly formulated trauma items that inquire about beliefs or opinions. These items may encourage overreporting of trauma, especially among individuals high on fantasy proneness (Merckelbach \& Jelicic, 2004). Moreover, self-report measures of trauma obviously are not designed to create a context that discourages reporting of traumatic experiences. Yet such a context would be necessary to suppress self-reports of traumatic experiences in highly suggestive individuals, so as to produce false negatives. Interestingly, data also refute the contention that cognitive failures and fantasy proneness lead to underreporting on self-report trauma questionnaires insofar as measures of both constructs are positively rather than negatively related to self-reported traumatic experiences on the Childhood Trauma Questionnaire (Merckelbach, Horselenberg, \& Schmidt, 2002).

\section{Dissociation, Information Processing, and Memory}

We have presented two contrasting views concerning the link between dissociation and trauma. The first, the trauma-dissociation view, is most prominently presented in the clinical literature and holds that traumatic experiences, particularly severe childhood abuse, constitute an important and direct developmental antecedent of dissociative tendencies (e.g., Classen, Koopman, \& Spiegel, 1993; Holmes et al., 2005; Kersting et al., 2003; Reinders et al., 2003). Some authors have argued that dissociation can also arise in response to other stressful, but not strictly traumatic, life events, including emotional abuse or neglect (Simeon, Guralnik, Schmeidler, et al., 2001).

The second view suggests that dissociation overlaps with fantasy proneness, suggestibility, and cognitive failures, all of which may artificially inflate the relationship between dissociation and self-reported trauma (e.g., Merckelbach, Horselenberg, \& Schmidt, 2002; Merckelbach \& Muris, 2001). According to this view, trauma and/or stressful life events are not prerequisites for dissociation. Importantly, these two views on the relationship between trauma and dissociation are not mutually exclusive. For example, one could argue that trauma does not play a critical role across the entire dissociative continuum but is restricted to cases of profound dissociative psychopathology (e.g., van der Hart et al. 2004). Another possibility is that fantasy proneness, suggestibility, and cognitive failures contribute to an overestimation of an otherwise genuine, albeit often weak, link between dissociation and trauma. Thus, although trauma may not be the dominant etiological factor, as some authors have proposed (Classen et al., 1993), it may still exert some influence on dissociative psychopathology.

One core assumption of the trauma-dissociation view can be traced to Pierre Janet (1889/1973), who argued that dissociation is accompanied by disturbances in memory for emotional events (van der Kolk \& van der Hart, 1989). Indeed, E. M. Bernstein and 
Putnam (1986) highlighted the importance of disruptions of memory and attention in their definition of dissociation. There is a broad consensus in the clinical literature that deficits in memory function (e.g., compartmentalization, psychogenic amnesia) are core features of dissociation and that these deficits serve a defensive function that enables trauma victims to detach psychologically from painful experiences (Ehlers \& Clark, 2000; Holmes et al., 2005; van der Kolk \& Fisler, 1995).

According to Ladwig et al. (2002, p. 242), "victims of a psychotraumatic event may protect themselves against the overwhelming exposure of threatening stimuli by inhibiting information processing." The detrimental effects of dissociation on attention and memory are thought to stem from informationprocessing disturbances that, in turn, are believed to be the byproduct of the alleged defensive function of dissociation (Spiegel \& Cardena, 1991; van der Kolk \& Fisler, 1995). Given the broad consensus about the profound influence of dissociation on attention and memory, it is not surprising that many authors have emphasized the importance of exploring information-processing characteristics that accompany heightened levels of dissociation (Brewin \& Saunders, 2001; Cardeña, 1994; Classen et al., 1993; Dorahy, 2001; Holmes, Brewin, \& Hennessy, 2004; Spiegel \& Cardena, 1991). For example, if dissociative symptoms (e.g., psychogenic amnesia and derealization) do, indeed, attenuate the impact of traumatic events, then individuals with heightened levels of dissociation should exhibit slower or impaired processing of threat-related information.

In sum, we have presented two views on possible cognitive concomitants of dissociation. However, we have based our description of these two views on studies that predominantly employed self-report measures. For example, cognitive failures were measured by means of the Cognitive Failures Questionnaire (Broadbent et al., 1982), and fantasy proneness is typically measured by the Creative Experiences Questionnaire (Merckelbach, Horselenberg, \& Muris, 2001). However, self-report measures assess beliefs pertaining to our perception of cognitive phenomena, which may or may not be accurate, and do not assess actual performance. For example, there is only moderate agreement between self-rated and actual neuropsychological performance in patients with traumatic brain injury (C. C. Allen \& Ruff, 1990; Bogod, Mateer, \& Macdonald, 2003). Therefore, in the sections that follow, we critically evaluate performance studies relevant to the issue of cognitive concomitants of dissociation.

\section{Study Selection}

We identified studies on cognitive correlates of dissociative tendencies through searches of the Medline and PsycINFO electronic databases. We used the entry terms dissociation, multiple personality disorder, dissociative, depersonalization, or depersonalisation, in combination with other terms including executive functioning, digit span, Wechsler Adult Intelligence Scale, Stroop, directed forgetting, amnesia, false memory, working memory, memory fragmentation, commission error, and autobiographical memory. We limited our search to articles written in English and published after 1980, the year in which the dissociative disorders were first introduced in the DSM-III (American Psychiatric Association, 1980).
Our literature search yielded 1,381 hits. We then examined titles and abstracts to identify studies using a standardized empirical methodology, adult samples, and cognitive laboratory tasks. With regard to dissociation, studies were required to (a) include at least one (sub)sample of patients with a dissociative disorder $(n \geq 10)$ or (b) rely on a standardized self-report measure of dissociation (e.g., DES) in a clinical or nonclinical sample $(N \geq 20)$. Another requirement was that the research presented statistics directly relevant to the relation between dissociation and cognitive functioning. This procedure yielded 60 eligible studies. We then identified additional articles that might have been relevant by examining references in articles selected during the literature search. Studies from the authors' archives were also included.

We present the basic findings of the selected studies separately for those that rely on participants with a diagnosis of a dissociative disorder and those that rely on self-report measures of dissociative symptoms in nonclinical and clinical samples. We make this distinction because some authors argued that there are qualitative differences between individuals with a diagnosed dissociative disorder and those who merely self-report dissociative symptoms (e.g., van der Hart et al., 2004).

Even though we agree with Holmes et al. (2005) that a more precise analysis of how different dissociative symptom constellations affect cognition may yield worthwhile findings, the current empirical literature has not lent itself to this endeavor due to its reliance on the DES, the lack of consensus about its factor structure, and the limited number of studies that actually examine individuals with different dissociative disorders. The selected studies and their main findings are summarized in the Appendix.

The present review is limited to chronic dissociative symptoms and excludes acute dissociative symptoms during traumatic experiences (i.e., peri-traumatic dissociation). There are three reasons for this restriction. First, although peri-traumatic and chronic dissociation are related, the precise nature of this relationship is far from clear (Sterlini \& Bryant, 2002). Second, the number of articles on peri-traumatic dissociation and its relation to PTSD is substantial and constitutes a large research domain of its own. We refer readers primarily interested in peri-traumatic dissociation to Candel and Merckelbach's (2004) review and Brewin, Andrews, and Valentine's (2000) and Ozer, Best, Lipsey, and Weiss's (2003) meta-analyses. Third, the focus of the present review is on cognitive dysfunctions implicated in dissociation. However, cognitive performance during peri-traumatic dissociation is difficult to investigate, insofar as high levels of peri-traumatic dissociation almost by definition occur during extremely stressful events, like motor vehicle accidents, and are consequently almost always assessed retrospectively. Thus, participants' acute dissociation levels may be expected to be lower when they eventually arrive in the laboratory. This makes it problematic to relate peri-traumatic dissociation to performance on cognitive tasks (but see Giesbrecht, Smeets, \& Merckelbach, 2008; Morgan et al., 2001; Sterlini \& Bryant, 2002).

\section{Neuropsychological Functioning}

Researchers have reported deficits in neuropsychological functioning in psychiatric disorders such as schizophrenia (Heinrichs \& Zakzanis, 1998), borderline personality disorder (Fertuck, Lenzenweger, Clarkin, Hoermann, \& Stanley, 2006), and depression 
(Rogers et al., 2004), conditions that often go along with heightened levels of dissociative symptoms (E. M. Bernstein \& Putnam, 1986). Additionally, because the symptoms of neurological conditions like temporal lobe epilepsy and transient global amnesia resemble dissociative symptoms (Sivec \& Lynn, 1995), it is tempting to speculate about whether a chronic state of dissociation hampers stimulus processing and consequently neuropsychological functioning.

Dissociative disorders. Several studies have examined the link between dissociation and general cognitive functioning in DID patients. Roca, Hart, Kimbrell, and Freeman (2006) found that veterans with PTSD and a diagnosis of a dissociative disorder $(n=10)$ did not differ significantly from veterans with PTSD but no dissociative disorder diagnosis $(n=17)$ on the Wechsler Abbreviated Scale of Intelligence (Hays, Reas, \& Shaw, 2002). Low statistical power renders these findings difficult to interpret. Yet, Rossini, Schwartz, and Braun (1996) administered the Wechsler Adult Intelligence Scale (WAIS; Wechsler, 1981) to a larger sample of 105 patients with DID $(n=50)$ or dissociative disorder not otherwise specified (DDNOS; $n=55$ ) and reached a similar conclusion: Patients do not show deleterious intellectual functioning attributable to fluctuating manifestations of their disorder. However, patients' test results showed abnormal (inter-test) scatter due to subtle deficits on the WAIS's Memory/Distractibility factor. Germane to this issue, Kirino (2006) conducted an event-related potential (ERP) study of 12 patients with DID and 12 matched non-DID control participants. This author measured the P300 component during an auditory oddball task. The P300 is thought to reflect updating of working memory (Donchin, 1981) and has been described as reflecting tonic arousal and arousal alteration to specific stimulus events (Polich \& Kok, 1995). Reduced P300 amplitudes are associated with information-processing deficits, as seen, for example, in schizophrenia (e.g., Friedman, Cornblatt, Vaughan, \& Erlenmeyer Kimling, 1986), whereas larger amplitudes are related to superior memory performance (Fabiani, Karis, \& Donchin, 1990). DID patients exhibit reduced P300 amplitudes as compared with control participants only during acute dissociative episodes, but not during remission (see also Fukuzako et al., 1999).

In the first extensive study of cognitive processes in DPD, Guralnik, Schmeidler, and Simeon (2000) found that DPD participants differed from normal control participants on specific cognitive dimensions within the general context of comparable intellectual ability. Specifically, DPD participants exhibited deficits in visual perception and visual-spatial reasoning for both two- and three-dimensional stimuli. Their visual and verbal short-term memories were also compromised, for both abstract and meaningful information, especially under information overload conditions. DPD participants experienced difficulty with early stimulus encoding tasks under conditions of heightened distraction to which they responded with more omission errors (lowered perceptual sensitivity). Thus, DPD appears to be characterized by a particular vulnerability in early information processing at the level of perception and attention (for a replication, see Guralnik, Giesbrecht, Knutelska, Sirroff, \& Simeon, 2007).

Elzinga et al. (2007) looked at working memory performance and brain activation by means of functional magnetic resonance imaging (fMRI), employing the n-back task in a mixed sample of patients with DDNOS and DID $(n=16)$ as compared with normal control participants $(n=16)$. Behaviorally, patients outperformed control participants when task demands increased, with their performance advantage being accompanied by greater anterior, dorsolateral, and ventrolateral prefrontal cortex as well as parietal cortex activation. In contrast to Elzinga et al. (2007), Rossini et al. (1996) and Guralnik et al. (2000, 2007) found no evidence for either superior working memory capacity or working memory deficits in DID, DDNOS, and DPD by using the Digit Span subtest.

Other samples. Several other studies investigated how intellectual functioning relates to dissociation in nondissociative disorder samples. Giesbrecht, Merckelbach, Geraerts, and Smeets (2004) investigated the link between dissociation and executive functioning in an undergraduate sample $(N=185)$ by using the random number generation task (Horne, Evans, \& Orne, 1982). In this task, participants are required to generate random patterns of numbers between 1 and 10, which requires efficient monitoring and inhibitory (i.e., executive or frontal) functions. The researchers found that minor disruptions in executive functioning were related to a subclass of dissociative experiences, particularly dissociative amnesia and elevated DES-T scores. Similarly, Cima, Merckelbach, Klein, Schellbach-Matties, and Kremer (2001) found a significant association between the DES and performance on the Behavioral Assessment of Dysexecutive Syndrome (B. Wilson, Alderman, Burgess, Emslie, \& Evans, 1996) in inmates of a psychiatric correctional institute $(N=30)$, with poorer performance on frontal tasks associated with higher DES scores $(r=$ -.39). Bruce, Ray, Bruce, Arnett, and Carlson (2007) failed to find executive impairments in a study comparing undergraduate students scoring high $(n=33)$ and low $(n=33)$ on the DES.

Mirroring research on dissociative disorders, findings concerning the association between memory capacity and dissociation have been mixed. Although most researchers have reported no evidence for a link between dissociation and working memory capacity (i.e., digit span, Giesbrecht, Geraerts, \& Merckelbach, 2007; Papageorgiou, Ventouras, Uzunoglu, Rabavilas, \& Stefanis, 2002; Stevens, Burkhardt, Hautzinger, Schwarz, \& Unckel, 2004; Wright \& Osborne, 2005), some have reported that dissociative individuals display superior verbal working memory capacity (De Ruiter, Phaf, Elzinga, \& Van Dyck, 2004; Veltman et al., 2005). Moreover, in a sample of adolescent psychiatric patients $(N=41$; Prohl, Resch, Parzer, \& Brunner, 2001), dissociative symptomatology was related to deficits in declarative and procedural memory performance, as indexed by the California Verbal Learning Test and the Tower of Toronto puzzle (but see Stein, Hanna, Vaerum, \& Koverola, 1999). In line with the assumption that dissociation accompanies working memory deficits, Papageorgiou et al. (2002) found that individuals with transient depersonalization/realization symptoms $(n=15)$ displayed reduced P300 amplitudes during the digit span task compared with nonsymptomatic participants ( $n=15$; see also Kirino, 2006).

De Ruiter et al. (2004) investigated verbal working memory by using the Verbal Working Memory Span Test in a sample of 119 undergraduates. They found that individuals with dissociation levels approaching the pathological range outperformed other participants - their verbal memory span was about half a word more than that of low or moderately dissociative individuals. Veltman et al. (2005) investigated neurophysiological correlates of the n-back task and the Sternberg Letter Task in 21 nonclinical participants 
who scored high and low on dissociation, respectively. High dissociators exhibited superior performance on both verbal working memory tasks compared with that of low dissociators. fMRI data showed that similar neural networks are activated in both groups during these tasks, notably the dorsolateral and ventrolateral prefrontal cortex, parietal cortex, and supplementary motor area, but that high dissociative participants activate these networks to a larger extent.

In sum, dissociation is associated with subtle and specific cognitive deficits within the context of otherwise normal intellectual ability on standard neuropsychological tests. This cognitive profile is striking given the phenomenology of the dissociative disorders, which are characterized by subjective reports of profound cognitive disturbances like amnesia, feelings of unreality, and identity alterations. Nevertheless, the relative absence of a robust general neuropsychological deficit in the dissociative disorders is interesting, as it seems to differentiate them from most other severe psychiatric disorders such as schizophrenia. These other conditions overlap with the dissociative disorders but, unlike dissociative disorders, are marked by a wide and consistent range of neuropsychological deficits (Heinrichs \& Zakzanis, 1998). In contrast, different dissociative disorders appear to be related to different cognitive deficiencies. DID is mainly characterized by performance fluctuations, whereas DPD is associated with disruptions in early stages of information processing. Interestingly, there are indications that under certain circumstances, dissociative individuals may exhibit a performance advantage relative to individuals who report low levels of dissociation. However, few investigations have controlled for general distress and psychopathology, or for scores on the personality dimension of openness to experience, which is moderately associated with both dissociative tendencies (Kihlstrom, Glisky, \& Angiulo, 1994) and with crystallized intelligence (DeYoung, Peterson, \& Higgins, 2005).

\section{Emotional Information Processing}

Although Janet's (1889/1973) concept of dissociation was grounded in the hypothesis that dissociative individuals exhibit deviant information processing of emotional material, few studies have followed Janet's lead. Dorahy and his coworkers (e.g., Dorahy, McCusker, Loewenstein, Colbert, \& Mulholland, 2006; Dorahy, Middleton, \& Irwin, 2005) and Freyd and her colleagues (DePrince \& Freyd, 1999; Freyd, Martorello, Alvardo, Hayes, \& Christman, 1998) conducted two series of studies that are notable exceptions.

Dissociative disorders. One line of research has investigated cognitive inhibitory functioning in DID (Dorahy, Irwin, \& Middleton, 2002, 2004; Dorahy et al., 2006; Dorahy, Middleton, \& Irwin, 2004; Dorahy et al., 2005). These studies suggest that individuals with DID possess intact cognitive inhibitory capabilities under neutral conditions (Dorahy, Middleton, \& Irwin, 2004) but that these capabilities become strained or degraded in an anxietyprovoking context (Dorahy et al., 2006, 2005). To investigate cognitive inhibition, Dorahy and colleagues (e.g., Dorahy, Middleton, \& Irwin, 2004) measured negative priming during a flanker task. Dorahy, Irwin, and Middleton (2004) compared negative priming in a sample of DID patients with that in independent samples of depressed, PTSD, psychotic, and control participants (each group: $n=10$ ). Interestingly, in a neutral context, the DID sample "showed no evidence of reduced negative priming" (Dorahy, Irwin, \& Middleton, 2004, p. 52; but see Dorahy et al., 2002). In another study, in which the researchers compared samples of DID patients, generalized anxiety disorder patients, and nonsymptomatic control participants (each group: $n=12$ ) across neutral and emotional contexts, a different pattern emerged (Dorahy et al., 2006). In line with their previous findings, the DID group exhibited intact cognitive inhibition in the neutral condition but poor cognitive inhibition in an emotional context, whereas the generalized anxiety disorder group displayed the opposite pattern (for a similar finding, see Dorahy et al., 2005).

Other samples. Employing a nonclinical sample, Giesbrecht, Merckelbach, and Smeets (2006) provided further evidence for a link between dissociation and poor cognitive inhibition during emotional states (Dorahy et al., 2006). The researchers used an undergraduate sample $(N=40)$ to investigate thought suppression in response to an emotional video fragment. They found that students with high DES-T scores experienced difficulties in suppressing emotional thoughts. However, due to the lack of a neutral control condition, this study could not rule out the presence of a general inhibitory control deficit in high dissociators. Much the same is true for G. Waller, Quinton, and Watson's (1995) study of undergraduates $(N=105)$, which showed that higher levels of dissociation are related to slower responding to threatening information.

Yet when neutral stimulus material is used, dissociation does not appear to be associated with superior memory suppression (Wessel, Wetzels, Jelicic, \& Merckelbach, 2005). Specifically, Wessel et al. (2005) employed Anderson and Green's (2001) think-no think task, which consists of three phases. In the study phase, participants are required to memorize cue-target pairs. In the think-no think (i.e., experimental) phase, participants are shown only the cues. However, for some cues, participants are asked to avoid thinking about the associated target (i.e., no-think items), whereas for other cues they are required to think of the associated target (i.e., think items). At the end of the task, memory for all target items is assessed. If high dissociation levels were associated with superior suppression capabilities, even for neutral material, one would expect high dissociators to show less recall of no-think items. However, Wessel et al. (2005) found no performance differences on the think-no think task between undergraduates who scored high $(n=35)$ and low $(n=33)$ on the DES, with the Critical Group $\times$ Instruction $\times$ Trial interaction failing to reach statistical significance.

DePrince and Freyd (1999) and Freyd et al. (1998) used the Stroop task (Stroop, 1935) to investigate attentional processes involved in dissociation. Freyd et al. (1998) administered a standard Stroop task consisting of color words, $x x x$ s as baseline, and words from four neutral categories (i.e., kinship, animals, household, and space) to undergraduates scoring high $(n=40)$ or low $(n=40)$ on the DES. Words were presented in colored ink on stimulus cards. The researchers determined that dissociation was associated with delayed color-naming latencies for incongruent color words (i.e., the standard Stroop effect) but not for other stimulus categories. Thus, high DES students displayed more Stroop interference than did low DES students. Freyd et al. (1998) concluded that heightened dissociation levels are accompanied by disruptions in attentional control, a conclusion that dovetails with the dissociation-cognitive failures link discussed earlier. 
In a follow-up study, DePrince and Freyd (1999) extended the standard Stroop task with emotional and neutral words. The task was combined with a surprise free-recall test that was administered after the Stroop procedure. On a second block of trials, a dual task version of the Stroop was employed such that participants had to respond as quickly as possible while they simultaneously encoded all stimuli. This condition was included to mimic the habitual divided attention that, according to Freyd (1996), high dissociators employ to protect themselves when exposed to the aversive stimuli. Again, encoding was followed by a free-recall task. Replicating previous work (Freyd et al., 1998), high DES students $(n=54)$ exhibited more interference during the traditional (i.e., selective attention) Stroop task than did low DES students $(n=54)$. However, during the dual task version (i.e., divided attention) of the Stroop task, this effect disappeared, with high DES individuals now performing better than low DES participants. Furthermore, high dissociators consistently reproduced fewer aversive words during free recall than did low dissociators.

On the basis of this pattern of findings, DePrince and Freyd (1999) concluded that dissociative individuals perform better in contexts that involve multiple tasks. However, the superior performance of high dissociators reached statistical significance only when a one-tailed test was conducted. More important, Giesbrecht (2006) failed to replicate this finding in a sample of high $(n=22)$ and low $(n=24)$ dissociators. Specifically, high dissociators responded slower to all Stroop stimuli, irrespective of attention condition or emotional valence of stimuli, whereas no group differences in recall performance were apparent.

The studies reviewed so far suggest that only emotionally negative material undermines the performance of high dissociators. However, this conclusion was refuted by de Ruiter, Phaf, Veltman, Kok, and van Dyck (2003), who compared reaction times and ERPs during letter detection (i.e., detecting the letter $A$ in neutral and negative stimulus words) and affective evaluation (i.e., classifying a word as neutral or negative). Interestingly, in the high dissociator group, letter detection performance and affective evaluation were facilitated, rather than disturbed, by negative valence. This effect was apparent in terms of both reaction times and ERP amplitudes. The authors concluded that "dissociative style does not correspond to a damaged or disturbed function but to an enhanced ability to direct and divide attention" (p. 376).

To summarize, studies have suggested that both poor and superior information-processing performance of high dissociative individuals are content (negative stimulus material) and context (dual task condition) dependent. However, the nature of these effects is far from clear. On the whole, evidence for a breakdown of cognitive inhibition in emotionally negative contexts seems more robust than that for superior performance of high dissociators under divided-attention conditions. Conceptually, the well-replicated breakdown of cognitive inhibition during emotional stress in DID stands in stark contrast to the widespread idea that psychogenic amnesia is a core symptom of dissociation. The point here is that extreme inhibition, rather than lack of inhibition, is one of the few plausible scenarios accounting for psychogenic amnesia (Anderson et al., 2004), if it exists at all (McNally, 2003; H. G. Pope, Barry, Bodkin, \& Hudson, 2006).

\section{Superior Forgetting or Superior Memory?}

Proponents of the trauma-dissociation view posit that the ability to forget or compartmentalize information linked to negative emotions is a core characteristic of highly dissociative individuals (van der Hart et al., 2004). Anecdotal evidence for this hypothesis is abundant (Terr, 1994), but controlled studies are scarce.

Nevertheless, a number of investigators have employed versions of the directed forgetting (DF) task to investigate memory in participants with dissociative disorders and other samples with dissociative symptoms (Cloitre, Cancienne, Brodsky, Dulit, \& Perry, 1996; DePrince \& Freyd, 2001, 2004; Devilly et al., 2007; Elzinga, de Beurs, Sergeant, Van Dyck, \& Phaf, 2000; Elzinga, Phaf, Ardon, \& van Dyck, 2003; McNally, Ristuccia, \& Perlman, 2005). There are two basic versions of this paradigm (Kihlstrom, 1983): item-wise and list-wise DF. During item-wise DF, participants are exposed to a series of words that are directly followed by a cue to either remember or forget. During list-wise DF, participants are exposed to a list of words. Typically, after the presentation of the first half of the stimulus words, participants are asked to forget all stimuli that they have seen so far while remembering all subsequent stimuli. At the end of both versions of the DF task, participants are asked to remember all stimulus words irrespective of remember or forget instructions.

In general, participants tend to recall fewer stimulus words that were coupled with a forget instruction in both variants of the DF task. However, different mechanisms are thought to underlie the respective effects. Briefly, the DF effect of the item-wise version is usually attributed to attentional disengagement (i.e., failure to encode) during presentation of stimuli coupled with a forget instruction. In contrast, DF effects during list-wise DF are thought to represent retrieval inhibition of words that were encoded initially but are rendered temporarily less accessible (MacLeod, 1999).

Given that dissociated memories are thought to be encoded and should consequently remain in storage, but not be amenable to retrieval (Kihlstrom, 2006; van der Hart et al., 2006), studies employing list-wise DF provide a more definitive test of the presumed underlying mechanisms of dissociation. Although some investigators have proposed that retrieval inhibition might be responsible for deficits in traumatic memory (Anderson \& Green, 2001), others have argued that the detrimental effects of dissociation on memory stem from avoidant information processing. Thus, dissociation may also accompany an increased ability to selectively forget or discard information on a conscious level (Cloitre, 1992). Accordingly, the cognitive avoidance hypothesis is best investigated by means of item-wise DF.

Dissociative disorders. By using item-wise DF, Elzinga et al. (2000, Study 2) investigated whether DID and heightened dissociative tendencies are associated with an increased ability to banish material from consciousness. The authors employed neutral, threat, and sexual words to compare the DF performance of a group of DID patients $(n=14)$, an undergraduate low dissociation group ( $n=23)$, and an undergraduate high dissociation group $(n=20)$ The researchers found that both patients and high dissociators displayed an inability to forget material when instructed to do so. This inability was most pronounced for sexual words, suggesting that patients and high dissociators are not characterized by a cognitive avoidance strategy but rather by a "higher general ability to elaborate" (Elzinga et al., 2000, p. 292). 
To extend their prior findings, Elzinga et al. (2003) tested 12 DID patients with neutral and emotional stimuli by using the item-wise DF paradigm. The patients responded to an implicit and explicit memory test both in the same and in a purportedly amnestic identity state. In line with Elzinga et al. (2000), when tested in the same identity state, patients with DID exhibited no DF effect (i.e., failure to forget). Moreover, in the amnestic state, patients exhibited selective forgetting of to-be-forgotten words but not to-be-remembered words. Implicit memory was preserved.

Other samples. Cloitre et al. (1996) investigated the link between dissociation and cognitive avoidance in terms of DF performance. By using positive, negative, and neutral stimuli, these researchers employed an item-wise DF procedure with the following subsamples: (a) 24 patients with borderline personality disorder and a history of childhood abuse, (b) 24 patients with borderline personality disorder but no history of childhood abuse, and (c) 24 nonsymptomatic control participants. Patients with an abuse history exhibited higher levels of dissociation and superior memory performance for to-be-remembered words rather than of enhanced forgetting for to-be-forgotten words. Moreover, dissociation levels, as measured by the DES, were significantly related to recall of to-be-remembered words $(r=.24)$ across all groups. Thus, higher levels of dissociation were related to superior recall of to-be-remembered words, rather than to superior forgetting (i.e., dissociative amnesia). In another study using item-wise DF, Elzinga et al. (2000, Study 1) investigated the relationship between dissociative tendencies and DF performance. The researchers compared undergraduate students who scored high $(n=17)$ and low $(n=18)$ on dissociation with respect to their performance on a DF task involving emotionally neutral words. In line with their previous findings with DID patients, and those of Cloitre et al. (1996), high dissociators failed to selectively forget to-be-forgotten words.

DePrince and Freyd $(2001,2004)$ argued that attentional context (selective vs. divided attention) may be an important determinant of whether trauma-related information is impaired. As noted earlier, they reasoned that high dissociators may display an advantage during divided-attention conditions. To explore this hypothesis, DePrince and Freyd (2004) employed a list-wise DF task but complemented it with both a selective-attention condition and a divided-attention condition (i.e., participants were instructed to push a button whenever the color of the background changed). Using both neutral and trauma-related words, the investigators studied the extent to which undergraduates who scored high $(n=21)$ and low $(n=24)$ on the DES were able to forget (i.e., dissociate) trauma words. Their results indicated that, under dual task conditions, high dissociators tend to recall fewer trauma words (i.e., superior forgetting) and thus seem to be superior in dividing their attention compared with low dissociators (for a similar pattern of findings using item-wise DF, see DePrince \& Freyd, 2001).

However, Devilly et al. (2007) failed to replicate DePrince and Freyd's (2001) findings in two samples of undergraduates. However, Devilly and coworkers have found increased memory fallibility in high dissociators, as demonstrated by lower general recall and, in one study, a heightened tendency to produce commission errors. High dissociators' lowered recall is reminiscent of a study by Holtgraves and Stockdale (1997), who found higher dissociation levels to be related to poorer recall for both positive and negative emotion words. When Devilly et al. (2007) used a meta- analytic approach and combined the data from their two studies with data from DePrince and Freyd's $(2001,2004)$ two studies, the integrated dataset did not yield the critical pattern of results. Specifically, high dissociators did not remember fewer trauma words than neutral words under divided-attention conditions as compared with low dissociators (for a comment, see DePrince, Freyd, \& Malle, 2007; for a response by the authors, see Devilly \& Ciorciari, 2007). Relying on more clinically relevant samples of women who reported either continuous or recovered memories of sexual childhood abuse, and women who reported no abuse history, McNally et al. (2005) were similarly unable to replicate DePrince and Freyd's (2004) list-wise DF findings. Taken together, Devilly et al.'s (2007) and McNally et al.'s (2005) findings have cast doubt on the robustness of high dissociators' capability to selectively forget emotional information under conditions of divided attention.

In sum, studies using the DF paradigm in both clinical and nonclinical samples have largely failed to find evidence for either (a) an excessive avoidant processing style or (b) a superior ability to exclude information from consciousness in high dissociators or participants with dissociative disorders (but see DePrince \& Freyd, 2001, 2004). Most evidence seems to point in the opposite direction, with dissociation being linked to an inability to forget or ignore stimulus words, especially those that are emotional. Thus, studies using DF in dissociation have failed to provide compelling evidence for one of the core assumptions of the traditional view of dissociation, namely that patients with dissociative disorders or individuals who report many dissociative symptoms should display gaps in memory for emotional material (i.e., dissociative amnesia). Theoretically, finding enhanced recall rather than avoidant encoding or poor recall of emotional stimulus words makes sense because it can be related to the breakdown of cognitive inhibition under conditions of emotional arousal in DID (cf. supra).

\section{Specificity and Fragmentation of Autobiographical Memories}

Another core assumption of the trauma-dissociation view, one that is particularly well represented in the clinical literature, is that dissociative individuals' memories become fragmented or disorganized in the face of emotional material. This assumption concurs with some trauma victims' complaints of difficulties in recalling the temporal order of events (e.g., van der Kolk \& Fisler, 1995) and self-reported memory disturbances of patients with DID (van der Hart, Bolt, \& van der Kolk, 2005) and DPD (Simeon, Hwu, \& Knutelska, 2007). Thus, one may expect dissociation to go along with reduced specificity of autobiographical memories (i.e., overgeneral memories; Williams \& Scott, 1988). Typically, researchers measure the specificity of autobiographical memory by providing participants with positive, neutral, and negative cue words (e.g., successful, lonely, friend) and instructing them to describe a specific autobiographical memory response to the cue word. When participants can describe a memory of an event that occurred within a restricted period (e.g., a day or an evening), the memory is classified as specific. However, when the memory response involves a category of events (e.g., "when I go swimming”), or a broad time period (e.g., "when I was young"), the memory is said to be overgeneral. 
Dissociative disorders. No studies to date have investigated autobiographical memory specificity or fragmentation by using objective measures in the dissociative disorders.

Other samples. Harvey, Bryant, and Dang (1998) examined the link between overgeneral memories and dissociation in patients with acute stress disorder (ASD; $n=12$ ) and nonsymptomatic control participants $(n=12)$. ASD manifests itself within the 1 st month after a trauma in symptoms of re-experiencing, avoidance, and hyperarousal, and its diagnosis requires that dissociative symptoms are present. The researchers found that individuals with more severe dissociative symptomatology exhibited less specific autobiographical memories (i.e., overgeneral memories; $r=.45$ ). Jones et al. (1999) showed that dissociative symptomatology predicted overgeneral memories in patients $(n=23)$ with borderline personality disorder $(r=.39)$. When the investigators analyzed the results in terms of the valence of the cue words, they discovered that the effect was carried by negative cue words but not by neutral or positive words. The finding that negative cue words were associated with less specific memories tentatively supports the notion that a dissociative information-processing style undermines encoding or retrieval of specific autobiographical memories.

Thus, Harvey et al. (1998) and Jones et al. (1999) found dissociation to be related to lack of autobiographical memory specificity. However, Renneberg, Theobald, Nobs, and Weisbrod (2005) investigated this link in patients with borderline personality disorder $(n=30)$, depression $(n=27)$, and nonsymptomatic control participants $(n=30)$, and Kremers, Spinhoven, and van der Does (2004) examined this association in a sample of borderline personality disorder patients $(N=83)$. Both studies found no indication that dissociation is associated with reduced autobiographical memory specificity. Moreover, Kremers, Spinhoven, van der Does, and van Dijk (2006) reported that changes in autobiographical memory specificity did not parallel treatment-related reduction in dissociative symptoms in a sample of borderline personality disorder patients $(N=55)$.

The two studies (Harvey et al., 1998; Jones et al., 1999) that did find a relationship between a lack of autobiographical memory specificity and dissociation focused on individuals who suffered not only from dissociative symptoms but from a broad range of psychopathological symptoms (i.e., depressive symptoms). Comorbidity is an important potential confound insofar as depressive symptoms and intrusions of traumatic memories are known to contribute independently to reduced autobiographical memory specificity (Wessel, Merckelbach, \& Dekkers, 2002). Thus, the extent to which high dissociative patients suffer from comorbid conditions like depression might explain why researchers sometimes, but not always, find that dissociation is associated with a lack of autobiographical memory specificity.

To minimize the contribution of co-occurring psychopathology, Wessel, Merckelbach, Kessels, and Horselenberg (2001) compared undergraduates who scored high $(n=23)$ or low $(n=23)$ on the DES to determine whether dissociation and lack of autobiographical memory specificity are linked. Contrary to Harvey et al. (1998) and Jones et al. (1999), and in line with Kremers et al. (2004) and Renneberg et al. (2005), Wessel et al. (2001) were unable to find evidence for a lack of autobiographical memory specificity in high dissociators (Cohen's $d=0.13$ ). Accordingly, in clinical samples, when researchers find an association between dissociation and overgeneral autobiographical memory, it may be attributable to comorbid symptoms of depression or intrusions.

In three studies, investigators attempted to study directly the link between memory fragmentation and dissociation in the laboratory (Kindt \& van den Hout, 2003; Kindt, van den Hout, \& Buck, 2005). Kindt and van den Hout (2003, $N=40)$ and Kindt et al. (2005; Study 1: $N=50$; Study 2: $N=50$ ) examined whether dissociative tendencies and state-like dissociation (i.e., peritraumatic dissociation) are related to memory fragmentation for material contained in a highly emotional video. As expected, individuals who reported that they engaged in extensive dissociation during the video reported more memory fragmentation compared with individuals who dissociated less during the video. These findings accord with trauma victims' reports about their own memory functioning. In addition to their subjective measure of memory fragmentation, the researchers quantified memory fragmentation objectively with a sequential memory task (Wegner, Quillian, \& Houston, 1996). During this task, participants are given short clips from an emotional video and are asked to sort them into the right order. Although the investigators determined that state-like dissociation was related to subjective fragmentation, it was unrelated to the objective measure of memory fragmentation. Thus, in this study, memory fragmentation was limited to meta-memory (i.e., ideas that people have about their memories). Also, dissociative tendencies, as measured by the DES, were unrelated to subjective or objective memory fragmentation, suggesting that the findings of Kind and van den Hout (2003) and Kind et al. (2005) bear little relevance to patients who experience trait dissociation. Germane to this issue are also studies (Berntsen, Willert, \& Rubin, 2003; Geraerts et al., 2007; Porter \& Birt, 2001) indicating that trauma victims' memories of their trauma are not fragmented when compared with either memories of positive life events (Porter \& Birt, 2001) or neutral memories (Geraerts et al., 2007).

\section{Inter-Identity Amnesia}

The most extreme manifestation of memory fragmentation is dissociative amnesia between identity states in DID. Dissociative amnesia is defined as the "inability to recall important personal information that is too extensive to be explained by ordinary forgetfulness" (criterion C; American Psychiatric Association, 1994, p. 487). Inter-identity amnesia is thought to reflect a severe disruption in autobiographical memory retrieval, encoding, or both (J. G. Allen, Console, \& Lewis, 1999). Putnam, Guroff, Silberman, Barban, and Post (1986) conducted a systematic case review among therapists $(N=100)$. Each therapist reported on one case of DID, and $98 \%$ of the therapists affirmed instances of amnesia in their DID patients. Moreover, case studies of DID have seemed to support the existence of amnesia on explicit memory tasks (Bryant, 1995; Larmore, Ludwig, \& Cain, 1977; Ludwig, Brandsma, Wilbur, Bendfeldt, \& Jameson, 1972; Nissen, Ross, Willingham, Mackenzie, \& Schacter, 1988; Schacter, Kihlstrom, Kihlstrom, \& Berren, 1989).

Generally, both case studies and experimental studies of interidentity transfer of knowledge have employed the following design (e.g., Eich, Macaulay, Loewenstein, \& Dihle, 1997b). Participants with DID first learn stimulus material in one identity state. Subsequently, they are asked to access, or to "switch" into, a different 
identity state, and when they report amnesia for the learned stimulus material, recall tests are administered. Patients who report conscious knowledge of practicing the material are typically excluded from the analyses.

By using this approach, Bryant (1995) found that a patient with DID demonstrated no memory for events after the age of 12 when tested in a child-like identity state but normal memory performance when tested in an adult identity state. In line with this case study, Schacter et al. (1989) reported on a patient with DID who when tested in one identity state, which supposedly emerged during adolescence, displayed profound amnesia for the first 14 years of her life. As both case studies were unable to corroborate reported memories objectively, it is important to note that Nissen et al. (1988) reported similar findings in a case study of a patient with DID using standardized explicit learning tasks (e.g., old-new discrimination).

In contrast, case studies using implicit memory paradigms cast a more complicated picture. Some case studies indicate that implicit memory transfer is intact in DID (Dick-Barnes, Nelson, \& Aine, 1987; Ludwig et al., 1972; Silberman, Putnam, Weingartner, Braun, \& Post, 1985), whereas Nissen et al. (1988) showed that the "implicit assessment of memory was a necessary but not sufficient condition for demonstrating interpersonality access" (p. 117). Specifically, implicit memory transfer was intact with simple stimulus material (e.g., sequence learning), but not in tasks with rich stimulus materials (e.g., Wechsler Memory Scales stories). In line with these case studies, Eich et al. (1997b) demonstrated priming effects across identity states for picture-fragment completion, but not for word stem completion, in a sample of nine patients with DID (but see M. L. Peters, Uyterlinde, Consemulder, \& van der Hart, 1998). Interestingly, this pattern of findings could not be readily mimicked by a sample of nine simulators (Eich, Macaulay, Loewenstein, \& Dihle, 1997a). However, strong inferences from the aforementioned studies are precluded by their small sample sizes.

By using large samples, Huntjens and coworkers (e.g., Huntjens, Peters, Woertman, van der Hart, \& Postma, 2007; Huntjens, Postma, Peters, Woertman, \& van der Hart, 2003) investigated the transfer of implicit knowledge between identity states in a series of studies. In all studies, they tested not only DID patients but also nonsymptomatic individuals, and participants were instructed to simulate DID and its concomitant memory impairments (i.e., simulators). The latter group was included to investigate possible symptom production, exaggeration, or both, in DID (Lilienfeld et al., 1999; Merckelbach, Devilly, \& Rassin, 2002; Spanos, 1994). Obviously, investigating transfer of implicit memory between identity states is relevant only in the context of (reported) impairment in explicit memory. That is why Huntjens and coworkers (2007, 2003) limited their analyses to DID patients who denied possessing explicit memory for the learning experience and the stimulus material learned in a different identity state.

In their first study, Huntjens et al. (2002) administered implicit memory tests (i.e., perceptual and conceptual priming tasks) to patients with DID $(n=31)$, nonsymptomatic individuals $(n=25)$, and simulators $(n=25)$. Of the patients, 25, 29, and 26 with DID denied conscious knowledge of the learning experience (i.e., explicit memory) in the perceptual priming, the conceptual priming, and the word stem completion task, respectively. Nevertheless, these patients displayed normal implicit memory performance.
Similarly, simulators were unable to feign inter-identity amnesia on implicit memory tasks.

In another study (Huntjens et al., 2003), patients with DID $(n=31)$, nonsymptomatic patients $(n=25)$, and simulators $(n=25)$ learned a word list containing words from three different semantic categories (i.e., names of flowers, vegetables, and animals) in one identity state (Identity 1). Next, patients were asked to change to another identity state (Identity 2), and all participants learned another very similar list (i.e., List 2) consisting of words from the same three categories. After an interval, participants underwent a recognition test consisting of all words from List 1 and List 2 and filler words in Identity 2. Recognition performance did not differ between patients with DID who denied conscious knowledge of the learning experiences $(n=23)$ and nonsymptomatic control participants. Thus, both groups exhibited the normal pattern of interference between Lists 1 and 2. Apparently, DID patients had access to the List 1 words, although they reported being amnestic for the learning experience when in Identity 2.

The studies discussed above relied on emotionally neutral stimulus material. However, it is often assumed that emotionally negative material is more likely to lead to compartmentalization of memory (Putnam, 1995). Importantly, in another study, Huntjens et al. (2007) demonstrated that the standard retroactive interference effect is not limited to DID patients learning emotionally neutral stimulus material in their amnestic state. Researchers have reported similar findings for the transfer of procedural information (Huntjens, Postma, Woertman, van der Hart, \& Peters, 2005) and stimulus valence (Huntjens, Peters, et al., 2005) from one interidentity state to the other.

In sum, Huntjens and coworkers' studies (Huntjens, Postma, et al., 2005; Huntjens et al., 2006, 2007, 2002, 2003; Huntjens, Peters, et al., 2005) showed that a substantial majority of patients with DID report no transfer of explicit memory between personality states but show intact implicit memory between identity states across a wide range of implicit memory tasks. Moreover, transfer of implicit memory does not seem to be influenced by stimulus valence. Mixed findings in earlier studies probably have been due to their very limited sample sizes.

Although studies of inter-identity amnesia in DID typically exclude DID participants who report memory of the learning experience, explicit memory of the stimulus material is assessed solely by self-report. However, self-reported lack of memory transfer between identity states may be prone to learned sociocognitive responses. With this in mind, participants may have learned to behave in a way that is consistent with their idea of DID (Dorahy \& Huntjens, 2007; Lilienfeld et al., 1999). Therefore, the veracity of explicit memory inaccessibility should be verified independently of self-report (J. J. B. Allen \& Movius, 2000).

Laboratory research on inter-identity memory performance in DID, which quantifies explicit memory independent of selfreported deficits, might therefore more fully inform us about memory processes underlying dissociative amnesia. That is why Huntjens et al. (2006) administered a multiple-choice recognition test for a story learned in a different identity state to patients with DID $(n=22)$, nonsymptomatic participants $(n=25)$, and simulators $(n=25)$. This type of recognition task is regularly employed to detect malingering of (explicit) memory problems in forensic settings, as malingerers tend to avoid correct answers and therefore perform below chance (Denny, 1999). As in previous studies, the 
majority of their patients with DID $(n=19)$ denied any knowledge of the learning experience. Yet strikingly, they performed below chance on the recognition task. Consequently, these patients did make use of the memory learned in the other identity state when determining their answers and deliberately avoided correct alternatives. Thus, the authors concluded "DID patients were found not to be characterized by an actual [explicit] memory retrieval inability, in contrast to their subjective reports" (Huntjens et al., 2006, p. 857).

In sum, studies investigating inter-identity amnesia in DID using laboratory tasks rather than self-report measures have consistently failed to find any objective evidence for inter-identity amnesia in spite of subjectively reported amnesia (for a review, see Dorahy \& Huntjens, 2007). Thus, it seems reasonable to conclude that interidentity amnesia is a meta-memory phenomenon rather than an objectively measurable memory impairment.

\section{Commission Errors in the Lab (but No Amnesia)}

Researchers have examined possible memory deficits in dissociation, including commission errors in terms of two types of memory errors: incomplete recall, also referred to as omission errors, and false recall, also referred to as commission errors. Amnesia can be conceptualized as a profound form of memory omission (Holmes et al., 2005). The question of the strength of evidence for omission errors in dissociation arises because amnesia is widely regarded as one of the core features of dissociation.

Dissociative disorders. Montagne et al. (2007) investigated memory performance for emotional stimulus material. Specifically, patients with DPD $(n=12)$ and nonsymptomatic individuals $(n=20)$ viewed 11 picture slides accompanied by an emotional narrative (Cahill \& McGaugh, 1995). The researchers found that patients' and control participants' memory performance was equivalent with respect to central, peripheral, and emotional details of the stimulus materials. However, the authors did not assess commission errors in both groups.

Other samples. Researchers have shown repeatedly that dissociation increases the risk of commission errors. For example, Hyman and Billings (1998; see also Ost, Foster, Costall, \& Bull, 2005; Ost, Granhag, Udell, \& Hjelmsater, 2008; Porter, Birt, Yuille, \& Lehman, 2000) questioned undergraduates $(N=48)$ about veridical childhood events that were supplied by their parents and also about a false event, presented to participants as if they were based on information provided by parents. Individuals with heightened levels of dissociation were more likely to report elaborate memories for the false event $(r=.48)$. Interestingly, in another study (Ost, Fellows, \& Bull, 1997; $N=36$ ), high dissociators, compared with low dissociators, were more confident in fabricated, but not veridical, autobiographical memories.

Merckelbach, Muris, Horselenberg, and Stougie (2000) examined the links between the DES and confabulation in two studies. In the first study, undergraduates $(N=42)$ viewed a series of 40 slides. Twenty were pictures of common objects or situations, whereas the other 20 consisted of a short paragraph describing an object or a situation. Ten of the latter were related to slides shown previously. Fifteen minutes later, a surprise recognition task followed. This task consisted of items that had been presented previously (old items) and new items. The participants had to say whether each item was old or new, and when they said it was old, they indicated whether they had seen it as a picture or as a paragraph. Participants could commit two types of errors: (a) misidentifying a paragraph as a photograph, or vice versa (i.e., reality monitoring errors); and (b) false positive responses (i.e., confabulation). Heightened dissociation levels were associated with a tendency to classify new items as old $(r=.39)$. Thus, high dissociators were more likely to claim having seen a picture that was not present during the study stage, which can be seen as a form of confabulatory responding. Increased dissociation levels were not accompanied by a heightened tendency to commit reality monitoring errors. Two other studies also failed to find a relationship between reality monitoring errors and dissociation (Koppenhaver, Kumar, \& Pekala, 1997; $N=220$; van den Hout, Merckelbach, \& Pool, 1996; $N=60$ ), whereas a third study found that individuals with a heightened tendency to dissociate took longer to discriminate perception from vivid imagery (Kunzendorf \& Karpen, 1997; $N=141$ ).

Merckelbach, Zeles, van Bergen, and Giesbrecht (2007) second study provided additional evidence for an association between the tendency to confabulate and dissociation. The researchers asked 70 participants to complete the Life Events Inventory (Cochrane \& Robertson, 1973), a questionnaire consisting of 60 items describing 20 negative, 20 positive, and 20 neutral childhood events. The items were detailed descriptions of specific experiences (e.g., "I went to Disneyland with my school."). Respondents were asked to indicate on a 7-point scale ranging from 1 (definitely did not happen) to 7 (definitely did happen) how certain they were that they had experienced each event before the age of 10 . Of course, many respondents will actually have experienced some of the events, and if dissociation does in fact arise from exposure to traumatic events, then one would expect high dissociators to report more negative events. Nevertheless, participants' endorsement of a large number of positive and negative as well as neutral events may reflect a tendency to confabulate. In this study, a significant correlation of $r=.39$ between the DES and a positive answering bias on the Life Events Inventory emerged. This correlation, however, disappeared when the influence of fantasy proneness was partialled out statistically. This study provides further support for the idea that individuals with a high frequency of dissociative experiences more readily endorse descriptions of events of differing affective valence due to a positive response bias linked to fantasy proneness. However, the precise causal status of fantasy proneness remains unclear.

A closely related line of research consists of studies reporting a heightened tendency for high dissociators to produce commission errors in paradigms relying on narratives (Candel, Merckelbach, \& Kuijpers, 2003), video fragments (Giesbrecht, Geraerts, \& Merckelbach, 2007), and staged events (Merckelbach, Zeles, et al., 2007). Interestingly, another consistent finding in these studies is that high dissociators' memory performance does not differ from that of low dissociators in terms of hits or the amount of accurate information produced. Sandberg, Lynn, and Matorin (2001) determined that high dissociators do not exhibit degraded recall of danger cues from a video of a potential sexual assault (see also Candel et al., 2003; Giesbrecht, Geraerts, \& Merckelbach, 2007). This finding implies that it is unlikely that the dissociationcommission error relationship can be accounted for by gap filling, as a result of a deficient memory for emotional material (i.e., dissociative amnesia). 
In two studies, Merckelbach, Zeles, et al. (2007) further investigated the dissociation-commission error link. In the first study, they examined whether individuals high on dissociation might be prone to relax their retrieval criteria, which in turn might increase their susceptibility to commission errors. The researchers surprised 36 undergraduates with a staged event followed by four subsequent free recall tasks. Briefly, Merckelbach, Zeles, et al. (2007) found that repeated retrieval attempts led to an increase in commission errors in participants irrespective of dissociation status. This increase in commission errors is a well-replicated finding closely related to the output-order effect (Schwartz, Fisher, \& Hebert, 1998). Thus, participants seem to relax their retrieval criterion to increase their memory output after being prompted for more information, but this output-order effect in itself is not related to dissociation. In fact, dissociation was related to an overall tendency to commit commission errors.

In a second study $(N=60)$, these authors investigated whether fragmented or disorganized encoding accounts for the dissociation-commission link. Participants watched a video that depicted a severe but nonfatal car accident. Participants watched the video fragment while the experimenters presented a series of high and low frequency tones, with half of the participants instructed to perform an oddball task (i.e., dual task condition). These participants were asked to watch the video while counting all the low tones. It was hypothesized that due to their tendency to encode information in a shallow or superficial manner, high dissociators' memory should be more easily disrupted by this dual task than should low dissociators' memory. The dissociationcommission link was apparent in the selective-attention condition but not the dual task condition. This result is reminiscent of DePrince and Freyd's (1999) finding that low dissociators are more susceptible to the attention-disrupting effect of a dual task condition than are high dissociators. Although Merckelbach, Zeles, et al.'s (2007) two attempts to identify the cognitive mechanisms responsible for high dissociators' tendencies to produce memory commission errors were largely unsuccessful, there was tentative evidence that this link is mediated at least partly by fantasy proneness (Giesbrecht, Geraerts, \& Merckelbach, 2007; but see Candel et al., 2003).

A number of researchers have examined how dissociation relates to false recognition errors on the Deese-RoedigerMcDermott (DRM) memory illusion task. In general, many participants falsely recognize nonpresented words (i.e., critical lures) that are thematically associated with studied word lists. Winograd, Peluso, and Glover (1998) reported that DES scores were positively related to remember judgments for nonpresented, thematically related words on the DRM task $(r=.34$; for a similar finding, see Clancy, McNally, Schacter, Lenzenweger, \& Pitman, 2002). However, contrary to the findings of Winograd et al. (1998), studies by Wright, Startup, and Mathews (2005), Platt, Lacey, Iobst, and Finkelman (1998), and Geraerts, Smeets, Jelicic, van Heerden, and Merckelbach (2005) failed to find evidence for a significant relation between the DES and false recognition of the critical lures on the DRM task, although Geraerts et al. (2005) did find that dissociation predicted the false recall of unstudied neutral and emotional words other than the critical lure.

Imagination inflation is another widely used paradigm for studying false memories in the laboratory (Garry, Manning, Loftus, \& Sherman, 1996). In this paradigm, participants are first asked to rate the probability that they have experienced various childhood events. In a second session, weeks later, they are asked to create detailed images of childhood events that they previously rated as improbable. Imagining these events increases participants' confidence that they actually occurred (i.e., imagination inflation). Paddock et al. (1998) showed that dissociative symptoms predicted the magnitude of the imagination inflation effect in undergraduates $(N=98)$. Heaps and Nash (1999) replicated this finding, whereas Wilkinson and Hyman (1998) showed that dissociation was related to changes in remember-know judgments after imagination in a theoretically meaningful way (e.g., more remember judgments after imagination in high DES persons). However, Horselenberg et al. (2000) found that heightened levels of dissociation were not associated with a larger imagination inflation effect. These authors speculated that dissociation is related primarily to eccentricity of false memories. Hence, dissociation may go along with more bizarre false memories rather than a higher frequency thereof (see also Spanos, 1994). Horselenberg et al. (2000) also argued that the imagination inflation effect might reflect a meta-memory phenomenon. Participants might change their beliefs about an event's probability rather than developing a false memory of it. This account implies that the imagination inflation procedure taps other mechanisms (e.g., meta-memory beliefs) than do the standard memory tasks in which dissociation is reliably related to the susceptibility of commission errors.

Putnam (1997) observed that because dissociative individuals exhibit subjective memory problems and lack confidence in their recollections, they are vulnerable to the misinformation effect. Eisen and Carlson (1998) and Eisen, Morgan, and Mickes (2002) examined the relation between dissociation and errors in response to misleading information. In these studies, college students took part in a staged event and returned 1 week later to complete a structured interview that included both highly suggestive, misleading questions, and factual, nonsuggestive questions about the event. In each study, pathological dissociation, as measured by the DES-T, was significantly related to errors in response to misleading questions (for a similar finding, see K. Wilson \& French, 2006; but see Drivdahl \& Zaragoza, 2001). In both studies, neither overall DES scores nor DES-T scores were related to errors on the specific, nonsuggestive questions.

In summary, there is a fairly consistent, yet small-to-moderate, link between dissociation and commission errors in studies across a variety of paradigms. The most notable exception to this pattern comes from studies using the DRM paradigm. The generally negative results from these studies may be due to the fact that false recognition on the DRM task is more fundamentally related to encoding errors (see Roediger, McDermott, \& Robinson, 1998, for a review) and is less sensitive to a tendency to react with atypical responses or to errors due to the explicit misinformation (Eisen \& Lynn, 2001). Thus, the dissociation-commission error link may be caused primarily by difficulties in withholding atypical responses and therefore typically emerges in paradigms that expose participants to misleading information.

Recently, laboratory studies using paradigms such as the DRM procedure and imagination inflation to elicit false memories have been criticized because "flawed memories and false memories are not the same thing, nor are identical cognitive processes likely to underlie the two" (Pezdek \& Lam, 2007, p. 7). These critics argued that only when entire new events have been successfully implanted 
can one speak of a genuine false memory. Thus, high dissociators' memories might well be susceptible to the incorporation of minor flaws rather than the implantation of completely fictitious events. Indeed, most studies showed that high dissociators exhibit commission errors that pertain to details (e.g., Candel et al., 2003). However, Hyman and Billings (1998) demonstrated convincingly that high dissociators are also more prone to develop entire false memories, such as a memory of having knocked over a punch bowl at a wedding as a child. Further evidence for this conclusion has come from studies that investigated the personality profiles of individuals who reported having been abducted by aliens (McNally et al., 2004), or who claim to have memories of previous lives (M. J. Peters, Horselenberg, Jelicic, \& Merckelbach, 2007). These studies have offered existence proofs for the idea that individuals with elevated levels of dissociation are especially prone to report extremely unlikely events.

To recapitulate, although it is often assumed that increased levels of dissociation are associated with omission errors (the kinds of errors one would expect to find in dissociative amnesia), this assumption lacks empirical support. Instead, accumulating evidence has indicated that dissociation is linked to memory commission errors (i.e., false memories). These findings have underscored why it is problematic to rely on uncorroborated reports of traumatic childhood experiences as evidence for a link between dissociation and traumatic experiences, including sexual abuse (e.g., Gleaves \& Eberenz, 1995). At least some of these reports may reflect inaccurate memories.

\section{Dissociation and Trauma}

The literature on cognitive processes involved in dissociation has provided scant evidence for deficits in autobiographical memory (e.g., compartmentalization, psychogenic amnesia) or avoidant information processing that would be expected to enable trauma victims to alleviate the impact of (recurrent) traumatic events. Yet advocates of this defensive function of dissociative experiences frequently cite positive correlations between measures of dissociation and retrospective self-reports of traumatic events as evidence for a direct causal link between trauma and dissociation (e.g., Holmes et al., 2005; van der Hart et al., 2006). Although a comprehensive review of the literature on the relationship between trauma and dissociation is beyond the scope of the present article, recent reviews investigating this matter systematically have arrived to the conclusion that "there is no good evidence for a traumatic etiology of DID or any other dissociative disorder" (Kihlstrom, 2005, p. 14; see also Lilienfeld et al., 1999; Merckelbach \& Muris, 2001).

Briefly, studies addressing the relationship between dissociation and trauma have nearly universally relied on retrospective selfreport of traumatic events. Moreover, the few longitudinal studies of dissociation that have been published have relied on nonrepresentative samples (Goodman et al., 2003; Macfie, Cicchetti, \& Toth, 2001; Ogawa, Sroufe, Weinfield, Carlson, \& Egeland, 1997). Thus, there is not a single epidemiological study of (verified) trauma and dissociation involving a sample of participants representative of the general population. What makes reliance on selfreport measures particularly problematic when investigating the trauma-dissociation link is that individuals with dissociative tendencies frequently endorse a wide range of common psychopatho- logical symptoms (Valdiserri \& Kihlstrom, 1995a, 1995b) and bizarre experiences and atypical symptoms (Giesbrecht \& Merckelbach, 2006a) on the Structured Inventory of Malingered Symptomatology (Smith \& Burger, 1997), which even psychiatric patients rarely endorse (Merckelbach \& Smith, 2003). Dissociation thus covaries with a positive response bias (R. C. Johnson, Edman, \& Danko, 1995; Merckelbach \& Jelicic, 2004) and a tendency to commit commission errors in memory (cf. supra).

Research based on objective indices of trauma also has failed to substantiate a direct and robust association between trauma and dissociation (Cima et al., 2001; B. Sanders \& Giolas, 1991). In both the study by B. Sanders and Giolas (1991) and the study by Cima et al. (2001), a researcher blind to the dissociative status of the participants scored hospital records for more objective indications of trauma. In both studies, this analysis yielded a nonsignificant and, more important, slightly negative correlation between ratings of traumatic experiences based on hospital records and dissociation (Sanders \& Giolas, 1991, $r=-.21$; Cima et al., 2001, $r=-.13)$. Moreover, most research on trauma and dissociation has failed to control for potentially confounding factors, including family pathology, general psychological distress, and specific variants of psychopathology associated with dissociation, such as eating disorders, impulsivity (van IJzendoorn \& Schuengel, 1996), and schizotypal traits (e.g., Merckelbach \& Giesbrecht, 2006; Merckelbach, Rassin, \& Muris, 2000; C. A. Pope \& Kwapil, 2000).

\section{Conclusion}

Several important conclusions can be drawn from our review. Studies of the link between dissociation and trauma are largely retrospective and do not justify the widely accepted idea that trauma and dissociation are causally related to each other (see also Kihlstrom, 2005). In addition, dissociation overlaps robustly with fantasy proneness, interrogative suggestibility, and susceptibility to cognitive failures, which may undermine the accuracy of retrospective reports of traumatic experiences. Additionally, research based on more objective indices of trauma (e.g., medical records or prospective methods) fails to substantiate a direct and solid relationship between trauma and dissociation.

In general, patients with dissociative disorders evidence subtle deficits in neuropsychological performance, although their overall cognitive functioning is unremarkable. More specifically, DID appears to be associated with fluctuating performance (i.e., subtest scatter), whereas DPD is related to subtle deficits in early stages of information processing.

The extant literature regarding dissociation and memory span is inconclusive. Some studies have found that high and low dissociative individuals exhibit similar working memory performance; others have found that highly dissociative participants exhibit superior performance; and still others have found that high dissociators perform more poorly than do low dissociators. Clearly, this issue requires clarification. One way to accomplish this goal is to study how working memory performance is related to different manifestations of dissociation (i.e, absorption, depersonalization, and amnesia).

An emerging line of research shows that some of the differences between high dissociators or individuals with a dissociative disorder and low dissociators or nonsymptomatic persons are dependent 
on the emotional or attentional context. More specifically, differences between high and low dissociators often emerge only when participants are tested under emotionally negative conditions, and high dissociators sometimes perform better under dividedattention conditions than do low dissociators. However, evidence for high dissociators' performance advantages under dividedattention conditions is not robust and requires replication.

A widespread assumption in the clinical literature is that dissociation is associated with avoidant information processing. However, controlled studies have generally failed to provide evidence for this belief: Higher levels of dissociation actually seem to be associated with enhanced retrieval, or less pronounced forgetting of emotional material. Also, high dissociators tend to develop pseudo-memories rather than gaps in their memories (i.e., amnesia). Furthermore, memory fragmentation reported by high dissociators and DID patients seems to be a subjective meta-memory phenomenon with no clear-cut objective manifestations.

Based on conceptual grounds, the assumed qualitative differences between pathological dissociation and nonpathological dissociation are frequently emphasized (e.g., Moskowitz, 2004; van der Hart et al., 2006). Proponents of this stance may argue that most of the findings based on nondissociative disordered samples may not be relevant to the dissociative disorders given the profound differences between pathological and nonpathological dissociation. However, even if one were to exclude all studies that were not conducted with patients diagnosed with dissociative disorders, this would not substantially change our conclusions. Even studies that rely exclusively on samples with dissociative disorders do not support-and sometimes even contradict - the assumed cognitive concomitants of dissociation (e.g., inter-identity amnesia, avoidant information processing, amnesia for emotional stimuli) when objective measures are employed.

Nevertheless, one may wonder how well research in nondissociative disorder samples generalizes to the dissociative disorders. This question is an empirical one to which our review offers a provisional answer. Whereas controlled laboratory research in the dissociative disorders is somewhat limited, two lines of research are relevant to the issue of generalization because they offer findings from both dissociative disorder samples and nondissociative disorder samples by using comparable paradigms. The best comparison has been offered by Elzinga et al. (2000). These researchers employed both DID patients and individuals who were nonpatients yet high dissociators. Across both samples, the DF effects were comparable. Second, an entire line of research in nonclinical samples consistently has shown that dissociation is not associated with inferior emotional memory performance for, for example, narratives in terms of hits (e.g., Candel et al., 2003). This finding has recently been replicated in DPD by Montagne et al. (2007). Thus, the available literature, including N. G. Waller et al.'s (1996) largely unsuccessful endeavor to discriminate pathological from nonpathological dissociation, has supported the assumption that cognitive findings from nonclinical high dissociators can be cautiously translated to dissociative disorders. In conclusion, the present review reveals substantial discrepancies between core assumptions in the clinical literature concerning dissociation (e.g., avoidant information processing, memory fragmentation) and systematic findings from cognitive studies.

\section{Future Studies}

Researchers interested in dissociative disorders have focused primarily on the alleged traumatic antecedents of dissociation. In doing so, many or most have taken for granted that profound deficits in attention and memory function (e.g., avoidant information processing, compartmentalization, psychogenic amnesia) are core features of dissociation (Ehlers \& Clark, 2000; Holmes et al., 2005). However, as our review indicates, controlled studies consistently fail to provide evidence for these and other widely alleged core features of dissociation. Accordingly, there is a large discrepancy between theoretical notions and empirical findings on dissociation. To begin to close this gap between theory and research, we propose that the field of dissociation can profit from attention to a number of relatively neglected domains of research.

For all research lines, it would be beneficial for researchers to examine different types or expressions of dissociation (e.g., absorption, depersonalization) in conjunction with fantasy proneness, cognitive failures, and suggestibility (see also Kihlstrom, 2005). Moreover, few (nonpatient) studies have included individuals who score in the middle range of dissociation and are therefore more typical of the general population than are participants selected for their extreme high or low scores. It may be worthwhile to include this middle group, as according to Preacher, Rucker, MacCallum, and Nicewander (2005), extreme group designs have numerous disadvantages, including (a) artificially increasing the variance, often resulting in spuriously inflated effect sizes; (b) assuming linearity when it may be absent (e.g., middle and highly dissociative participants may exhibit similar cognitive deficits); and (c) rendering interpretations of group differences ambiguous (i.e., difficulty in delineating whether the obtained effects are due to the high group's cognitive deficits, the low group's superior abilities, or some mixture of both possibilities). Accordingly, the failure to include dissociative participants in the normative range could create the superficial appearance of a distinctly different profile of deficits or abilities that is more apparent than "real" (Lynn, Kirsch, Knox, \& Lilienfeld, 2006). In addition, most studies employed measures of trait dissociation only and failed to quantify symptom fluctuations (i.e., state dissociation). This is probably due to the assumption that dissociative symptomatology in dissociative disorders is persistent and consistently high in intensity (Sierra \& Berrios, 1998). Whereas measures of trait dissociation like the DES show very good test-retest stability, little is known about fluctuations in dissociation levels in dissociative disorders over shorter time periods, and acute dissociation during task performance is not routinely quantified.

\section{Dissociation and Sleep Experiences}

An area that is worthy of exploration is the relationship between dissociation and sleep-related experiences. Indeed, starting with the pioneering work of Watson (Watson, 2001, 2003b), a number of recent studies (Giesbrecht, Jongen, Smulders, \& Merckelbach, 2006; Giesbrecht \& Merckelbach, 2004, 2006b) have linked dissociative symptoms in undergraduate students to self-reported sleep anomalies, such as dreams of flying, hypnopompic imagery, or sensing the presence of someone else. There also has been anecdotal evidence that symptoms in patients with DPD worsen when they feel tired. Thus, Simeon and Abugel (2006, p. 210) 
reported that these patients "often liken it to bad jet lag and feel much worse when they travel across time zones." Similarly, Agargun et al. (2003) emphasized the importance of nightmares in DID. Moreover, when healthy undergraduates $(N=25)$ were deprived from sleep for 36 hours, dissociative symptoms increased dramatically and were affected earlier than other measures such as mood (Giesbrecht, Smeets, Leppink, Jelicic, \& Merckelbach, 2007). Thus, there are good empirical reasons to assume that dissociative symptoms are related to deviant sleep patterns.

This association between sleep-related experiences and dissociation could help us to understand why dissociation overlaps with cognitive failures and the tendency to commit commission errors in memory. Specifically, the fact that disruptions in sleep-wake patterns exert a detrimental effect on attention (Jewett, Dijk, Kronauer, \& Dinges, 1999) could explain why dissociation overlaps with a susceptibility to cognitive failures. Moreover, if it is the case that the progression of waking state to rapid eye movement sleep is marked by an increase in "fluid" and hyperassociative thinking (Stickgold, Hobson, Fosse, \& Fosse, 2001), it is tempting to speculate that dreamlike and fantasy intrusions into the waking state (which are typical for dissociation) interfere with memory performance and promote commission errors. Indeed, fantasy proneness and absorption are consistently correlated with both measures of sleep experiences and dissociation (see Fassler, Knox, \& Lynn, 2006). Studies that examine the correlates of dissociative symptoms induced by sleep deprivation, and studies directed at normalizing sleep in dissociative disorders, promise to shed more light on these possibilities.

The fact that dissociative experiences and deviant sleep phenomena are linked does not preclude the possibility that early aversive life experience, including childhood trauma, plays a role in the development of dissociative symptoms. Such aversive experiences might play a distal role, whereas sleep disruptions seem to play a proximal role. Germane to this issue are studies showing that patients with PTSD exhibit abnormal sleep phenomena, with the prevalence of nightmares among patients diagnosed with PTSD ranging up to 70\% (Wittmann, Schredl, \& Kramer, 2006). It is, of course, true that deviant sleep phenomena are not specific to dissociation and are evident in a wide range of disorders (e.g., schizophrenia, mood disorders; Benca, Obermeyer, Thisted, \& Gillin, 1992). However, because there are wellarticulated theories concerning the involvement of sleep in cognitive function like memory and memory commission errors (Crick \& Mitchison, 1995; Stickgold et al., 2001), the study of dissociation might profit from a closer look at sleep patterns of high dissociative individuals.

\section{Pharmacologically Induced Dissociative Symptoms}

Certain drugs, notably low doses of the anesthetic ketamine, produce dream-like states and dissociative symptoms. For example, participants in the Krystal et al. (1994) study reported slowing of time and alterations in the vividness, form, and context of sensory experiences following the administration of ketamine. These dissociative experiences may be the byproduct of diminished NMDA-related neurotransmission (Simeon, 2004). Interestingly, the dissociation-inducing properties of cannabinoids (Simeon, Knutelska, Nelson, \& Guralnik, 2003), such as marijuana, may also be mediated via NMDA receptors. Another class of chemicals that elicits dissociation, and more specifically deper- sonalization reactions in healthy participants, are the hallucinogens, such as lysergic acid diethylamide (LSD). The fact that these chemicals act as agonists of serotonin $5-\mathrm{HT}_{2 \mathrm{~A}}$ and $5-\mathrm{HT}_{2 \mathrm{C}}$ receptors imply that serotonin also may play a mediational role in dissociation (Simeon, 2004). If research reveals that drugs with well-delineated links to neurotransmitter systems produce symptoms consistent with dissociative disorders in healthy volunteers, it could hint at the neurobiological basis of dissociative symptoms.

\section{Studying Cognitive Processes in the Dissociative Disorders}

Only a small number of the studies we review relied on patients with dissociative disorders. The field would benefit from a thorough cognitive analysis of the dissociative disorders that compares memory and other cognitive functions and processes across these disorders. Due to the mixed findings regarding the cognitive morphology of dissociation, it is impossible at the present time to formulate a well-articulated comprehensive cognitive framework of this still elusive phenomenon. Yet given the prominent place of dissociation in clinical psychology and psychiatry, there is an urgent need for a cognitive analysis of dissociation that includes patients with dissociative disorders. Such an analysis should not only advance our understanding of the etiology of dissociation, but ultimately contribute to the treatment of dissociative disorders.

\section{References}

Agargun, M. Y., Kara, H., Ozer, O. A., Selvi, Y., Kiran, U., \& Ozer, B. (2003). Clinical importance of nightmare disorder in patients with dissociative disorders. European Archives of Psychiatry and Clinical Neurosciences, 57, 575-579.

Allen, C. C., \& Ruff, R. M. (1990). Self-rating versus neuropsychological performance of moderate versus severe head-injured patients. Brain Injury, 4, 7-17.

Allen, J. G. (2001). Traumatic relationships and serious mental disorders. New York: Wiley.

Allen, J. G., Console, D. A., \& Lewis, L. (1999). Dissociative detachment and memory impairment: Reversible amnesia or encoding failure? Comprehensive Psychiatry, 40, 160-171.

Allen, J. J. B., \& Movius, H. L., II. (2000). The objective assessment of amnesia in dissociative identity disorder using event-related potentials. International Journal of Psychophysiology, 38, 21-41.

American Psychiatric Association. (1980). Diagnostic and statistical manual of mental disorders (3rd. ed.). Washington, DC: Author.

American Psychiatric Association. (1994). Diagnostic and statistical manual of mental disorders (4th. ed.). Washington, DC: Author.

American Psychiatric Association. (2000). Diagnostic and statistical manual of mental disorders (text revision). Washington, DC: Author.

Anderson, M. C., \& Green, C. (2001, March). Suppressing unwanted memories by executive control. Nature, 410, 366-369.

Anderson, M. C., Ochsner, K. N., Kuhl, B., Cooper, J., Robertson, E., Gabrieli, S. W., et al. (2004, January). Neural systems underlying the suppression of unwanted memories. Science, 303, 232-235.

Becker-Blease, K. A., Deater-Deckard, K., Eley, T., Freyd, J. J., Stevenson, J., \& Plomin, R. (2004). A genetic analysis of individual differences in dissociative behaviors in childhood and adolescence. Journal of Child Psychology and Psychiatry and Allied Disciplines, 45, 522-532.

Benca, R. M., Obermeyer, W. H., Thisted, R. A., \& Gillin, J. C. (1992). Sleep and psychiatric disorders: A meta-analysis. Archives of General Psychiatry, 49, 651-668.

Bergeman, C. S., Plomin, R., Pedersen, N. L., McClearn, G. E., Nessel- 
road, J. R., Costa, P. T., et al. (1993). Genetic and environmental effects on openness to experience, agreeableness, and conscientiousness. Journal of Personality, 61, 159-179.

Bernstein, D. P., Fink, L., Handelsman, L., Foote, J., Lovejoy, M., Wenzel, K., et al. (1994). Initial reliability and validity of a new retrospective measure of child abuse and neglect. American Journal of Psychiatry, 151, 1132-1136.

Bernstein, D. P., Stein, J. A., Newcomb, M. D., Walker, E., Pogge, D., Ahluvalia, T., et al. (2003). Development and validation of a brief screening version of the Childhood Trauma Questionnaire. Child Abuse and Neglect, 27, 169-190.

Bernstein, E. M., \& Putnam, F. W. (1986). Development, reliability, and validity of a dissociation scale. Journal of Nervous and Mental Disease, 174, 727-735.

Bernstein-Carlson, E., \& Putnam, F. W. (1993). An update on the Dissociative Experiences Scale. Dissociation, 6, 19-27.

Berntsen, D., Willert, M., \& Rubin, D. C. (2003). Splintered memories or vivid landmarks? Qualities and organization of traumatic memories with and without PTSD. Applied Cognitive Psychology, 17, 675-693.

Bogod, N. M., Mateer, C. A., \& Macdonald, S. W. S. (2003). Selfawareness after traumatic brain injury: A comparison of measures and their relationship to executive functions. Journal of the International Neuropsychological Society, 9, 450-458.

Boomsma, D. I. (1998). Genetic analysis of Cognitive Failures (CFQ): A study of Dutch adolescent twins and their parents. European Journal of Personality, 12, 321-330.

Brewer, N. T., Lillie, S. E., \& Hallman, W. K. (2006). Why people believe they were exposed to biological or chemical warfare: A survey of gulf war veterans. Risk Analysis, 26, 337-345.

Brewin, C. R., Andrews, B., \& Valentine, J. D. (2000). Meta-analysis of risk factors for posttraumatic stress disorder in trauma-exposed adults. Journal of Consulting and Clinical Psychology, 68, 748-766.

Brewin, C. R., \& Saunders, J. (2001). The effect of dissociation at encoding on intrusive memories for a stressful film. British Journal of Medical Psychology, 74, 467-472.

Broadbent, D. E., Cooper, P. F., Fitzgerald, P., \& Parkes, K. R. (1982). The cognitive failures questionnaire (CFQ) and its correlates. British Journal of Clinical Psychology, 21, 1-16.

Bruce, A. S., Ray, W. J., Bruce, J. M., Arnett, P. A., \& Carlson, R. A. (2007). The relationship between executive functioning and dissociation. Journal of Clinical and Experimental Neuropsychology, 29, 626-633.

Bruce, A. S., Ray, W. J., \& Carlson, R. A. (2007). Understanding cognitive failures: What's dissociation got to do with it? American Journal of Psychology, 120, 553-563.

Bryant, R. A. (1995). Autobiographical memory across personalities in dissociative identity disorder: A case report. Journal of Abnormal Psychology, 104, 625-631.

Cahill, L., \& McGaugh, J. L. (1995). A novel demonstration of enhanced memory associated with emotional arousal. Consciousness and Cognition, 4, 410-421.

Candel, I., \& Merckelbach, H. (2004). Peritraumatic dissociation as a predictor of PTSD: A critical review. Comprehensive Psychiatry, 45, 44-50.

Candel, I., Merckelbach, H., \& Kuijpers, M. (2003). Dissociative experiences are related to commissions in emotional memory. Behaviour Research and Therapy, 41, 719-725.

Cardeña, E. (1994). The domain of dissociation. In S. J. Lynn \& J. Rue (Eds.), Dissociation: Clinical and theoretical perspectives (pp. 15-31). New York: Guilford Press.

Carlson, E. B., Putnam, F. W., Ross, C. A., Anderson, G., Clark, P., Torem, M., et al. (1991). Factor analysis of the Dissociative Experiences Scale: A multicenter study. In B. G. Braun \& E. B. Carlson (Eds.), Proceedings of the eighth international conference on multiple personality and dissociative states (p. 16) Chicago: Rush.
Cima, M., Merckelbach, H., Klein, B., Schellbach-Matties, R., \& Kremer, K. (2001). Frontal lobe dysfunctions, dissociation, and trauma selfreports in forensic psychiatric patients. Journal of Nervous and Mental Disease, 189, 188-190.

Clancy, S. A., McNally, R. J., Schacter, D. L., Lenzenweger, M. F., \& Pitman, R. K. (2002). Memory distortion in people reporting abduction by aliens. Journal of Abnormal Psychology, 111, 455-461.

Classen, C., Koopman, C., \& Spiegel, D. (1993). Trauma and dissociation. Bulletin of the Menninger Clinic, 57, 178-194.

Cloitre, M. (1992). Avoidance of emotional processing: A cognitive science perspective. In J. E. Young \& D. J. Stein (Eds.) Cognitive science and clinical disorders (pp. 19-41). San Diego, CA: Academic Press.

Cloitre, M., Cancienne, J., Brodsky, B., Dulit, R., \& Perry, S. W. (1996). Memory performance among women with parental abuse histories: Enhanced directed forgetting or directed remembering? Journal of $A b$ normal Psychology, 105, 204-211.

Cochrane, R., \& Robertson, A. (1973). The Life Events Inventory: A measure of the relative severity of psycho-social stressors. Journal of Psychosomatic Research, 17, 135-139.

Crick, F., \& Mitchison, G. (1995). REM sleep and neural nets. Behavioural Brain Research, 69, 147-155.

Davis-Merritt, R., \& You, S. (2008). Is there really a dissociative taxon on the dissociative experiences scale? Journal of Personality Assessment, 90, 201-203.

Denny, R. L. (1999). A brief symptom validity testing procedure for logical memory of the Wechsler Memory Scale-Revised which can demonstrate verbal memory in the face of claimed disability. Journal of Forensic Neuropsychology, 1, 5-26.

DePrince, A. P., \& Freyd, J. J. (1999). Dissociative tendencies, attention, and memory. Psychological Science, 10, 449-452.

DePrince, A. P., \& Freyd, J. J. (2001). Memory and dissociative tendencies: The roles of attentional context and word meaning in a directed forgetting task. Journal of Trauma and Dissociation, 2, 67-82.

DePrince, A. P., \& Freyd, J. J. (2004). Forgetting trauma stimuli. Psychological Science, 15, 488-492.

DePrince, A. P., Freyd, J. J., \& Malle, B. F. (2007). A replication by another name: A response to Devilly et al. (2007). Psychological Science, 18, 218-219.

De Ruiter, M. B., Phaf, H. R., Elzinga, B. M., \& Van Dyck, R. (2004). Dissociative style and individual differences in verbal working memory span. Consciousness and Cognition, 13, 821-828.

De Ruiter, M. B., Phaf, R. H., Veltman, D. J., Kok, A., \& van Dyck, R. (2003). Attention as a characteristic of nonclinical dissociation: An event-related potential study. NeuroImage, 19, 376-390.

Devilly, G. J., \& Ciorciari, J. (2007). Conclusions in science when theory and data collide. Psychological Science, 18, 220-221.

Devilly, G. J., Ciorciari, J., Piesse, A., Sherwell, S., Zammit, S., Cook, F., et al. (2007). Dissociative tendencies and memory performance on directed forgetting tasks. Psychological Science, 18, 212-217.

DeYoung, C. G., Peterson, J. B., \& Higgins, D. M. (2005). Sources of openness/intellect: Cognitive and neuropsychological correlates of the fifth factor of personality. Journal of Personality, 73, 825-858.

Dick-Barnes, M., Nelson, R. O., \& Aine, C. J. (1987). Behavioral measures of multiple personality. Journal of Behavior Therapy and Experimental Psychiatry, 18, 229-239.

Donchin, E. (1981). Presidential address, 1980: Surprise, surprise? Psychophysiology, 18, 493-513.

Dorahy, M. J. (2001). Dissociative identity disorder and memory dysfunction: The current state of experimental research and its future directions. Clinical Psychology Review, 21, 771-795.

Dorahy, M. J., \& Huntjens, R. J. C. (2007). Memory and attentional processes in dissociative identity disorder: A review of the empirical literature. In E. Vermetten, M. J. Dorahy, \& D. Spiegel (Eds.), Trau- 
matic dissociation: Neurobiology and treatment (pp. 55-75). Washington, DC: American Psychiatric Publishing.

Dorahy, M. J., Irwin, H. J., \& Middleton, W. (2002). Cognitive inhibition in dissociative identity disorder (DID): Developing an understanding of working memory function in DID. Journal of Trauma and Dissociation, 3, 111-132.

Dorahy, M. J., Irwin, H. J., \& Middleton, W. (2004). Assessing markers of working memory function in dissociative identity disorder using neutral stimuli: A comparison with clinical and general population samples. Australian and New Zealand Journal of Psychiatry, 38, 47-55.

Dorahy, M. J., McCusker, C. G., Loewenstein, R. J., Colbert, K., \& Mulholland, C. (2006). Cognitive inhibition and interference in dissociative identity disorder: The effects of anxiety on specific executive functions. Behaviour Research and Therapy, 44, 749-764.

Dorahy, M. J., Middleton, W., \& Irwin, H. J. (2004). Investigating cognitive inhibition in dissociative identity disorder compared to depression, posttraumatic stress disorder and psychosis. Journal of Trauma and Dissociation, 5, 93-110.

Dorahy, M. J., Middleton, W., \& Irwin, H. J. (2005). The effect of emotional context on cognitive inhibition and attentional processing in dissociative identity disorder. Behaviour Research and Therapy, 43, 555-568.

Draijer, N., \& Boon, S. (1993). The validation of the Dissociative Experiences Scale against the criterion of the SCID-D, using receiver operating characteristics (ROC) analysis. Dissociation, 6, 28-37.

Drivdahl, S. B., \& Zaragoza, M. S. (2001). The role of perceptual elaboration and individual differences in the creation of false memories for suggested events. Applied Cognitive Psychology, 15, 265-281.

Ehlers, A., \& Clark, D. M. (2000). A cognitive model of posttraumatic stress disorder. Behaviour Research and Therapy, 38, 319-345.

Eich, E., Macaulay, D., Loewenstein, R. J., \& Dihle, P. H. (1997a). Implicit memory, interpersonality amnesia, and dissociative identity disorder: Comparing patients with simulators. In J. D. Read \& D. S. Lindsay (Eds.), Recollections of trauma: Scientific research and clinical practice (pp. 469-474). New York: Plenum Press.

Eich, E., Macaulay, D., Loewenstein, R. J., \& Dihle, P. H. (1997b). Memory, amnesia, and dissociative identity disorder. Psychological Science, 8, 417-422.

Eisen, M. L., \& Carlson, E. B. (1998). Individual differences in suggestibility: Examining the influence of dissociation, absorption, and a history of childhood abuse. Applied Cognitive Psychology, 12, S47-S61.

Eisen, M. L., \& Lynn, S. J. (2001). Dissociation, memory and suggestibility in adults and children. Applied Cognitive Psychology, 15, S49-S73.

Eisen, M. L., Morgan, D. Y., \& Mickes, L. (2002). Individual differences in eyewitness memory and suggestibility: Examining relations between acquiescence, dissociation and resistance to misleading information. Personality and Individual Differences, 33, 553-572.

Eisen, M. L., Qin, J., Goodman, G. S., \& Davis, S. L. (2002). Memory and suggestibility in maltreated children: Age, stress arousal, dissociation, and psychopathology. Journal of Experimental Child Psychology, 83, 167-212.

Elzinga, B. M., Ardon, A. M., Heijnis, M. K., de Ruiter, M. B., Van Dyck, R., \& Veltman, D. J. (2007). Neural correlates of enhanced workingmemory performance in dissociative disorder: A functional MRI study. Psychological Medicine, 37, 235-245.

Elzinga, B. M., de Beurs, E., Sergeant, J. A., Van Dyck, R., \& Phaf, R. H. (2000). Dissociative style and directed forgetting. Cognitive Therapy and Research, 24, 279-295.

Elzinga, B. M., Phaf, R. H., Ardon, A. M., \& van Dyck, R. (2003). Directed forgetting between, but not within, dissociative personality states. Journal of Abnormal Psychology, 112, 237-243.

Fabiani, M., Karis, D., \& Donchin, E. (1990). Effects of mnemonic strategy manipulation in a Von Restorff paradigm. Electroencephalography and Clinical Neurophysiology, 75, 22-35.

Fassler, O., Knox, J., \& Lynn, S. J. (2006). The Iowa Sleep Experiences
Survey: Hypnotizability, absorption, and dissociation. Personality and Individual Differences, 41, 675-684.

Fertuck, E. A., Lenzenweger, M. F., Clarkin, J. F., Hoermann, S., \& Stanley, B. (2006). Executive neurocognition, memory systems, and borderline personality disorder. Clinical Psychology Review, 26, 346-375.

First, M. B., Spitzer, R. L., Gibbon, M., \& Williams, J. B. W. (1994). Structured Clinical Interview for Axis I DSM-IV Disorders. New York: Biometrics Research.

Freyd, J. J. (1996). Betrayal trauma: The logic of forgetting childhood abuse. Cambridge, MA: Harvard University Press.

Freyd, J. J., Martorello, S. R., Alvardo, J. S., Hayes, A. E., \& Christman, J. C. (1998). Cognitive environments and dissociative tendencies: Performance on the standard Stroop task for high versus low dissociators. Applied Cognitive Psychology, 12, S91-S103.

Friedman, D., Cornblatt, B., Vaughan, H., \& Erlenmeyer Kimling, L. (1986). Event-related potentials in children at risk for schizophrenia during two versions of the continuous performance test. Psychiatry Research, 18, 161-177.

Fukuzako, H., Fukuzaki, S., Fukuzako, T., Jing, H., Ueyama, K., \& Takigawa, M. (1999). P300 event-related potentials in probable dissociative generalized amnesia. Progress in Neuro-Psychopharmacology and Biological Psychiatry, 23, 1319-1327.

Garry, M., Manning, C. G., Loftus, E. F., \& Sherman, S. J. (1996). Imagination inflation: Imagining a childhood event inflates confidence that it occurred. Psychonomic Bulletin and Review, 3, 208-214.

Gast, U., Rodewald, F., Nickel, V., \& Emrich, H. M. (2001). Prevalence of dissociative disorders among psychiatric inpatients in a German university clinic. Journal of Nervous and Mental Disease, 189, 249-257.

Geraerts, E., Kozaric Kovacic, D., Merckelbach, H., Peraica, T., Jelicic, M., \& Candel, I. (2007). Traumatic memories of war veterans: Not so special after all. Consciousness and Cognition, 16, 170-177.

Geraerts, E., Merckelbach, H., Jelicic, M., Smeets, E., \& van Heerden, J. (2006). Dissociative symptoms and how they relate to fantasy proneness in women reporting repressed or recovered memories. Personality and Individual Differences, 40, 1143-1151

Geraerts, E., Smeets, E., Jelicic, M., van Heerden, J., \& Merckelbach, H. (2005). Fantasy proneness, but not self-reported trauma is related to DRM performance of women reporting recovered memories of childhood sexual abuse. Consciousness and Cognition, 14, 602-612.

Gershuny, B. S., \& Thayer, J. F. (1999). Relations among psychological trauma, dissociative phenomena, and trauma-related distress: A review and integration. Clinical Psychology Review, 19, 631-637.

Giesbrecht, T. (2006). Dissociation: A defensive maneuver? Maastricht, the Netherlands: Maastricht University.

Giesbrecht, T., Geraerts, E., \& Merckelbach, H. (2007). Dissociation, memory commission errors, and heightened autonomic reactivity. Psychiatry Research, 150, 277-285.

Giesbrecht, T., Jongen, E., Smulders, F., \& Merckelbach, H. (2006). Dissociation, cortical activity, and sleep. Journal of Nervous and Mental Disease, 194, 362-368.

Giesbrecht, T., \& Merckelbach, H. (2004). Subjective sleep experiences are related to dissociation. Personality and Individual Differences, 37, $1341-1345$

Giesbrecht, T., \& Merckelbach, H. (2006a). Dissociatieve symptomen en slaap [Dissociative symptoms and sleep]. Tijdschrift voor Psychiatrie, 48, 207-215.

Giesbrecht, T., \& Merckelbach, H. (2006b). Dreaming to reduce fantasy: Fantasy proneness, dissociation and subjective sleep experiences. Personality and Individual Differences, 41, 697-706.

Giesbrecht, T., Merckelbach, H., \& Geraerts, E. (2007). The dissociative experiences taxon is related to fantasy proneness. Journal of Nervous and Mental Disease, 195, 769-772.

Giesbrecht, T., Merckelbach, H., Geraerts, E., \& Smeets, E. (2004). Dis- 
ruptions in executive functioning and dissociation in undergraduate students. Journal of Nervous and Mental Disease, 192, 567-569.

Giesbrecht, T., Merckelbach, H., Kater, M., \& Sluis, A. F. (2007). Why dissociation and schizotypy overlap: The joint influence of fantasy proneness, cognitive failures, and childhood trauma. Journal of Nervous and Mental Disease, 195, 812-818.

Giesbrecht, T., Merckelbach, H., \& Smeets, E. (2006). Thought suppression, dissociation, and context effects. Netherlands Journal of Psychology, 62, 73-80.

Giesbrecht, T., Smeets, T., Leppink, J., Jelicic, M., \& Merckelbach, H. (2007). Acute dissociation after 1 night of sleep loss. Journal of Abnormal Psychology, 116, 599-606.

Giesbrecht, T., Smeets, T., \& Merckelbach, H. (2008). Dissociative experiences on ice: Peritraumatic and trait dissociation during the cold pressor test. Psychiatry Research, 157, 115-121.

Gilbert, D. T. (1991). How mental systems believe. American Psychologist, 46, 107-119.

Gilbert, D. T., Tafarodi, R. W., \& Malone, P. S. (1993). You can't not believe everything you read. Journal of Personality and Social Psychology, 65, 221-233.

Gleaves, D. H., \& Eberenz, K. P. (1995). Correlates of dissociative symptoms among women with eating disorders. Journal of Psychiatric Research, 29, 417-426.

Goodman, G. S., Ghetti, S., Quas, J. A., Edelstein, R. S., Alexander, K. W., Redlich, A. D., et al. (2003). A prospective study of memory for child sexual abuse: New findings relevant to the repressed-memory controversy. Psychological Science, 14, 113-118.

Gow, K., Lang, T., \& Chant, D. (2004). Fantasy proneness, paranormal beliefs and personality features in out-of-body experiences. Contemporary Hypnosis, 21, 107-125.

Green, J. P., Kvaal, S., Lynn, S. J., Mare, C., \& Sandberg, M. S. (1991, August). Dissociations, fantasy proneness, and hypnotizability: A test of context effects. Paper presented at the 99th Annual Convention of the American Psychological Association, San Francisco.

Gudjonsson, G. H. (1984). A new scale of interrogative suggestibility. Personality and Individual Differences, 5, 303-314.

Gudjonsson, G. H., \& Clark, N. K. (1986). Suggestibility in police interrogation: A social psychological model. Social Behaviour, 1, 83-104.

Guralnik, O., Giesbrecht, T., Knutelska, M., Sirroff, B., \& Simeon, D. (2007). Cognitive functioning in Depersonalization Disorder. Journal of Nervous and Mental Disease, 12, 983-988.

Guralnik, O., Schmeidler, J., \& Simeon, D. (2000). Feeling unreal: Cognitive processes in depersonalization. American Journal of Psychiatry, 157, 103-109.

Hacking, I. (1995). Rewriting the soul: Multiple personality and the sciences. Princeton, NJ: Princeton University Press.

Harvey, A. G., Bryant, R. A., \& Dang, S. T. (1998). Autobiographical memory in acute stress disorder. Journal of Consulting and Clinical Psychology, 66, 500-506.

Hasson, U., \& Glucksberg, S. (2006). Does understanding negation entail affirmation? An examination of negated metaphors. Journal of Pragmatics, 38, 1015-1032.

Hays, J. R., Reas, D. L., \& Shaw, J. B. (2002). Concurrent validity of the Wechsler Abbreviated Scale of Intelligence and the Kaufman Brief Intelligence Test among psychiatric inpatients. Psychological Reports, 90, 355-359.

Heaps, C., \& Nash, M. (1999). Individual differences in imagination inflation. Psychonomic Bulletin and Review, 6, 313-318.

Heinrichs, R. W., \& Zakzanis, K. K. (1998). Neurocognitive deficit in schizophrenia: A quantitative review of the evidence. Neuropsychology, $12,426-445$.

Holmes, E. A., Brewin, C. R., \& Hennessy, R. G. (2004). Trauma films, information processing, and intrusive memory development. Journal of Experimental Psychology: General, 133, 3-22.
Holmes, E. A., Brown, R. J., Mansell, W., Fearon, R., Hunter, E. C. M., Frasquilho, F., et al. (2005). Are there two qualitatively distinct forms of dissociation? A review and some clinical implications. Clinical Psychology Review, 25, 1-23.

Holtgraves, T., \& Stockdale, G. (1997). The assessment of dissociative experiences in a non-clinical population: Reliability, validity, and factor structure of the Dissociative Experiences Scale. Personality and Individual Differences, 22, 699-706.

Horne, R. L., Evans, F. J., \& Orne, M. T. (1982). Random number generation, psychopathology and therapeutic change. Archives of General Psychiatry, 39, 680-683.

Horselenberg, R., Merckelbach, H., Muris, P., Rassin, E., Sijsenaar, M., \& Spaan, V. (2000). Imagining fictitious childhood events: The role of individual differences in imagination inflation. Clinical Psychology and Psychotherapy, 7, 128-137.

Huntjens, R. J. C., Peters, M. L., Postma, A., Woertman, L., Effting, M., \& van der Hart, O. (2005). Transfer of newly acquired stimulus valence between identities in dissociative identity disorder (DID). Behaviour Research and Therapy, 43, 243-255.

Huntjens, R. J. C., Peters, M. L., Woertman, L., Bovenschen, L. M., Martin, R. C., \& Postma, A. (2006). Inter-identity amnesia in dissociative identity disorder: A simulated memory impairment? Psychological Medicine, 36, 857-863

Huntjens, R. J. C., Peters, M. L., Woertman, L., van der Hart, O., \& Postma, A. (2007). Memory transfer for emotionally valenced words between identities in dissociative identity disorder. Behaviour Research and Therapy, 45, 775-789.

Huntjens, R. J. C., Postma, A., Hamaker, E. L., Woertman, L., van der Hart, O., \& Peters, M. (2002). Perceptual and conceptual priming in patients with dissociative identity disorder. Memory and Cognition, 30, 1033-1043.

Huntjens, R. J. C., Postma, A., Peters, M. L., Woertman, L., \& van der Hart, O. (2003). Interidentity amnesia for neutral, episodic information in dissociative identity disorder. Journal of Abnormal Psychology, 112, 290-297.

Huntjens, R. J. C., Postma, A., Woertman, L., van der Hart, O., \& Peters, M. L. (2005). Procedural memory in dissociative identity disorder: When can inter-identity amnesia be truly established? Consciousness and Cognition, 14, 377-389.

Hyman, I. E., Jr., \& Billings, F. J. (1998). Individual differences and the creation of false childhood memories. Memory, 6, 1-20.

Irwin, H. J. (1998). Dissociative tendencies and the sitting duck: Are self-reports of dissociation and victimization symptomatic of neuroticism? Journal of Clinical Psychology, 54, 1005-1015.

Irwin, H. J. (1999). Pathological and nonpathological dissociation: The relevance of childhood trauma. Journal of Psychology: Interdisciplinary and Applied, 133, 157-164.

Janet, P. (1973). L'automatisme psychologique. Paris: Société Pierre Janet. (Original work published 1889)

Jewett, M. E., Dijk, D.-J., Kronauer, R. E., \& Dinges, D. F. (1999) Dose-response relationship between sleep duration and human psychomotor vigilance and subjective alertness. Sleep, 22, 171-179.

Johnson, M. K., Hashtroudi, S., \& Lindsay, D. S. (1993). Source monitoring. Psychological Bulletin, 114, 3-28.

Johnson, R. C., Edman, J. L., \& Danko, G. P. (1995). Self-reported negative experiences and dissociation. Personality and Individual Differences, 18, 793-795.

Jones, B., Heard, H., Startup, M., Swales, M., Williams, J. M. G., \& Jones, R. S. P. (1999). Autobiographical memory and dissociation in borderline personality disorder. Psychological Medicine, 29, 1397-1404.

Jureidini, J. (2003). Does dissociation offer a useful explanation for psychopathology? Psychopathology, 37, 259-265.

Kersting, A., Reutemann, M., Gast, U., Ohrmann, P., Suslow, T., Michael, N., et al. (2003). Dissociative disorders and traumatic childhood expe- 
riences in transsexuals. Journal of Nervous and Mental Disease, 191, 182-189.

Kihlstrom, J. F. (1983). Instructed forgetting: Hypnotic and nonhypnotic. Journal of Experimental Psychology: General, 112, 73-79.

Kihlstrom, J. F. (2005). Dissociative disorders. Annual Review of Clinical Psychology, 1, 227-253.

Kihlstrom, J. F. (2006). Trauma and memory revisited. In B. Uttl, N. Otha, \& A. L. Siegenthaler, (Eds.), Memory and emotions: Interdisciplinary perspectives (pp. 259-293). New York: Blackwell Publishing.

Kihlstrom, J. F., Glisky, M. L., \& Angiulo, M. J. (1994). Dissociative tendencies and dissociative disorders. Journal of Abnormal Psychology, $103,117-124$.

Kindt, M., \& van den Hout, M. (2003). Dissociation and memory fragmentation: Experimental effects on meta-memory but not on actual memory performance. Behaviour Research and Therapy, 41, 167-178.

Kindt, M., van den Hout, M., \& Buck, N. (2005). Dissociation related to subjective memory fragmentation and intrusions but not to objective memory disturbances. Journal of Behavior Therapy and Experimental Psychiatry, 36, 43-59.

Kirino, E. (2006). P300 is attenuated during dissociative episodes. Journal of Nervous and Mental Disease, 194, 83-90.

Koppenhaver, J. M., Kumar, V. K., \& Pekala, R. J. (1997). Dissociativity, imagery vividness, and reality monitoring. Dissociation: Progress in the Dissociative Disorders, 10, 21-28.

Kremers, I. P., Spinhoven, P., \& Van der Does, A. J. W. (2004). Autobiographical memory in depressed and nondepressed patients with borderline personality disorder. British Journal of Clinical Psychology, 43, 17-29.

Kremers, I. P., Spinhoven, P., Van der Does, A. J. W., \& Van Dyck, R. (2006). Autobiographical memory in depressed and nondepressed patients with borderline personality disorder after long-term psychotherapy. Cognition and Emotion, 20, 448-465.

Krystal, J. H., Karper, L. P., Seibyl, J. P., Freeman, G. K., Delaney, R., Bremner, J. D., et al. (1994). Subanesthetic effects of the noncompetitive NMDA antagonist, ketamine, in humans. Psychotomimetic, perceptual, cognitive, and neuroendocrine responses. Archives of General Psychiatry, 51, 199-214

Kunzendorf, R. G., \& Karpen, J. (1997). Dissociative experiences and reality-testing deficits in college students. Imagination, Cognition and Personality, 16, 227-238.

Kwapil, T. R., Wrobel, M. J., \& Pope, C. A. (2002). The five-factor personality structure of dissociative experiences. Personality and Individual Differences, 32, 431-443.

Ladwig, K. H., Marten-Mittag, B., Deisenhofer, I., Hofmann, B., Schapperer, J., Weyerbrock, S., et al. (2002). Psychophysiological correlates of peritraumatic dissociative responses in survivors of life-threatening cardiac events. Psychopathology, 35, 241-248.

Lang, K. L., Paris, J., Zweig-Frank, H., \& Livesley, W. J. (1998). Twin study of dissociative experiences. Journal of Abnormal Psychology, 186, 345351.

Larmore, K., Ludwig, A. M., \& Cain, R. L. (1977). Multiple personality: An objective case study. British Journal of Psychiatry, 131, 35-40.

Leavitt, F. (1999). Dissociative experiences scale taxon and measurement of dissociative pathology: Does the taxon add to an understanding of dissociation and its associated pathologies? Journal of Clinical Psychology in Medical Settings, 6, 427-440.

Levin, R., Sirof, B., Simeon, D., \& Guralnick, O. (2004). Role of fantasy proneness, imaginative involvement, and psychological absorption in depersonalization disorder. Journal of Nervous and Mental Disease, 192, 69-71.

Lilienfeld, S. O., Kirsch, I., Sarbin, T. R., Lynn, S. J., Chaves, J. F., Ganaway, G. K., et al. (1999). Dissociative identity disorder and the sociocognitive model: Recalling the lessons of the past. Psychological Bulletin, 125, 507-523.
Loftus, E. F. (1993). The reality of repressed memories. American Psychologist, 48, 518-537.

Ludwig, A. M., Brandsma, J. M., Wilbur, C. B., Bendfeldt, F., \& Jameson, D. H. (1972). The objective study of multiple personality-or, are four heads better than one? Archives of General Psychiatry, 26, 298-310.

Lynn, S. J., Kirsch, I., Knox, J., \& Lilienfeld, S. O. (2006). Hypnosis and neuroscience: Implications for the altered state debate. In G. Jamieson (Ed.), Hypnosis and conscious states: The cognitive-neuroscience perspective (pp. 145-167). New York: Oxford University Press.

Macfie, J., Cicchetti, D., \& Toth, S. L. (2001). The development of dissociation in maltreated preschool-aged children. Development and Psychopathology, 13, 233-254.

MacLeod, C. M. (1999). The item and list methods of directed forgetting: Test differences and the role of demand characteristics. Psychonomic Bulletin and Review, 6, 123-129.

Maltby, J., Day, L., McCutcheon, L. E., Houran, J., \& Ashe, D. (2006). Extreme celebrity worship, fantasy proneness and dissociation: Developing the measurement and understanding of celebrity worship within a clinical personality context. Personality and Individual Differences, 40, 273-283.

McNally, R. J. (2003). Remembering trauma. Cambridge, MA: Harvard University Press.

McNally, R. J., Lasko, N. B., Clancy, S. A., Macklin, M. L., Pitman, R. K., \& Orr, S. P. (2004). Psychophysiological responding during scriptdriven imagery in people reporting abduction by space aliens. Psychological Science, 15, 493-497.

McNally, R. J., Ristuccia, C. S., \& Perlman, C. A. (2005). Forgetting of trauma cues in adults reporting continuous or recovered memories of abuse. Psychological Science, 16, 336-340.

Meehl, P. E., \& Golden, R. R. (1982). Taxometric methods. In C. Kendall \& J. N. Butcher (Eds.), Handbook of research methods in clinical psychology (pp. 127-182). New York: Wiley.

Merckelbach, H., à Campo, J., Hardy, S., \& Giesbrecht, T. (2005). Dissociation and fantasy proneness in psychiatric patients: A preliminary study. Comprehensive Psychiatry, 16, 181-185.

Merckelbach, H., Devilly, G. J., \& Rassin, E. (2002). Alters in dissociative identity disorder: Metaphors or genuine entities? Clinical Psychological Review, 22, 481-497.

Merckelbach, H., \& Giesbrecht, T. (2006). Subclinical dissociation, schizotypy, and traumatic distress. Personality and Individual Differences, 40, 365-374.

Merckelbach, H., Horselenberg, R., \& Muris, P. (2001). The Creative Experiences Questionnaire (CEQ): A brief self-report measure of fantasy proneness. Personality and Individual Differences, 31, 987-995.

Merckelbach, H., Horselenberg, R., \& Schmidt, H. (2002). Modeling the connection between self-reported trauma and dissociation in a student sample. Personality and Individual Differences, 32, 695-705.

Merckelbach, H., \& Jelicic, M. (2004). Dissociative symptoms are related to endorsement of vague trauma items. Comprehensive Psychiatry, 45, 70-75.

Merckelbach, H., \& Muris, P. (2001). The causal link between selfreported trauma and dissociation: A critical review. Behaviour Research and Therapy, 39, 245-254.

Merckelbach, H., Muris, P., Horselenberg, R., \& Stougie, S. (2000). Dissociative experiences, response bias, and fantasy proneness in college students. Personality and Individual Differences, 28, 49-58.

Merckelbach, H., Muris, P., \& Rassin, E. (1999). Fantasy proneness and cognitive failures as correlates of dissociative experiences. Personality and Individual Differences, 26, 961-967.

Merckelbach, H., Muris, P., Rassin, E., \& Horselenberg, R. (2000). Dissociative experiences and interrogative suggestibility in college students. Personality and Individual Differences, 29, 1133-1140.

Merckelbach, H., Rassin, E., \& Muris, P. (2000). Dissociation, schizotypy, and fantasy proneness in undergraduate students. Journal of Nervous and Mental Disease, 188, 428-431. 
Merckelbach, H., \& Smith, G. P. (2003). Diagnostic accuracy of the Structured Inventory of Malingered Symptomatology (SIMS) in detecting instructed malingering. Archives of Clinical Neuropsychology, 18, $145-152$.

Merckelbach, H., van Roermund, H., \& Candel, I. (2007). Effects of collaborative recall: Denying true information is as powerful as suggesting misinformation. Psychology, Crime and Law, 13, 573-581.

Merckelbach, H., Zeles, G., van Bergen, S., \& Giesbrecht, T. (2007). Trait dissociation and commission errors in memory reports of emotional events. American Journal of Psychology, 120, 1-14.

Modestin, J., \& Erni, T. (2004). Testing the dissociative taxon. Psychiatry Research, 126, 77-82.

Montagne, B., Sierra, M., Medford, N., Hunter, E. C. M., Baker, D., Kessels, R. P. C., et al. (2007). Emotional memory and perception of emotional faces in patients suffering from depersonalization disorder. British Journal of Psychology, 98, 517-527.

Morgan, C. A., 3rd, Hazlett, G., Wang, S., Richardson, E. G., Jr., Schnurr, P., \& Southwick, S. M. (2001). Symptoms of dissociation in humans experiencing acute, uncontrollable stress: A prospective investigation. American Journal of Psychiatry, 158, 1239-1247.

Moskowitz, A. (2004). Dissociation and violence: A review of the literature. Trauma, Violence, and Abuse, 5, 21-46.

Nijenhuis, E. R., Spinhoven, P., Vanderlinden, J., van Dyck, R., \& van der Hart, O. (1998). Somatoform dissociative symptoms as related to animal defensive reactions to predatory imminence and injury. Journal of $A b$ normal Psychology, 107, 63-73.

Nijenhuis, E. R., Spinhoven, P., Van Dyck, R., Van der Hart, O., \& Vanderlinden, J. (1996). The development and psychometric characteristics of the Somatoform Dissociation Questionnaire (SDQ-20). Journal of Nervous and Mental Disease, 184, 688-694.

Nijenhuis, E. R., Spinhoven, P., van Dyck, R., van der Hart, O., \& Vanderlinden, J. (1998). Psychometric characteristics of the Somatoform Dissociation Questionnaire: A replication study. Psychotherapy \& Psychosomatics, 67, 17-23.

Nissen, M. J., Ross, J. L., Willingham, D. B., Mackenzie, T. B., \& Schacter, D. L. (1988). Memory and awareness in a patient with multiple personality disorder. Brain and Cognition, 8, 117-134.

Ogawa, J. R., Sroufe, L. A., Weinfield, N. S., Carlson, E. A., \& Egeland, B. (1997). Development and the fragmented self: Longitudinal study of dissociative symptomatology in a nonclinical sample. Development and Psychopathology, 9, 855-879.

Ost, J., Fellows, B., \& Bull, R. (1997). Individual differences and the suggestibility of human memory. Contemporary Hypnosis, 14, 132-137.

Ost, J., Foster, S., Costall, A., \& Bull, R. (2005). False reports of childhood events in appropriate interviews. Memory, 13, 700-710.

Ost, J., Granhag, P. A., Udell, J., \& Hjelmsater, E. R. (2008). Familiarity breeds distortion: The effects of media exposure on false reports concerning media coverage of the terrorist attacks in London on 7 July 2005. Memory, 16, 76-85.

Ozer, E. J., Best, S. R., Lipsey, T. L., \& Weiss, D. S. (2003). Predictors of posttraumatic stress disorder and symptoms in adults: A meta-analysis. Psychological Bulletin, 129, 52-73.

Paddock, J. R., Joseph, A. L., Chan, F. M., Terranova, S., Manning, C., \& Loftus, E. F. (1998). When guided visualization procedures may backfire: Imagination inflation and predicting individual differences in suggestibility. Applied Cognitive Psychology, 12, S63-S75.

Pandelaere, M., \& Dewitte, S. (2006). Is this a question? Not for long. Journal of Experimental Social Psychology, 42, 525-531.

Papageorgiou, C., Ventouras, E., Uzunoglu, N., Rabavilas, A., \& Stefanis, C. (2002). Changes of P300 elicited during a working memory test in individuals with depersonalization-derealization experiences. Neuropsychobiology, 46, 70-75.

Pekala, R. J., Angelini, F., \& Kumar, V. K. (2001). The importance of fantasy-proneness in disassociation: A replication. Contemporary Hypnosis, 18, 204-214.

Pekala, R., Kumar, V. K., Ainslie, V. K., Elliott, N. C., Mullen, K. J., Saninger, M. M., et al. (1999-2000). Dissociation as a function of child abuse and fantasy proneness in a substance abuse population. Imagination, Cognition and Personality, 19, 105-129.

Peters, M. J., Horselenberg, R., Jelicic, M., \& Merckelbach, H. (2007). The false fame illusion in people with memories about a previous life. Consciousness and Cognition, 16, 162-169.

Peters, M. L., Uyterlinde, S. A., Consemulder, J., \& van der Hart, O. (1998). Apparent amnesia on experimental memory tests in dissociative identity disorder: An exploratory study. Consciousness and Cognition, 7, 27-41.

Pezdek, K., \& Lam, S. (2007). What research paradigms have cognitive psychologists used to study "False memory," and what are the implications of these choices? Consciousness and Cognition, 16, 2-17.

Pezdek, K., \& Roe, C. (1997). The suggestibility of children's memory for being touched: Planting, erasing, and changing memories. Law and Human Behavior, 21, 95-106.

Platt, R. D., Lacey, S. C., Iobst, A. D., \& Finkelman, D. (1998). Absorption, dissociation, fantasy-proneness as predictors of memory distortion in autobiographical and laboratory-generated memories. Applied Cognitive Psychology, 12, S77-S89.

Polczyk, R. (2005). Interrogative suggestibility: Cross-cultural stability of psychometric and correlational properties of the Gudjonsson Suggestibility Scales. Personality and Individual Differences, 38, 177-186.

Polich, J., \& Kok, A. (1995). Cognitive and biological determinants of P300: An integrative review. Biological Psychology, 41, 103-146.

Pope, C. A., \& Kwapil, T. R. (2000). Dissociative experiences in hypothetically psychosis-prone college students. Journal of Nervous and Mental Disease, 188, 530-536.

Pope, H. G., Jr., Barry, S., Bodkin, A., \& Hudson, J. I. (2006). Tracking scientific interest in the dissociative disorders: A study of scientific publication output 1984-2003. Psychotherapy \& Psychosomatics, 75, 19-24.

Porter, S., \& Birt, A. R. (2001). Is traumatic memory special? A comparison of traumatic memory characteristics with memory for other emotional life experiences. Applied Cognitive Psychology, 15, S101-S117.

Porter, S., Birt, A. R., Yuille, J. C., \& Lehman, D. R. (2000). Negotiating false memories: Interviewer and rememberer characteristics relate to memory distortion. Psychological Science, 11, 507-510.

Preacher, K. J., Rucker, D. D., MacCallum, R. C., \& Nicewander, W. A. (2005). Use of the extreme groups approach: A critical reexamination and new recommendations. Psychological Methods, 10, 178-192.

Prohl, J., Resch, F., Parzer, P., \& Brunner, R. (2001). Relationship between dissociative symptomatology and declarative and procedural memory in adolescent psychiatric patients. Journal of Nervous and Mental Disease, 198, 602-607.

Putnam, F. W. (1995). Development of dissociative disorders. In D. J. Cohen \& D. Cicchetti (Eds.), Developmental psychopathology: Risk, disorder, and adaptation (pp. 581-608). Oxford, England: Wiley.

Putnam, F. W. (1997). Dissociation in children and adolescents: A developmental perspective. New York: Guilford Press.

Putnam, F. W., Carlson, E. B., Ross, C. A., \& Anderson, G. (1996). Patterns of dissociation in clinical and nonclinical samples. Journal of Nervous and Mental Disease, 184, 673-679.

Putnam, F. W., Guroff, J. J., Silberman, E. K., Barban, L., \& Post, R. M. (1986). The clinical phenomenology of multiple personality disorder: Review of 100 recent cases. Journal of Clinical Psychiatry, 47, 285-293.

Rauschenberger, S. L., \& Lynn, S. J. (1995). Fantasy proneness, DSM$I I I-R$ Axis I psychopathology and dissociation. Journal of Abnormal Psychology, 104, 373-380.

Ray, W., \& Faith, M. (1994). Dissociative experiences in a college age population. Personality and Individual Differences, 18, 223-230.

Reason, J. (1993). Self-report questionnaires in cognitive psychology: Have they delivered the goods? New York: Oxford University Press. 
Reinders, A. A. T. S., Nijenhuis, E. R., Paans, A. M., Korf, J., Willemsen, A. T., \& den Boer, J. A. (2003). One brain, two selves. NeuroImage, 20, $2119-2125$.

Reinders, A. A. T. S., Nijenhuis, E. R. S., Quak, J., Korf, J., Haaksma, J., Paans, A. M. J., et al. (2006). Psychobiological characteristics of dissociative identity disorder: A symptom provocation study. Biological Psychiatry, 60, 730-740.

Renneberg, B., Theobald, E., Nobs, M., \& Weisbrod, M. (2005). Autobiographical memory in borderline personality disorder and depression. Cognitive Therapy and Research, 29, 343-358.

Rhue, J. W., Lynn, S. J., \& Sandberg, D. (1995). Dissociation, fantasy and imagination in childhood: A comparison of physically abused, sexually abused, and non-abused children. Contemporary Hypnosis, 12, 131-136.

Riley, K. C. (1988). Measurement of dissociation. Journal of Nervous and Mental Disease, 176, 449-450.

Roca, V., Hart, J., Kimbrell, T., \& Freeman, T. (2006). Cognitive function and dissociative disorder status among veteran subjects with chronic posttraumatic stress disorder: A preliminary study. Journal of Neuropsychiatry and Clinical Neurosciences, 18, 226-230.

Roche, S. M., \& McConkey, K. M. (1990). Absorption: Nature, assessment, and correlates. Journal of Personality and Social Psychology, 59, 91-101.

Roediger, H. L., McDermott, K. B., \& Robinson, K. J. (1998). The role of associative processes in creating false memories. In M. A. Conway, S. E. Gathercole, \& C. Cornoldi (Eds.), Theories of memory: Volume II (pp. 187-245). Hove, Sussex, England: Psychological Press.

Rogers, M. A., Kasai, K., Koji, M., Fukuda, R., Iwanami, A., Nakagome, K., et al. (2004). Executive and prefrontal dysfunction in unipolar depression: A review of neuropsychological and imaging evidence. Neuroscience Research, 50, 1-11.

Ross, C., Heber, S., Norton, G. R., Anderson, D., Anderson, G., \& Barchet, P. (1989). The Dissociative Disorders Interview Schedule: A structured interview. Dissociation, 2, 169-189.

Ross, C. A., Ellason, J. W., \& Anderson, G. (1995). A factor analysis of the dissociative experiences scale (DES) in dissociative identity disorder. Dissociation, 8, 229-235.

Ross, C. A., Joshi, S., \& Currie, R. (1991). Dissociative experiences in the general population: A factor analysis. Hospital and Community Psychiatry, 42, 297-301.

Rossini, E. D., Schwartz, D. R., \& Braun, B. G. (1996). Intellectual functioning of inpatients with dissociative identity disorder and dissociative disorder not otherwise specified. Cognitive and neuropsychological aspects. Journal of Nervous and Mental Disease, 184, 289-294.

Ruiz, M. A., Pincus, A. L., \& Ray, W. J. (1999). The relationship between dissociation and personality. Personality and Individual Differences, 27, 239-249.

Sandberg, D. A., Lynn, S. J., \& Matorin, A. I. (2001). Information processing of an acquaintance rape scenario among high- and lowdissociating college women. Journal of Traumatic Stress, 14, 585-603.

Sanders, B., \& Giolas, M. H. (1991). Dissociation and childhood trauma in psychological disturbed adolescents. American Journal of Psychiatry, $148,50-54$.

Sanders, B., \& Green, A. (1994). The factor structure of dissociative experiences in college students. Dissociation, 7, 23-27.

Sanders, S. (1986). The Perceptual Alteration Scale: A scale measuring dissociation. American Journal of Clinical Hypnosis, 29, 95-102.

Schacter, D. L., Kihlstrom, J. F., Kihlstrom, L. C., \& Berren, M. B. (1989). Autobiographical memory in a case of multiple personality disorder. Journal of Abnormal Psychology, 98, 508-514.

Schwartz, B. L., Fisher, R. P., \& Hebert, K. S. (1998). The relation of output order and commission errors in free recall and eyewitness accounts. Memory, 6, 257-275.

Segal, D., \& Lynn, S. J. (1992-1993). Predicting dissociative experiences: Imagination, hypnotizability, psychopathology, and alcohol use. Imagination, Cognition and Personality, 12, 287-300.
Sierra, M., \& Berrios, G. E. (1998). Depersonalization: Neurobiological perspectives. Biological Psychiatry, 44, 898-908.

Sierra, M., \& Berrios, G. E. (2000). The Cambridge Depersonalisation Scale: A new instrument for the measurement of depersonalisation. Psychiatry Research, 93, 163-164.

Silberman, E. K., Putnam, F. W., Weingartner, H., Braun, B. G., \& Post, R. M. (1985). Dissociative states in multiple personality disorder: A quantitative study. Psychiatry Research, 15, 253-260.

Silva, C. E., \& Kirsch, I. (1992). Interpretive sets, expectancy, fantasy proneness, and dissociation as predictors of hypnotic response. Journal of Personality and Social Psychology, 63, 847-856.

Simeon, D. (2004). Depersonalisation disorder: A contemporary overview. CNS Drugs, 18, 343-354.

Simeon, D., \& Abugel, J. (2006). Feeling unreal: Depersonalization disorder and the loss of the self. New York: Oxford University Press.

Simeon, D., Guralnik, O., Gross, S., Stein, D. J., Schmeidler, J., \& Hollander, E. (1998). The detection and measurement of depersonalization disorder. Journal of Nervous and Mental Disease, 186, 536-542.

Simeon, D., Guralnik, O., \& Schmeidler, J. (2001). Development of a depersonalization severity scale. Journal of Traumatic Stress, 14, 341-349.

Simeon, D., Guralnik, O., Schmeidler, J., Sirof, B., \& Knutelska, M. (2001). The role of childhood interpersonal trauma in depersonalization disorder. American Journal of Psychiatry, 158, 1027-1033.

Simeon, D., Hwu, R., \& Knutelska, M. (2007). Temporal disintegration in depersonalization disorder. Journal of Trauma and Dissociation, 8, 11-24.

Simeon, D., Knutelska, M., Nelson, D., \& Guralnik, O. (2003). Feeling unreal: A depersonalization disorder update of 117 cases. Journal of Clinical Psychiatry, 64, 990-997.

Simeon, D., Knutelska, M., Nelson, D., Guralnik, O., \& Schmeidler, J. (2003). Examination of the pathological dissociation taxon in depersonalization disorder. Journal of Nervous and Mental Disease, 191, 738-744.

Simeon, D., Smith, R. J., Knutelska, M., \& Smith, L. M. (in press). Somatoform dissociation in depersonalization disorder. Journal of Trauma and Dissociation.

Singh, K. K., \& Gudjonsson, G. H. (1992). Interrogative suggestibility among adolescent boys and its relationship with intelligence, memory, and cognitive set. Journal of Adolescence, 15, 155-161.

Sivec, H. J., \& Lynn, S. J. (1995). Dissociative and neuropsychological symptoms: The question of differential diagnosis. Clinical Psychology Review, 15, 297-316.

Smith, G. P., \& Burger, G. K. (1997). Detection of malingering: Validation of the Structured Inventory of Malingered Symptomatology (SIMS). Journal of the American Academy of Psychiatry and the Law, 25, 183-189.

Spanos, N. P. (1994). Multiple identity enactments and multiple personality disorder: A sociocognitive perspective. Psychological Bulletin, 116, 143-165.

Spiegel, D., \& Cardena, E. (1991). Disintegrated experience: The dissociative disorders revisited. Journal of Abnormal Psychology, 100, 366-378.

Spitzer, R. L., Williams, J. B. W., Gibbon, M., \& First, M. B. (1990). Structured Clinical Interview for DSM-III-R: SCID. Washington, DC: American Psychiatric Association.

Stein, M. B., Hanna, C., Vaerum, V., \& Koverola, C. (1999). Memory functioning in adult women traumatized by childhood sexual abuse. Journal of Traumatic Stress, 12, 527-534.

Steinberg, M. (1993). Structured clinical interview for DSM-IV dissociative disorders $(S C I D-D)$. Washington, DC: American Psychiatric Press.

Steinberg, M. (1994). Structured clinical interview for DSM-IV dissociative disorders revised (SCID-D-R). Washington, DC: American Psychiatric Press.

Steinberg, M., Rounsaville, B., Buchanan, J., \& Cicchetti, D. (1992). The Mini-Structured Clinical Interview for DSM-IV Dissociative Disorders: A new screening tool for dissociative symptoms and disorders. Unpublished manuscript, Yale University School of Medicine. 
Sterlini, G. L., \& Bryant, R. A. (2002). Hyperarousal and dissociation: A study of novice skydivers. Behaviour Research and Therapy, 40, 431-437.

Stevens, A., Burkhardt, M., Hautzinger, M., Schwarz, J., \& Unckel, C. (2004). Borderline personality disorder: Impaired visual perception and working memory. Psychiatry Research, 125, 257-267.

Stickgold, R., Hobson, J. A., Fosse, R., \& Fosse, M. (2001, November). Sleep, learning, and dreams: Off-line memory reprocessing. Science, 294, 1052-1057.

Stroop, J. R. (1935). Studies on interference in serial verbal reactions. Journal of Experimental Psychology, 18, 643-662.

Tampke, A. K., \& Irwin, H. J. (1999). Dissociative processes and symptoms of posttraumatic stress in Vietnam Veterans. Journal of Traumatic Stress, 12, 725-738.

Terr, L. (1994). Unchained memories: True stories of traumatic memories, lost and found. New York: Basic Books.

Valdiserri, S., \& Kihlstrom, J. F. (1995a). Abnormal eating and dissociative experiences. International Journal of Eating Disorders, 17, 373-380.

Valdiserri, S., \& Kihlstrom, J. F. (1995b). Abnormal eating and dissociative experiences: A further study of college women. International Journal of Eating Disorders, 18, 145-150.

van den Hout, M., Merckelbach, H., \& Pool, K. (1996). Dissociation, reality monitoring, trauma, and thought suppression. Behavioural and Cognitive Psychotherapy, 24, 97-108.

van der Hart, O., Bolt, H., \& van der Kolk, B. A. (2005). Memory fragmentation in dissociative identity disorder. Journal of Trauma and Dissociation, 6, 55-70.

van der Hart, O., Nijenhuis, E., Steele, K., \& Brown, D. (2004). Traumarelated dissociation: Conceptual clarity lost and found. Australian and New Zealand Journal of Psychiatry, 38, 906-914.

van der Hart, O., Nijenhuis, E., Steele, K., \& Brown, D. (2006). The haunted self: Structural dissociation and the treatment of chronic traumatization. New York: Norton.

van der Kolk, B. A., \& Fisler, R. (1995). Dissociation and the fragmentary nature of traumatic memories: Overview and exploratory study. Journal of Traumatic Stress, 8, 505-525.

van der Kolk, B. A., \& van der Hart, O. (1989). Pierre Janet and the breakdown of adaptation in psychological trauma. American Journal of Psychiatry, 146, 1530-1540.

Vanderlinden, J., Van Dyck, R., Vandereycken, W., \& Vertommen, H. (1991). Dissociative experiences in the general population in the Netherlands and Belgium: A study with the Dissociative Questionnaire (DIS-Q). Dissociation: Progress in the Dissociative Disorders, 4, 180-184.

van IJzendoorn, M. H., \& Schuengel, C. (1996). The measurement of dissociation in normal and clinical populations: Meta-analytic validation of the Dissociative Experience Scale (DES). Clinical Psychology Review, 16, 365-382.

Veltman, D. J., de Ruiter, M. B., Rombouts, S. A., Lazeron, R. H., Barkhof, F., Van Dyck, R., et al. (2005). Neurophysiological correlates of increased verbal working memory in high-dissociative participants: A functional MRI study. Psychological Medicine, 35, 175-185.

Waldo, T. G., \& Merritt, R. D. (2000). Fantasy proneness, dissociation, and DSM-IV Axis II symptomatology. Journal of Abnormal Psychology, 109, 555-558.

Walker, R., Gregory, J., Oakley, S., Jr., Bloch, R., \& Gardener, M. (1996). Reduction in dissociation due to aging and cognitive deficit. Comprehensive Psychiatry, 37, 31-36.

Waller, G., Ohanian, V., Meyer, C., Everill, J., \& Rouse, H. (2001). The utility of dimensional and categorical approaches to understanding dissociation in the eating disorders. British Journal of Clinical Psychology, 40, 387-397.

Waller, G., Quinton, S., \& Watson, D. (1995). Dissociation and the processing of threat-related information. Dissociation, 8, 84-90.

Waller, N. G. (1995). The Dissociative Experiences Scale. In J. C. Conoley \& J. C. Impara (Eds.), Twelfth mental measurements yearbook. Lincoln: University of Nebraska Press.
Waller, N. G., Putnam, F. W., \& Carlson, E. B. (1996). Types of dissociation and dissociative types: A taxometric analysis of dissociative experiences. Psychological Methods, 1, 300-321.

Waller, N. G., \& Ross, C. A. (1997). The prevalence and biometric structure of pathological dissociation in the general population: Taxometric and behavior genetic findings. Journal of Abnormal Psychology, 106, 499-510.

Watson, D. (2001). Dissociations of the night: Individual differences in sleep-related experiences and their relation to dissociation and schizotypy. Journal of Abnormal Psychology, 110, 526-535.

Watson, D. (2003a). Investigating the construct validity of the dissociative taxon: Stability analysis of normal and pathological dissociation. Journal of Abnormal Psychology, 112, 298-305.

Watson, D. (2003b). To dream, perchance to remember: Individual differences in dream recall. Personality and Individual Differences, 34, 1271-1286.

Wechsler, D. (1981). Manual of the Wechsler Adult Intelligence ScaleRevised. San Antonio, TX: Psychological Corporation.

Wegner, D. M., Quillian, F., \& Houston, C. E. (1996). Memories out of order: Thought suppression and the disturbance of sequence memory. Journal of Personality and Social Psychology, 71, 680-691.

Wessel, I., Merckelbach, H., \& Dekkers, T. (2002). Autobiographical memory specificity, intrusive memory, and general memory skills in Dutch-Indonesian survivors of the World War II era. Journal of Traumatic Stress, 15, 227-234.

Wessel, I., Merckelbach, H., Kessels, C., \& Horselenberg, R. (2001). Dissociation and autobiographical memory specificity. Clinical Psychology and Psychotherapy, 8, 411-415.

Wessel, I., Wetzels, S., Jelicic, M., \& Merckelbach, H. (2005). Dissociation and memory suppression: A comparison of high and low dissociative individuals' performance on the think-no think task. Personality and Individual Differences, 39, 1461-1470.

Wilkinson, C., \& Hyman, I. E., Jr. (1998). Individual differences related to two types of memory errors: Word lists may not generalize to autobiographical memory. Applied Cognitive Psychology, 12, S29-S46.

Williams, J. M., \& Scott, J. (1988). Autobiographical memory in depression. Psychological Medicine, 18, 689-695.

Wilson, B., Alderman, N., Burgess, P., Emslie, H., \& Evans, J. (1996). Behavioural assessment of the dysexecutive syndrome. Bury St. Edmunds, England: Thames Valley Test Company.

Wilson, K., \& French, C. C. (2006). The relationship between susceptibility to false memories, dissociativity, and paranormal belief and experience. Personality and Individual Differences, 41, 1493-1502.

Wilson, S. C., \& Barber, T. X. (1983). Fantasy-prone personality: Implications for understanding imagery, hypnosis and parapsychological phenomena. In A. A. Sheikh (Ed.), Imagery: Current theory, research and application (pp. 340-387). New York: Wiley.

Winograd, E., Peluso, J. P., \& Glover, T. A. (1998). Individual differences in susceptibility to memory illusions. Applied Cognitive Psychology, 12, S5-S27.

Wittmann, L., Schredl, M., \& Kramer, M. (2006). Dreaming in posttraumatic stress disorder: A critical review of phenomenology, psychophysiology and treatment. Psychotherapy \& Psychosomatics, 76, 25-39.

Wolfradt, U., \& Meyer, T. (1998). Interrogative suggestibility, anxiety and dissociation among anxious patients and normal controls. Personality and Individual Differences, 25, 425-432.

Wright, D. B., \& Loftus, E. F. (1999). Measuring dissociation: Comparison of alternative forms of the Dissociative Experiences Scale. American Journal of Psychology, 112, 497-519.

Wright, D. B., Loftus, E. F., \& Hall, M. (2001). Now you see it; now you don't: Inhibiting recall and recognition of scenes. Applied Cognitive Psychology, 15, 471-482.

Wright, D. B., \& Osborne, J. E. (2005). Dissociation, cognitive failures, and working memory. American Journal of Psychology, 118, 103-113.

Wright, D. B., Startup, H. M., \& Mathews, S. A. (2005). Mood, dissociation and false memories using the Deese-Roediger-McDermott procedure. British Journal of Psychology, 96, 283-293. 


\section{Appendix}

Table A1. Summary of Studies Examining Cognitive Functioning in Dissociation Using Standardized Laboratory Tasks

\begin{tabular}{|c|c|c|c|c|}
\hline Paradigm & Study & Group & Control group & $\begin{array}{l}\text { Main finding with respect to } \\
\text { dissociation }\end{array}$ \\
\hline \multicolumn{5}{|c|}{ Neuropsychological functioning } \\
\hline WAIS & $\begin{array}{l}\text { Guralnik et } \\
\text { al. (2000) }\end{array}$ & $\operatorname{DPD}(n=15)$ & $\mathrm{HC}(n=15)$ & $\begin{array}{l}\text {-No difference on full-scale IQ } \\
\text {-Compromised visual and } \\
\text { verbal short-term memory }\end{array}$ \\
\hline WAIS, WMS & $\begin{array}{l}\text { Guralnik et } \\
\text { al. (2007) }\end{array}$ & $\operatorname{DPD}(n=21)$ & $\mathrm{HC}(n=17)$ & $\begin{array}{l}\text {-No difference in full-scale IQ } \\
\text {-Compromised on immediate } \\
\text { visual and verbal recall }\end{array}$ \\
\hline Auditory oddball & Kirino (2006) & $\operatorname{DID}(n=12)$ & $\mathrm{HC}(n=12)$ & $\begin{array}{l}\text {-Attenuation of P300 amplitude } \\
\text { during dissociative episodes } \\
\text { but recovery to HC levels in } \\
\text { remission }\end{array}$ \\
\hline WASI & $\begin{array}{l}\text { Roca et al. } \\
\text { (2006) }\end{array}$ & PTSD with DD $(n=10)$ & $\begin{array}{l}\text { PTSD without DD } \\
\quad(n=17)\end{array}$ & -No group differences \\
\hline WAIS & $\begin{array}{l}\text { Rossini et al. } \\
\text { 1996) }\end{array}$ & DID $(n=50)$, DDNOS $(n=55)$ & & -Abnormal intertest scatter \\
\hline $\mathrm{N}$-letter back task & $\begin{array}{l}\text { Elzinga et al. } \\
\text { (2007) }\end{array}$ & DID $(n=16)$ & $\mathrm{HC}(n=16)$ & $\begin{array}{l}\text {-Smaller decline in performance } \\
\text { with increasing task load in } \\
\text { DID }\end{array}$ \\
\hline $\begin{array}{l}\text { IGT, O-SPAN, WCST, } \\
\text { WTAR }\end{array}$ & $\begin{array}{l}\text { Bruce, Ray, } \\
\text { Bruce, et } \\
\text { al. (2007) }\end{array}$ & $\begin{array}{l}\text { High DES }(>29) \text { undergraduate } \\
\text { students }(n=33)\end{array}$ & $\begin{array}{l}\text { Low DES }(<6) \\
\text { undergraduate } \\
\text { students }(n=33)\end{array}$ & -No group differences \\
\hline BADS & $\begin{array}{l}\text { Cima et al. } \\
\text { (2001) }\end{array}$ & $\begin{array}{l}\text { Inmates, psychiatric correctional } \\
\text { institute }(n=30)\end{array}$ & & $\begin{array}{l}\text {-Performance deficits on frontal } \\
\text { tasks }\end{array}$ \\
\hline Word Span & $\begin{array}{l}\text { De Ruiter et } \\
\text { al. (2004) }\end{array}$ & $\begin{array}{l}\text { High DIS-Q }(M=2.20, n=40) \\
\text { undergraduates }\end{array}$ & $\begin{array}{l}\text { Low }(M=1.24, \\
n=38) \text { and medium } \\
(M=1.58, n=41) \\
\text { DIS-Q } \\
\text { undergraduates }\end{array}$ & -Larger word span \\
\hline RNG & $\begin{array}{l}\text { Giesbrecht et } \\
\text { al. (2004) }\end{array}$ & Undergraduates $(N=185)$ & & $\begin{array}{l}\text {-Subtle disruptions in executive } \\
\text { functioning }\end{array}$ \\
\hline DS & $\begin{array}{l}\text { Papageorgiou } \\
\text { et al. } \\
\text { (2002) }\end{array}$ & $\begin{array}{l}\text { Participants with transient } \\
\text { depersonalization/derealization } \\
\text { symptoms }(n=15)\end{array}$ & $\mathrm{HC}(n=15)$ & $\begin{array}{l}\text {-Decreased amplitude of P300 } \\
\text { during DS }\end{array}$ \\
\hline CVLT, TOT & $\begin{array}{l}\text { Prohl et al. } \\
\quad(2001)\end{array}$ & $\begin{array}{l}\text { Adolescent psychiatric patients } \\
\quad(N=41)\end{array}$ & & $\begin{array}{l}\text {-Deficits in declarative (i.e., } \\
\text { CVLT) and procedural (i.e., } \\
\text { TOT) memory performance }\end{array}$ \\
\hline CVLT & $\begin{array}{l}\text { Stein et al. } \\
\text { (1999) }\end{array}$ & $\begin{array}{l}\text { Adults with a history of CSA } \\
\quad(n=22)\end{array}$ & $\mathrm{HC}(n=20)$ & $\begin{array}{l}\text {-Dissociation unrelated to } \\
\text { CVLT performance }\end{array}$ \\
\hline Subtests of WAIS & $\begin{array}{l}\text { Stevens et al. } \\
\text { (2004) }\end{array}$ & $\mathrm{BPD}(n=22)$ & $\mathrm{HC}(n=25)$ & $\begin{array}{l}\text {-Dissociation was not } \\
\text { significantly related to any } \\
\text { measure of WM performance }\end{array}$ \\
\hline $\begin{array}{l}\text { N-letter back task, } \\
\text { letter Sternberg task }\end{array}$ & $\begin{array}{l}\text { Veltman et } \\
\text { al. (2005) }\end{array}$ & $\begin{array}{l}\text { High DIS-Q }(M=2.24) \\
\quad \text { undergraduates }(n=11)\end{array}$ & $\begin{array}{l}\text { Low }(M=1.33) \text { DIS-Q } \\
\text { undergraduates } \\
(n=10)\end{array}$ & $\begin{array}{l}\text {-Superior performance on both } \\
\text { tasks -Greater dorsolateral } \\
\text { (DL) and ventrolateral } \\
\text { prefrontal cortex (PFC), } \\
\text { parietal cortex, and } \\
\text { supplementary motor area } \\
\text { activation }\end{array}$ \\
\hline $\begin{array}{l}\text { DS, Visual Patterns } \\
\text { Test, and CBT }\end{array}$ & $\begin{array}{l}\text { Wright \& } \\
\text { Osborne } \\
\text { (2005) }\end{array}$ & Undergraduates $(N=80)$ & & $\begin{array}{l}\text {-Dissociation unrelated to task } \\
\text { performance }\end{array}$ \\
\hline
\end{tabular}

\begin{tabular}{|c|c|c|c|c|}
\hline \multicolumn{5}{|c|}{ Information processing } \\
\hline $\begin{array}{l}\text { Flanker task (neutral } \\
\text { words) }\end{array}$ & $\begin{array}{l}\text { Dorahy et al. } \\
\text { (2002) }\end{array}$ & DID $(n=20)$ & $\begin{array}{l}\text { MDD, HC (both } \\
\quad n s=20)\end{array}$ & $\begin{array}{l}\text {-No negative priming in DID } \\
\text { and MDD -DID slower to } \\
\text { respond than HC }\end{array}$ \\
\hline Flanker task (digits) & $\begin{array}{l}\text { Dorahy, } \\
\text { Irwin, \& } \\
\text { Middleton } \\
(2004)\end{array}$ & DID $(n=10)$ & $\begin{array}{l}\text { HC, MDD, PTSD, } \\
\text { psychosis (all } \\
n \mathrm{~s}=10 \text { ) }\end{array}$ & -Intact cognitive inhibition \\
\hline $\begin{array}{l}\text { Flanker task (digits), } \\
\text { word naming task } \\
\text { (focal attention and } \\
\text { distracter, neutral and } \\
\text { emotional) }\end{array}$ & $\begin{array}{l}\text { Dorahy et al. } \\
\text { (2006) }\end{array}$ & DID $(n=12)$ & $\begin{array}{l}\mathrm{GAD}, \mathrm{HC} \text { (both } \\
n \mathrm{~s}=12 \text { ) }\end{array}$ & $\begin{array}{l}\text {-Negative priming in the } \\
\text { neutral but not negative } \\
\text { condition }\end{array}$ \\
\hline
\end{tabular}


Table A1 (continued)

\begin{tabular}{|c|c|c|c|c|}
\hline Paradigm & Study & Group & Control group & $\begin{array}{l}\text { Main finding with respect to } \\
\text { dissociation }\end{array}$ \\
\hline Flanker task (digits) & $\begin{array}{l}\text { Dorahy, } \\
\text { Middleton, } \\
\text { \& Irwin } \\
(2004)\end{array}$ & DID $(n=10)$ & $\begin{array}{l}\text { HC, MDD, PTSD (all } \\
\quad n \mathrm{~s}=10), \text { psychosis } \\
(n=9)\end{array}$ & $\begin{array}{l}\text {-Significant negative priming, } \\
\text { comparable with that of } \\
\text { depressed and PTSD }\end{array}$ \\
\hline $\begin{array}{l}\text { Flanker task (word } \\
\text { stimuli, neutral and } \\
\text { negative context) }\end{array}$ & $\begin{array}{l}\text { Dorahy et al. } \\
\text { (2005) }\end{array}$ & $\operatorname{DID}(n=11)$ & $\begin{array}{l}\text { MDD, HC (both } \\
\quad n \mathrm{~s}=11)\end{array}$ & $\begin{array}{l}\text {-Negative priming in neutral } \\
\text { context, but not in the } \\
\text { negative context }- \text { Slower } \\
\text { reaction time (RT) to negative } \\
\text { stimuli }\end{array}$ \\
\hline $\begin{array}{l}\text { Stroop task (neutral and } \\
\text { emotional, selective } \\
\text { and divided } \\
\text { attention) }\end{array}$ & $\begin{array}{l}\text { DePrince \& } \\
\text { Freyd } \\
\text { (1999) }\end{array}$ & $\begin{array}{l}\text { High DES }(>20) \text { undergraduates } \\
\quad(n=54)\end{array}$ & $\begin{array}{l}\text { Low DES }(<10) \\
\text { undergraduates } \\
\quad(n=54)\end{array}$ & $\begin{array}{l}\text {-More Stroop interference in } \\
\text { high DES group during } \\
\text { selective attention and less } \\
\text { during divided attention - } \\
\text { High DES group exhibited } \\
\text { lower rates of recall emotional } \\
\text { stimuli }\end{array}$ \\
\hline $\begin{array}{l}\text { Letter detection task, } \\
\text { affective evaluative } \\
\text { task }\end{array}$ & $\begin{array}{l}\text { De Ruiter et } \\
\text { al. (2003) }\end{array}$ & $\begin{array}{l}\text { High DIS-Q }(M=2.19) \\
\quad \text { undergraduates }(n=16)\end{array}$ & $\begin{array}{l}\text { Low }(M=1.32) \text { DIS-Q } \\
\text { undergraduates } \\
(n=16)\end{array}$ & $\begin{array}{l}\text {-Larger valence effect on RTs } \\
\text { and ERPs in the affective } \\
\text { evaluation task -Faster RT } \\
\text { and ERP positivity for } \\
\text { relevant stimuli during letter } \\
\text { detection }\end{array}$ \\
\hline $\begin{array}{l}\text { Stroop (selective } \\
\text { attention, standard } \\
\text { Stroop stimuli, } \\
\text { kinship, animal, } \\
\text { household, and space } \\
\text { words) }\end{array}$ & $\begin{array}{l}\text { Freyd et al. } \\
\quad(1998)\end{array}$ & High DES $(>20, n=40)$ & Low DES $(<10, n=40)$ & $\begin{array}{l}\text {-Greater level of interference on } \\
\text { the Stroop color-naming task }\end{array}$ \\
\hline $\begin{array}{l}\text { Thought suppression of } \\
\text { emotional video } \\
\text { fragment }\end{array}$ & $\begin{array}{l}\text { Giesbrecht, } \\
\text { Merckelbach, } \\
\text { \& Smeets } \\
(2006)\end{array}$ & Undergraduates $(N=40)$ & & $\begin{array}{l}\text {-DES-T related to inferior } \\
\text { suppression performance }\end{array}$ \\
\hline $\begin{array}{l}\text { Information-processing } \\
\text { task (neutral and } \\
\text { threatening stimuli) }\end{array}$ & $\begin{array}{l}\text { G. Waller et } \\
\text { al. (1995) }\end{array}$ & Undergraduates $(N=105)$ & & $\begin{array}{l}\text {-Levels of dissociation related } \\
\text { to slowness identifying the } \\
\text { presence of threat words }\end{array}$ \\
\hline TNT & $\begin{array}{l}\text { Wessel et al. } \\
\quad(2005)\end{array}$ & $\begin{array}{l}\text { High DES ( }>20) \text { undergraduates } \\
\quad(n=35)\end{array}$ & $\begin{array}{l}\text { Low DES }(<10) \\
\text { undergraduates } \\
(n=35)\end{array}$ & $\begin{array}{l}\text {-No group differences in TNT } \\
\text { performance }\end{array}$ \\
\hline \multicolumn{5}{|c|}{ Directed forgetting } \\
\hline $\begin{array}{l}\text { Item-wise, neutral and } \\
\text { emotional, within } \\
\text { and between } \\
\text { personality state), } \\
\text { picture-fragment } \\
\text { completion task }\end{array}$ & $\begin{array}{l}\text { Elzinga et al. } \\
\text { (2003) }\end{array}$ & $\operatorname{DID}(N=12)$ & & $\begin{array}{l}\text {-Directed forgetting between } \\
\text { states, but not within the same } \\
\text { identity state -Reduction of } \\
\text { explicit memory performance } \\
\text { between states -Implicit } \\
\text { memory was preserved }\end{array}$ \\
\hline $\begin{array}{l}\text { Item-wise, positive, } \\
\text { negative, and neutral } \\
\text { stimuli }\end{array}$ & $\begin{array}{l}\text { Cloitre et al. } \\
\text { (1996) }\end{array}$ & $\begin{array}{l}\text { Patients with BPD and abuse } \\
(n=24), \text { patients with BPD } \\
\text { and abuse, HC }(n=24)\end{array}$ & & $\begin{array}{l}\text {-Dissociation across all groups } \\
\text { predicted better recall of to- } \\
\text { be-remembered words }\end{array}$ \\
\hline $\begin{array}{l}\text { Item-wise, selective and } \\
\text { divided attention, } \\
\text { negative and neutral } \\
\text { stimuli) }\end{array}$ & $\begin{array}{l}\text { DePrince \& } \\
\text { Freyd } \\
\text { (2001) }\end{array}$ & $\begin{array}{l}\text { High DES }(>20) \text { undergraduates } \\
\quad(n=28)\end{array}$ & $\begin{array}{l}\text { Low DES }(<10) \\
\text { undergraduates } \\
\quad(n=28)\end{array}$ & $\begin{array}{l}\text {-Lower recall rate of emotional } \\
\text { and better recall of neutral } \\
\text { words during divided attention }\end{array}$ \\
\hline $\begin{array}{l}\text { List-wise, selective and } \\
\text { divided attention, } \\
\text { negative, and neutral } \\
\text { stimuli }\end{array}$ & $\begin{array}{l}\text { DePrince \& } \\
\text { Freyd } \\
\text { (2004) }\end{array}$ & $\begin{array}{l}\text { High DES }(>20) \text { undergraduates } \\
\quad(n=21)\end{array}$ & $\begin{array}{l}\text { Low DES }(<10) \\
\text { undergraduates } \\
(n=24)\end{array}$ & $\begin{array}{l}\text {-Lower rates of recall of } \\
\text { emotional stimuli during } \\
\text { divided attention }\end{array}$ \\
\hline \multirow{2}{*}{$\begin{array}{l}\text { Item-wise, selective and } \\
\text { divided attention, } \\
\text { neutral and emotional } \\
\text { stimuli }\end{array}$} & $\begin{array}{l}\text { Devilly et al. } \\
\text { (2007) }\end{array}$ & $\begin{array}{l}\text { Study 1: High DES }(>20) \\
\quad \text { undergraduates }(n=19)\end{array}$ & $\begin{array}{l}\text { Study 1: Low DES } \\
(<10) \text { undergraduates } \\
(n=23)\end{array}$ & -Lower recall rates of all stimuli \\
\hline & & $\begin{array}{l}\text { Study 2: High DES }(>20) \\
\quad \text { undergraduates }(n=20)\end{array}$ & $\begin{array}{l}\text { Study 2: Low DES } \\
\quad(<10) \text { undergraduates } \\
(n=17)\end{array}$ & $\begin{array}{l}\text {-Higher rates of false } \\
\text { recognition (Study 1) }\end{array}$ \\
\hline
\end{tabular}


Table A1 (continued)

\begin{tabular}{|c|c|c|c|c|}
\hline Paradigm & Study & Group & Control group & $\begin{array}{c}\text { Main finding with respect to } \\
\text { dissociation }\end{array}$ \\
\hline \multirow{2}{*}{$\begin{array}{l}\text { Item-wise, neutral } \\
\text { (Study } 1 \text { and 2), } \\
\text { threat and sex stimuli } \\
\text { (Study 2) }\end{array}$} & $\begin{array}{l}\text { Elzinga et al. } \\
\quad(2000)\end{array}$ & $\begin{array}{l}\text { Study 1: High DIS-Q }(>1.5, \\
\quad n=17)\end{array}$ & $\begin{array}{l}\text { Study 1: Low DIS-Q } \\
\quad(<1.5, n=18)\end{array}$ & $\begin{array}{l}\text {-Inability to forget, most } \\
\text { pronounced for sex words }\end{array}$ \\
\hline & & $\begin{array}{l}\text { Study } 2 \text { : High DIS-Q }(\geq 1.7 \\
\quad n=20), \text { DID }(n=14)\end{array}$ & $\begin{array}{l}\text { Study 2: Low DIS-Q } \\
\quad(<1.7, n=23)\end{array}$ & $\begin{array}{l}\text {-Better memory performance in } \\
\text { general }\end{array}$ \\
\hline \multirow[t]{2}{*}{$\begin{array}{l}\text { List-wise, selective and } \\
\text { divided attention, } \\
\text { negative, and neutral } \\
\text { stimuli }\end{array}$} & $\begin{array}{l}\text { McNally et al. } \\
\text { (2005) }\end{array}$ & $\begin{array}{l}\text { Participants with recovered } \\
\quad(n=11), \text { and continuous } \\
(n=21) \text { memories of abuse, } \\
\text { HC }(n=16)\end{array}$ & & $\begin{array}{l}\text {-No effect of dissociation on } \\
\text { DF performance }\end{array}$ \\
\hline & \multicolumn{3}{|c|}{ Inter-identity amnesia } & \\
\hline $\begin{array}{l}\text { Serial reaction time } \\
\text { task }\end{array}$ & $\begin{array}{l}\text { Huntjens, } \\
\text { Postma, et } \\
\text { al. (2005) }\end{array}$ & DID $(n=31)$ & $\begin{array}{l}\mathrm{HC}(n=25), \mathrm{HC} \text { with } \\
\quad \text { simulation instruction } \\
\quad(n=25)\end{array}$ & $\begin{array}{l}\text {-DID patients showed a pattern } \\
\text { of inter-identity amnesia that } \\
\text { was readily mimicked by } \\
\text { simulators }\end{array}$ \\
\hline $\begin{array}{l}\text { Evaluative conditioning } \\
\text { task with subsequent } \\
\text { affective priming } \\
\text { task }\end{array}$ & $\begin{array}{l}\text { Huntjens, } \\
\text { Peters, et al. } \\
(2005)\end{array}$ & DID $(n=21)$ & $\begin{array}{l}\mathrm{HC}(n=25), \mathrm{HC} \text { with } \\
\quad \text { simulation instruction } \\
\quad(n=25)\end{array}$ & $\begin{array}{l}\text {-Intact transfer of learned } \\
\text { valence between identities }\end{array}$ \\
\hline $\begin{array}{l}\text { Logical memory-Story } \\
\text { A and visual } \\
\text { reproduction from } \\
\text { WMS-R (learning } \\
\text { and delayed recall in } \\
\text { different identity } \\
\text { states) }\end{array}$ & $\begin{array}{l}\text { Huntjens et al. } \\
\quad(2006)\end{array}$ & DID $(n=22)$ & $\begin{array}{l}\mathrm{HC}(n=25), \mathrm{HC} \text { with } \\
\quad \text { simulation instruction } \\
\quad(n=25), \text { guessors } \\
(n=25)\end{array}$ & $\begin{array}{l}\text {-Patients and simulators } \\
\text { performed below chance, but } \\
\text { differed in strategy }\end{array}$ \\
\hline $\begin{array}{l}\text { Word list (positive, } \\
\text { negative, and neutral } \\
\text { stimuli) learned in } \\
\text { different identity } \\
\text { states }\end{array}$ & $\begin{array}{l}\text { Huntjens et al. } \\
\text { (2007) }\end{array}$ & DID $(n=22)$ & $\begin{array}{l}\mathrm{HC}(n=25), \mathrm{HC} \text { with } \\
\quad \text { simulation instruction } \\
\quad(n=25), \text { guessors } \\
(n=25)\end{array}$ & $\begin{array}{l}\text {-Frequency of intrusions } \\
\text { between word lists were } \\
\text { equal between DID and HC } \\
\text {-DID recognized a } \\
\text { considerable amount of } \\
\text { words learned in other } \\
\text { identity state }\end{array}$ \\
\hline $\begin{array}{l}\text { Perceptual priming } \\
\text { task, word stem } \\
\text { completion task }\end{array}$ & $\begin{array}{l}\text { Huntjens et al. } \\
\quad(2002)\end{array}$ & $\mathrm{DID}(n=31)$ & $\begin{array}{l}\mathrm{HC}(n=25), \mathrm{HC} \text { with } \\
\quad \text { simulation instruction } \\
\quad(n=25)\end{array}$ & $\begin{array}{l}\text {-Inter-identity priming was } \\
\text { apparent for both tasks }\end{array}$ \\
\hline \multirow[t]{2}{*}{$\begin{array}{l}\text { Word list (neutral } \\
\text { stimuli) learned in } \\
\text { different identity } \\
\text { states }\end{array}$} & $\begin{array}{l}\text { Huntjens et al. } \\
\text { (2003) }\end{array}$ & DID $(n=31)$ & $\begin{array}{l}\mathrm{HC}(n=25), \mathrm{HC} \text { with } \\
\quad \text { simulation instruction } \\
\quad(n=25)\end{array}$ & $\begin{array}{l}\text {-DID performed equally as did } \\
\text { control participants in terms } \\
\text { of memory performance }\end{array}$ \\
\hline & \multicolumn{3}{|c|}{ Autobiographical memory specificity and fragmentation } & \\
\hline $\begin{array}{l}\text { Neutral and negative } \\
\text { cues, recall } \\
\text { constrained to period } \\
\text { of trauma or } \\
\text { unconstrained }\end{array}$ & $\begin{array}{l}\text { Harvey et al. } \\
\text { (1998) }\end{array}$ & $\operatorname{ASD}(n=12)$ & $\mathrm{HC}(n=12)$ & $\begin{array}{l}\text {-Low specificity in the } \\
\text { unconstrained condition was } \\
\text { associated with dissociative } \\
\text { symptoms }\end{array}$ \\
\hline $\begin{array}{l}\text { Neutral, negative, and } \\
\text { positive cues }\end{array}$ & $\begin{array}{l}\text { Jones et al. } \\
\text { (1999) }\end{array}$ & $\operatorname{BPD}(n=23)$ & $\mathrm{HC}(n=23)$ & $\begin{array}{l}\text {-Dissociation predicted } \\
\text { overgeneral memory to } \\
\text { negative cue words }\end{array}$ \\
\hline $\begin{array}{l}\text { Positive and negative } \\
\text { cue words }\end{array}$ & $\begin{array}{l}\text { Kremers et al. } \\
\qquad(2004)\end{array}$ & $\operatorname{BPD}(N=83)$ & & $\begin{array}{l}\text {-No significant relation with } \\
\text { memory specificity }\end{array}$ \\
\hline $\begin{array}{l}\text { Pre- and posttreatment } \\
\text { change }\end{array}$ & $\begin{array}{l}\text { Kremers et al. } \\
\qquad(2006)\end{array}$ & $\operatorname{BPD}(N=55)$ & & $\begin{array}{c}\text {-Increase in specific memories } \\
\text { was not related to decrease } \\
\text { in dissociative symptoms }\end{array}$ \\
\hline $\begin{array}{l}\text { Neutral, negative, and } \\
\text { positive cue words }\end{array}$ & $\begin{array}{l}\text { Renneberg et } \\
\text { al. (2005) }\end{array}$ & $\begin{array}{l}\text { BPD }(n=30), \text { depression } \\
\quad(n=27)\end{array}$ & $\mathrm{HC}(n=30)$ & $\begin{array}{l}\text {-No significant relation with } \\
\text { memory specificity }\end{array}$ \\
\hline $\begin{array}{l}\text { Positive and negative } \\
\text { cue words }\end{array}$ & $\begin{array}{l}\text { Wessel et al. } \\
\text { (2001) }\end{array}$ & $\begin{array}{l}\text { High DES }(>30) \text { undergraduates } \\
\quad(n=23)\end{array}$ & $\begin{array}{l}\text { Low DES }(<15) \\
\quad \text { undergraduates } \\
\quad(n=25)\end{array}$ & $\begin{array}{l}\text {-No group differences in } \\
\text { autobiographical memory } \\
\text { specificity }\end{array}$ \\
\hline $\begin{array}{l}\text { Emotional video } \\
\text { fragment and } \\
\text { memory } \\
\text { fragmentation task }\end{array}$ & $\begin{array}{l}\text { Kindt \& van } \\
\text { den Hout } \\
(2003)\end{array}$ & $\begin{array}{l}\text { High DES }(>30) \text { undergraduates } \\
\quad(n=20)\end{array}$ & $\begin{array}{l}\text { Low DES }(<10) \\
\quad \text { undergraduates } \\
\quad(n=20)\end{array}$ & $\begin{array}{l}\text {-Dissociation unrelated to } \\
\text { objective memory } \\
\text { fragmentation }\end{array}$ \\
\hline
\end{tabular}


Table A1 (continued)

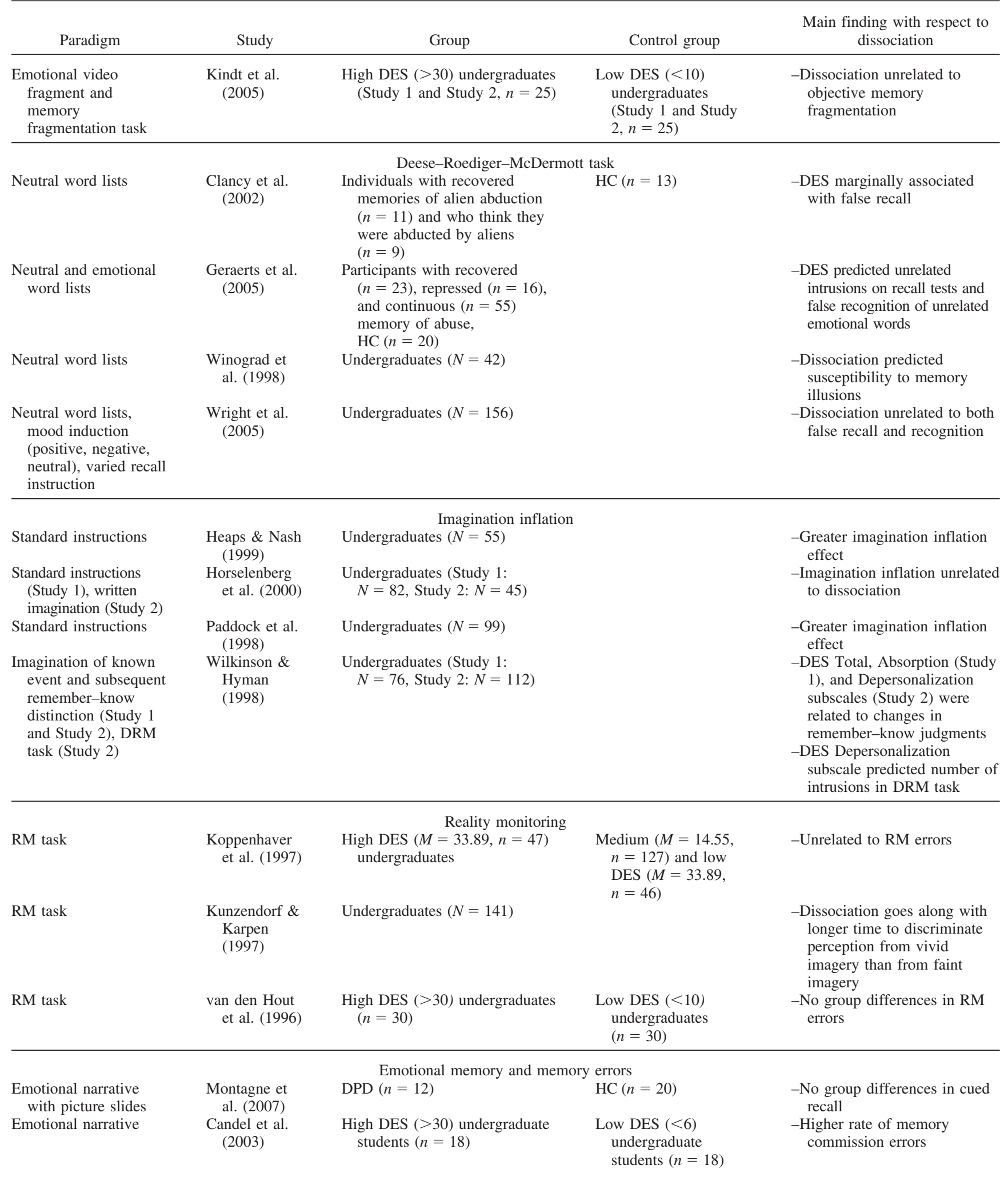


Table A1 (continued)

\begin{tabular}{|c|c|c|c|c|}
\hline Paradigm & Study & Group & Control group & $\begin{array}{c}\text { Main finding with respect to } \\
\text { dissociation }\end{array}$ \\
\hline $\begin{array}{l}\text { Video fragment and } \\
\text { subsequent } \\
\text { misleading } \\
\text { suggestions (with and } \\
\text { without perceptual } \\
\text { elaboration) }\end{array}$ & $\begin{array}{l}\text { Drivdahl \& } \\
\quad \text { Zaragoza } \\
(2001)\end{array}$ & Undergraduates $(N=132)$ & & $\begin{array}{l}\text {-DES unrelated to false } \\
\text { memory creation }\end{array}$ \\
\hline $\begin{array}{l}\text { Staged event with } \\
\text { suggestive } \\
\text { questioning }\end{array}$ & $\begin{array}{l}\text { Eisen \& } \\
\quad \text { Carlson } \\
\text { (1998) }\end{array}$ & Undergraduates $(N=132)$ & & $\begin{array}{l}\text {-DES related to errors on } \\
\text { misleading questions }\end{array}$ \\
\hline Staged event & $\begin{array}{l}\text { Eisen, } \\
\text { Morgan, et } \\
\text { al. (2002) }\end{array}$ & Undergraduates $(N=111)$ & & $\begin{array}{l}\text {-DES-T was related to errors } \\
\text { on misleading questions }\end{array}$ \\
\hline $\begin{array}{l}\text { Emotional video } \\
\text { fragment }\end{array}$ & $\begin{array}{l}\text { Giesbrecht, } \\
\text { Geraerts, \& } \\
\text { Merckelbach } \\
\text { (2007) }\end{array}$ & Undergraduates $(N=62)$ & & $\begin{array}{l}\text {-Higher rate of memory } \\
\text { commission errors }\end{array}$ \\
\hline $\begin{array}{l}\text { Imagination and } \\
\text { subsequent recall of } \\
\text { positive and threat } \\
\text { words }\end{array}$ & $\begin{array}{l}\text { Holtgraves \& } \\
\text { Stockdale } \\
(1997)\end{array}$ & Undergraduates $(N=201)$ & & $\begin{array}{l}\text {-Poorer explicit memory for } \\
\text { the emotion words }\end{array}$ \\
\hline $\begin{array}{l}\text { Creation of false } \\
\text { childhood memory }\end{array}$ & $\begin{array}{l}\text { Hyman \& } \\
\text { Billings } \\
\text { (1998) }\end{array}$ & Undergraduates $(N=48)$ & & $\begin{array}{l}\text {-DES was related to false } \\
\text { memory creation }\end{array}$ \\
\hline $\begin{array}{l}\text { Old new picture } \\
\text { recognition (Study 1), } \\
\text { LEI (Study 2) }\end{array}$ & $\begin{array}{l}\text { Merckelbach, } \\
\text { Muris, } \\
\text { Horselenberg, } \\
\text { \& Stougie } \\
\text { (2000) }\end{array}$ & Undergraduates $(N=42)$ & & $\begin{array}{l}\text {-DES related to higher } \\
\text { tendency to claim having } \\
\text { seen new pictures -DES } \\
\text { predicted endorsement of } \\
\text { positive, negative, and } \\
\text { neutral LEI items }\end{array}$ \\
\hline $\begin{array}{l}\text { Staged event (Study 1), } \\
\text { emotional video } \\
\text { fragment with or } \\
\text { without divided } \\
\text { attention (Study 2) } \\
\text { and subsequent } \\
\text { repeated free recall }\end{array}$ & $\begin{array}{l}\text { Merckelbach, } \\
\text { Zeles, et al. } \\
\text { (2007) }\end{array}$ & $\begin{array}{l}\text { Undergraduates (Study 1: } \\
\qquad N=36 \text {, Study } 2: N=60 \text { ) }\end{array}$ & & $\begin{array}{l}\text {-DES was related to } \\
\text { commission errors in both } \\
\text { studies }\end{array}$ \\
\hline $\begin{array}{l}\text { Cued recall of } \\
\text { introductory week } \\
\text { with genuine, } \\
\text { distorted, and } \\
\text { fabricated statements }\end{array}$ & $\begin{array}{r}\text { Ost et al. } \\
\text { (1997) }\end{array}$ & Undergraduates $(N=36)$ & & $\begin{array}{l}\text {-Higher confidence in } \\
\text { memories of fabricated } \\
\text { events }\end{array}$ \\
\hline $\begin{array}{l}\text { Parental misinformation } \\
\text { paradigm }\end{array}$ & $\begin{array}{l}\text { Ost et al. } \\
\quad(2005)\end{array}$ & Undergraduates $(N=31)$ & & $\begin{array}{l}\text {-DES and DES-T predicted } \\
\text { false recall }\end{array}$ \\
\hline $\begin{array}{l}\text { Crashing memories } \\
\text { paradigm }\end{array}$ & $\begin{array}{l}\text { Ost et al. } \\
(2008)\end{array}$ & Undergraduates $(N=34)$ & & $\begin{array}{l}\text {-Higher DES scores were } \\
\text { related to claim of having } \\
\text { seen events participants were } \\
\text { not exposed to }\end{array}$ \\
\hline $\begin{array}{l}\text { Spontaneous distortion } \\
\text { of memory of } \\
\text { Simpson verdict, } \\
\text { DRM task (neutral) }\end{array}$ & $\begin{array}{l}\text { Platt et al. } \\
\quad(1998)\end{array}$ & Undergraduates $(N=82)$ & & $\begin{array}{l}\text {-DES unrelated to spontaneous } \\
\text { memory distortion -DES } \\
\text { unrelated to DRM perfor- } \\
\text { mance }\end{array}$ \\
\hline $\begin{array}{l}\text { Generation of false } \\
\text { memories for } \\
\text { emotional childhood } \\
\text { event }\end{array}$ & $\begin{array}{l}\text { Porter et al. } \\
\quad(2000)\end{array}$ & Undergraduates $(N=47)$ & & $\begin{array}{l}\text {-Individuals that did generate a } \\
\text { false memory of a childhood } \\
\text { event exhibited higher DES } \\
\text { scores }\end{array}$ \\
\hline Emotional video & $\begin{array}{l}\text { Sandberg et al. } \\
\text { (2001) }\end{array}$ & $\begin{array}{l}\text { High DES ( } \geq 27) \text { undergraduates } \\
\quad(n=20)\end{array}$ & $\begin{array}{l}\text { Low DES }(<14) \\
\text { matched for SCL-90 } \\
(n=20) \text { or low } \\
\text { SCL-90 }(<0.54 \\
n=26) \\
\text { undergraduates }\end{array}$ & $\begin{array}{l}\text {-No diminished recall for } \\
\text { danger cues in high } \\
\text { dissociators }\end{array}$ \\
\hline $\begin{array}{l}\text { Crashing memories } \\
\text { paradigm }\end{array}$ & $\begin{array}{l}\text { Wilson \& } \\
\text { French } \\
\text { (2006) }\end{array}$ & Undergraduates $(N=100)$ & & $\begin{array}{l}\text {-Dissociation related to } \\
\text { tendency to report having } \\
\text { seen non-existent footage }\end{array}$ \\
\hline
\end{tabular}


Table A2. List of Abbreviations

\begin{tabular}{|c|c|}
\hline Abbreviation & Definition \\
\hline ASD & Acute stress disorder \\
\hline BADS & Behavioral Assessment of Dysexecutive Syndrome \\
\hline BPD & Borderline personality disorder \\
\hline CBT & Corsi Block Test \\
\hline CSA & Childhood sexual abuse \\
\hline CVLT & California Verbal Learning Test \\
\hline $\mathrm{DD}$ & Dissociative disorder \\
\hline DDNOS & Dissociative disorder not otherwise specified \\
\hline DES & Dissociative Experiences Scale \\
\hline DES-II & Dissociative Experiences Scale II \\
\hline DES-T & Dissociative Experiences Scale Taxon \\
\hline DF & Directed forgetting \\
\hline DID & Dissociative identity disorder \\
\hline DIS-Q & Dissociation Questionnaire \\
\hline DPD & Depersonalization disorder \\
\hline DRM & Deese-Roediger-McDermott \\
\hline DS & Digit Span \\
\hline DSM-III & Diagnostic and Statistical Manual of Mental Disorders (3rd ed.) \\
\hline$D S M-I V$ & Diagnostic and Statistical Manual of Mental Disorders (4th ed.) \\
\hline ERP & Event-related potential \\
\hline fMRI & Functional magnetic resonance imaging \\
\hline GAD & Generalized anxiety disorder \\
\hline GSS & Gudjonsson Scale of Interrogative Suggestibility \\
\hline $\mathrm{HC}$ & Healthy control participants \\
\hline IGT & Iowa gambling task \\
\hline LEI & Life Events Inventory \\
\hline MDD & Major depressive disorder \\
\hline O-SPAN & Operation Span \\
\hline PTSD & Posttraumatic stress disorder \\
\hline RM & Reality monitoring \\
\hline RNG & Random number generation \\
\hline SCID-D & Structured Clinical Interview for the Dissociative Disorders \\
\hline SCL-90 & Symptom Checklist 90 \\
\hline TNT & Think-no think task \\
\hline TOT & Tower of Toronto \\
\hline WAIS & Wechsler Adult Intelligence Scale \\
\hline WASI & Wechsler Abbreviated Scale of Intelligence \\
\hline WCST & Wisconsin Card Sorting Test \\
\hline WM & Working memory \\
\hline WMS-R & Wechsler Memory Scale—-Revised \\
\hline WTAR & Wechsler Test of Adult Reading \\
\hline
\end{tabular}

Received May 31, 2007

Revision received March 10, 2008

Accepted March 19, 2008 